\title{
Chapter 5 \\ Life Cycle and Life History Strategies of Parasitic Crustacea
}

\author{
Ernest H. Williams Jr and Lucy Bunkley-Williams
}

\begin{abstract}
Different parasitic life strategies are described including four new life cycles: complex rebrooding, micro-male, mesoparasite and prey-predator transfer. Four new life cycle behaviours are named: nursery hiding, mid-moult stage, positive precursor (intraspecific antagonism) and negative precursor (ambush strategy). Further strategies discussed are opossum attack, double parasitism (doubling of the normal reproductive set), duplex arrangement (separated male-female pairs), simple rebrooding, and describing how displaced parasites and superinfections may partly elucidate life cycles. Proportional stunting masks life history effects of parasitism; cuckoo copepods are true parasites and not just associates; burrowing barnacles (acrothoracicans) are not parasites. Further findings based on life cycle information: branchiurans and pentastomes are possibly not related; firefly seed shrimp are not parasites; copepod pre-adult life cycle stages are common in the western pacific but rare in Caribbean; harpacticoids on vertebrates are not parasites; cuckoo copepods are true parasites; explained the importance of pennellid intermediate hosts. Crustacean parasite life cycles are largely unknown (1\% of species). Most crustacean life cycles represent minor modifications from the ancestral freeliving mode. Crustacean parasites have less complex and less modified life cycles than other major parasite groups. This limits their exploitation of, and effectiveness, in parasitism. However, these life cycles will be an advantage in Global Change. Most metazoan parasites will be eliminated while crustaceans (and nematodes) will inherit the new world of parasites.
\end{abstract}

E. H. Williams, Jr $(\bowtie) \cdot$ L. Bunkley-Williams

Water Research Group, Unit for Environmental Sciences and Management, North-West

University, Potchefstroom, South Africa

University of Puerto Rico at Mayagüez, Mayagüez, Puerto Rico

e-mail: ermest.williams1@upr.edu; lucy.williams1@upr.edu 


\subsection{Introduction}

Life cycles and life histories are arguably the most significant functional traits of all organisms (e.g. Stearns 1992; Roff 1993; McGill et al. 2006), and understanding those life cycles and life histories is essential to understanding the autecology and evolution of each organism, as well as its impact on community and ecosystem processes (e.g. Heppell et al. 2000; McGill et al. 2006).

Parasitism is the most common consumer strategy, and parasites are estimated to account for approximately half of all biodiversity (reviewed by Hatcher and Dunn 2011). Carlson et al. (2017 and references) considered that conservation of parasites is essential to maintain the diversity in major ecosystems, particularly during global climate change. Because parasites are typically small and cryptic and often infect multiple hosts and/or host species during their life cycle, unravelling the life cycles of even a small percentage of parasite species has proven to be challenging. Indeed, while life cycles and life histories have been extensively investigated for a small number of model species (mostly species that impact the health of humans and/or plants and animals of economic importance to humans), we know virtually nothing about the vast majority of species.

The phylum Arthropoda is the most diverse animal phylum, with more than $13,00,000$ described species. While insects are the most diverse class within this phylum, the class Crustacea has more than 73,000 described species (Zhang 2013). The Crustacea also includes the greatest diversity of parasitic forms, with over one quarter of the described species. As with parasites generally, details of the life histories for most of these remain unknown.

The goal of this chapter is to provide an overview of the current state of knowledge regarding life cycles of parasitic Crustacea and offer insights and suggestions for future research; our suggestions and analyses are based on the authors' combined 100 years of experience working with this group.

We consider each parasite group separately in phylogenetic order, giving a brief summary of the life cycle(s) with recent discoveries and new details regarding life history strategies and concluding with some new information. We only present a brief overview of the impacts on hosts and on broader ecological aspects as these are reviewed in Chaps. 6 and 10, respectively.

General larval descriptions (unless new) have been kept to a minimum because Martin et al. (2014) presented an extensive description and collection of drawings and photographs of larval forms. The classification given in Chaps. 2 and 3 has been followed. To improve readability and referencing, an annotated glossary has been included with less familiar terms in italics in the text. Common names, with accompanying scientific names, are at the end (Sect. 5.17). 


\subsection{Branchiura: Fish Lice}

This is a small group of $\sim 158$ (WoRMS 2018) species in four genera that largely ectoparasitise freshwater fishes (Poly 2008), with a few taxa on coastal marine fishes $(<5$; Møller 2009), and some attach to tadpoles, salamanders, and even alligators (Møller 2009). Most non-fish infections appear to be incidental or accidental, but Poly (2003) described a species from a Mexican salamander. Because of their temporary association with hosts, they may more appropriately be referred to as 'micropredators' (e.g. Lafferty and Kuris 2002); however, we feel that serial parasites ${ }^{1}$ is more appropriate. Much of the interest in this group stems from their negative effects on aquaculture and aquarium fishes (Lafferty et al. 2015) and vector fish viral diseases (Møller 2015). The Japanese fish louse, Argulus japonicus Thiele, 1900, is probably the most famous and has been spread around the world with cyprinids (BunkleyWilliams and Williams 1994). However, the common fish louse, Argulus foliaceus (Linnaeus, 1758), is also widespread, and occurs from fresh to marine waters (Møller 2015). In two cases, these parasites have infected humans. Hargis (1958) found Argulus laticauda Smith, 1873, in the eye orbit of a child in Virginia; and an argulid has also been observed in the orbit of a tilapia aquaculturalist in Venezuela (Williams and Bunkley-Williams, personal observation).

\section{Life Cycle}

The life cycles of only 20 branchiuran species have been examined, mostly in Argulus Müller, 1785, and a few species of Dolops Audouin, 1837. Most males transfer sperm directly to the females using a variety of modified structures on the third and fourth thoracic legs; however, in Dolops, sperm are transferred in chitinous spermatophores. Sperm morphology originally linked fish lice with tongue worms (see Sect. 5.3). Molecular evidence also supports their similarities. Only the life cycle of Argulus is well known (Poly 2008; Neethling and Avenant-Oldewage 2016), and no life cycles of marine species are known. A mature female Argulus leaves its host and lays eggs in rows on a hard, submerged surface (Fig. 5.1). As many as 1200 eggs are laid at any one time and are cemented to the substrate. The eggs hatch 12-80 days later, varying by species and water temperature. Eggs hatch into (1) free-swimming metanauplius-like larvae (7 species of Argulus), (2) freeswimming juvenile-like larvae (4 Argulus, 2 Dolops) or (3) non-swimming larvae (6 Chonopeltis Thiele, 1900). The three larval stages (above) moult into secondstage juveniles, which are parasitic and repeatedly change hosts (serial parasite). The 8-12 stages before the adult are also parasitic and host-hopping*. The maxillule undergoes a profound metamorphosis around the fifth stage, changing from a long limb bearing a powerful distal claw, into a short but powerful circular sucker (Martin et al. 2014). This is a remarkable transformation. Møller et al. (2007) described swimming and self-cleaning in the hatching, free-swimming stage and the subsequent juvenile stages of Argulus foliaceus.

\footnotetext{
${ }^{1}$ An asterisk indicates our new suggested names throughout chapter.
} 


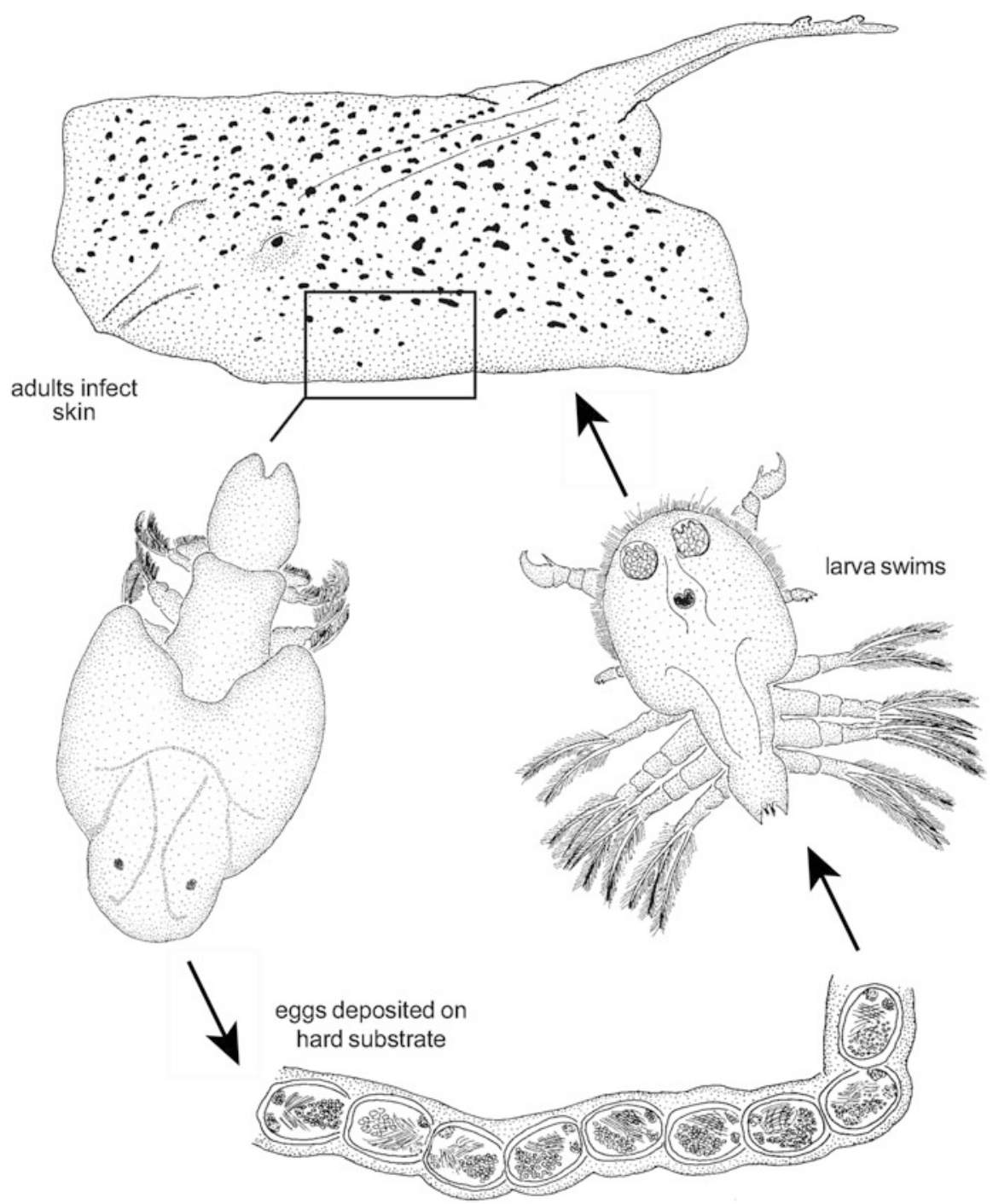

Fig. 5.1 The constructed life cycle of Argulus megalops Smith, 1874, an ectoparasite of the little skate, Leucoraja erinacea (Mitchill, 1825), based on information in Wilson (1904) and reproduced with permission from Benz and Bullard (2004). Mature adults copulate on or off the host, and gravid females will then swim and find hard inanimate objects (such as stones, walls, equipment, etc.) on which to deposit eggs. Hatching times vary according to temperatures and can take from weeks to months to occur. Once hatched, infective larvae will search for a host, attach to the suitable host, and undergo multiple moults before reaching maturation. Image modified from Benz and Bullard (2004) 
Neither larvae, nor juveniles, nor adult Chonopeltis can swim and are therefore referred to here as 'Non-swimming fish lice*'. Adults leave the host, mate, and deposit eggs, and how, or if, they return to a host is unknown. They have seven to eight free-living, developmental stages and are said to have intermediate hosts, but, as in other fish lice, these are really transfer hosts*. All host infection and reinfection are through host contact with the bottom. Intermediate hosts are small, bottomdwelling fishes, and the definitive hosts are larger, bottom-dwelling fishes (Grundlingh 1996). How they infect or attach to hosts is still unknown, possibly only floating to a new host (Fryer 1961; Piasecki and Avenant-Oldewage 2008).

Few parasite embryos have ever had mutualistic symbionts, but Banerjee et al. (2016) have found one. A rotifer, Philodina roseola Ehrenberg, 1832, feeds off the jelly coat of the egg strips of Argulus bengalensis Ramakrishna, 1951. This makes the coating thin enough for larvae to break out. If the rotifer does not feed, the larvae cannot emerge. They suggested this knowledge of the life cycle could afford parasite control. Van As and Van As (2015) found adult and larvae Chonopeltis lisikili Van As \& Van As, 1996, on the same host specimens and suggested host-change does not occur in C. lisikili, as was reported for other Chonopeltis spp. These stages, and freeswimming adults, are attracted by bright objects, light, and motion, as Mikheev et al. (2015) demonstrated in aquarium studies. In daylight, the parasite employed hoverand-wait tactics with low swimming speed and an inclined position of the body. In the dark, cruising tactics were employed, characterised by a much higher swimming speed and a horizontal position of the body. Vision, olfaction and mechanoreception are used in daylight, whereas only the latter two are used at night. Swimming speed was 5-6 times greater at night than in the daylight. Host-induced cues increased mean swimming speed by a factor of 1.5-3. In adults starved for 1-2 days, the swimming speed was 3-4 times greater than those freshly detached from the host. A longer starvation caused a decrease in swimming activity (Mikheev et al. 2015).

\section{Further Life History}

Mikheev et al. (2015) found receptive females largely rested on hosts and attracted free-swimming males with pheromones. They also found females deposit eggs in fish spawning or nursery areas, where their offspring will have access to many fish.

\section{Additional Information}

Mikheev et al. (2015) suggested fish lice manipulate the behaviour of hosts for their benefit: (1) when one attaches to a fish, the host reaction attracts other lice; (2) injuring a host by attacking it may cause a predator-attack tightening of a school, favouring more parasite attachment. However, these effects seem too inadvertent, reactive, and temporal, to be called parasite-induced host behavioural changes. They do not help the individual parasite causing the reaction, possibly even harming it, similar to a positive precursor. They are certainly nothing like the host behaviour changes such as found in parasitic barnacles. Mikheev et al. (2015) also suggested microbial pathogens were changing the behaviour of hosts and fish lice to spread their infection. They found 'sick' fish had more fish lice and stated that the parasites vector these diseases (see Chap. 7). 
Banerjee's et al. (2016) mutualistic rotifer has obviously co-evolved with Argulus bengalensis. We suggest that at one point, the rotifer appears to have been a hyperparasite (many in its genus are parasites) or predator harming the egg strip. The parasite gradually thickened the coating on its egg strip, protecting it from the rotifer. Finally, the embryos were sufficiently protected, to turn the rotifer into a mutualist, and the organisms became inexorably linked. Our suggestion is that this is first evidence of a hyperparasite evolving into a mutualist.

While fish lice metamorphosis of suckers is an interesting change from the freeliving forms, they show no other major morphological developments towards parasitism. Thus, while unusual, their larvae are strange, but not necessarily modified well for parasitism.

\subsection{Pentastomida: Tongue Worms}

There are $\sim 130$ extant species mostly parasitising the respiratory tracks of terrestrial vertebrates (Christoffersen and De Assis 2013; Siveter et al. 2015). They are of little commercial importance even though they may be found on crocodile and alligator farms, and the eggs of ten species can infect humans with nymphs ( $\mathrm{Li}$ et al. 2016). Their phylogenetic relationship was once mysterious because they only have reduced parasitic morphologies. Until recently, no fossil forms ( 0.5 billion years ago) were known. Molecular work has suggested a relation to fish lice (e.g. Li et al. 2016 and references), although this is still debated.

Williams (1995) suggested that these parasites were important and were once parasites of dinosaurs since the remaining species parasitise many extant close relatives of dinosaurs (e.g. crocodilians and birds). Bunkley-Williams and Williams (1994) found sebekid nymphs in freshwater largemouth bass and peacock bass in Puerto Rico and speculated that spectacled caiman was the final host (Williams and Britton 1995). We now identify these nymphs as Sebekia oxycephalum (Diesing, 1836), and they are common in Puerto Rico (Williams and Bunkley-Williams unpublished data). Williams et al. (1996) reported nymphs in coral reef fishes in Okinawa and suggested the final hosts were sea snakes.

\section{Life Cycle}

Males fertilize females soon after they mature in the respiratory tract. Males do not live long, and often only females are found in the definitive host. Stored sperm fertilize ova released continuously from the ovaries of mature females. Fertilized eggs mature as they descend the uterus of porocephalids. Gravid females of Armillifer Sambon, 1922, and Linguatula Frölich, 1789, species may contain millions of eggs. The eggs of cephalobaenids are stored in a saccate uterus until they contain 30-50\% fully mature primary larva and are infectious; then egg deposition begins. The vagina is equipped with a sieve-like mechanism only allowing mature eggs to escape. They lay eggs in the respiratory track of vertebrates, which are either coughed or sneezed out by the host or leave the host body through the digestive system. Usually, an 
insect or vertebrate ingests the eggs. The larva hatches into a nymph, penetrates the intestinal wall, and forms a cyst in the intermediate host's body. The nymph is rounded in form, with 4-6 short legs. The final host is infected when it eats the intermediate host, and the nymph crawls into the respiratory tract from the oesoph agus or stomach. It moults several times to become a post-larval juvenile and finally an adult. A few species, mostly in birds, have direct life cycles. Subtriquetra subtriquetra (Diesing, 1836), in South American crocodiles, is the only tongue worm known to have a free-swimming larva. It searches for fishes as its intermediate hosts (Winch and Riley 1986).

\section{Further Life History}

They occur worldwide but mostly in the tropics and subtropics. Very few reliable taxonomic characters exist, even in adults, and these few characters change in different adult stages (supra-adults).

\section{Additional Information}

The long cherished hope of fossil forms revealing clues to relations with other groups has not been realised. Siveter et al. (2015 and references) found these forms as nearly characterless and enigmatic as the extant species.

The few fossil forms known are isolated larvae, which appear to have been freeliving. Siveter et al. (2015) found adults ectoparasitic on a marine ostracod. These life cycle forms are completely different from the present-day endoparasites of terrestrial, semiterrestrial, and vertebrates. There has been either a monumental and complete change between the fossil and extant life cycles, or, which is more likely, the fossil forms are not in the same lineage as extant tongue worms. The fossils may be related to extant tongue worms, but do not represent their ancestors. Furthermore, without any interconnecting forms over half a billion years, it is difficult to try to join these fossils in a lineage with the extant tongue worms. More likely, the fossil and extant forms represent parallel evolution.

Chapter 3 does not recognise Siveter et al. (2015) fossil as a tongue worm. If correct, this leaves tongue worm fossil forms without an adult and without a host. These apparently free-swimming and unattached forms do have a modern equivalent in the larvae of Subtriquetra subtriquetra. Sanders and Lee (2010) suggested that these larval forms parasitised conodonts (early, eel-like organisms, famous for first teeth in the fossil record). This would agree with this only modern analogue, which parasitises fishes as intermediate hosts. However, they considered the small fossil forms adults, not larvae, with direct life cycles. Large forms with indirect life cycles only developed after the air-breathing tetropods were available $\sim 365$ million years ago. While these are interesting life strategy hypotheses, they lack any supporting evidence.

Tongue worm life cycles are like those of any other crustacean parasite. In their life evolution, they have invaded the land and colonised all four classes of terrestrial vertebrates. They are completely endoparasitic, with the exception of a free-living stage in one species. No other crustacean parasite is even similar. Their drastically different life cycles suggest they may not be crustaceans. Many other analyses agree 
(e.g. Christoffersen and De Assis (2013, 2015), place them in their own phylum), but most place them with the fish lice (Branchiura).

Sebekia oxycephalum is a generalist having little specificity in fish intermediate, and crocodilian and snake definitive, hosts (Silva et al. 2015). Vague reports of nymphs in lizards and reports in snakes probably represent paratenic hosts. It has the greatest range (southeastern USA to southern South America) of any tongue worm and the greatest host diversity.

\subsection{Ostracoda: Seed Shrimp}

Seed shrimp are a large group of largely free-living, marine species. A few are commensal on invertebrates, and extremely few are apparently parasitic on a shark, a ray, Pacific sea urchins, one polychaete, groundwater isopods, and gammaridean amphipods (Smith 2017). Many host records are based on few observations and specimens, and some relationships are unclear. Their shells in sediments and extensive fossils are very useful indicators of past conditions, climate changes, oil deposits, and crustacean sexual development. They are well known to scuba divers for their painful bites at night, for their bioluminescent glow and for their nocturnal attacks on injured fishes (Stepien and Brusca 1985).

\section{Life Cycle}

Mating typically occurs in swarms with large numbers of females swimming to join the males. However, some are partially or wholly partheno-genetic. All seed shrimp, except punciids (no shell), brood their eggs between the upper (dorsal) part of the body and the shell. Most ostracods shed eggs directly into the water as plankton or attach them to vegetation or the substratum. In some groups, one or two larval moults occur before the larvae are shed. Eggs hatch into nauplius larvae with a hard, bivalve shell, except punciids that have a single headshield. A nauplius stage is usually followed by 5-8 metanaupliar moults. Kretzler (1984) described the seven instars in the life cycle of Echinophilus xiphidion Kretzler, 1984, in Pacific sea urchins. He also found intense wave action inhibited the infection of sea urchins.

\section{Further Life History}

Males and females occur together on hosts. Most adults do not moult. Often, only a few specimens of parasitic seed shrimp are reported, although they can be very abundant. Kretzler (1984) found 5000 specimens in 218 host specimens of four species of sea urchins. He reported no damage; therefore, even heavy infections do not obviously affect hosts.

\section{Additional Information}

Bennett et al. (1997) found 17 of 28 epaulette sharks examined had Sheina orri Harding, 1966, ostracods attached in the gills. Light and scanning electron microscopy showed ostracods were anchored to gill tissues with their mandibular and maxillular claws. They damaged host tissues and were often located in distinct 
pockets, formed by local distortion of shark respiratory lamellae, strongly suggesting that they had been attached to the gills for considerable time. These details were presented because of some controversy whether Sheina orri was parasitic. It has also been found in the bluespotted ribbontail ray, Skogsbergia squamosa (Mueller, 1894), and may be a bony fish parasite (Monod 1923), but this was not clear.

Wilson (1913) found 50, 50, and 12 Photeros parasitica (Wilson 1913) in the gills and nasal tubes of three smooth hammerheads, one on the gills of a rock hind, and three on a blue runner in Jamaica. Williams and Bunkley-Williams (1996) hypothesised that $P$. parasitica was specific to sharks and rays and only accidental on bony fishes in the Caribbean. Cohen and Morin (2010) reported that $P$. parasitica is a luciferin bioluminescent carrion feeder, not a parasite.

Brian (1931) found Cypridina sp. on the gills of dolphinfish (Coryphaena Linnaeus, 1758) and called them parasites. However, this form is another luciferin bioluminescent seed shrimp, like $P$. parasitica, and is unlikely to be a parasite (Williams and Bunkley-Williams 2010). It is related to the famous sea firefly. Thus, 'firefly seed shrimp' do not appear to be parasites. Bioluminescent seed shrimp are sometimes reported as gill parasites because they feed on detritus, and the gills of an organism are the first part to deteriorate.

\subsection{Copepoda: Copepods}

Most of the $\sim 14,000$ described copepod species (WoRMS 2018) are free-living, some are commensal of invertebrates, and many parasitise invertebrates and fishes ( $\sim 6500$ described species, $\sim 1700$ species in fishes alone). Some parasites are little changed from the free-living form and even capable of free swimming between hosts (serial parasites). At the other end of the copepod, parasite spectrums are highly modified forms, which are fully embedded inside their hosts and can only be recognised as copepods by their larval forms.

\section{Life Cycle}

The basic life cycle of copepods has two phases (naupliar and copepodid) (Fig. 5.2). The egg usually hatches into a nauplius larva with a small, unsegmented body, and three pairs of functional appendages (antennules, antennae and mandibles). A maximum of six naupliar stages can occur, and all six are found in most freeliving copepods and in some parasites. Nauplii may be planktotrophic (feed on plankton) or rely on its yolk (lecithotrophic). Parasitic nauplii are usually lecithotrophic, have reduced setation on the three limb pairs, and no naupliar feeding process on the coxae of the antenna. In many parasites, the naupliar phase is abbreviated or occasionally lost. The final nauplius stage moults to become the first copepodid with a segmented body, a full adult set of cephalic appendages, and the first and second swimming legs. Free-living copepods have a maximum of five copepodid stages with one body somite added at each moult. In almost all copepod parasites, copepodid I is a free-swimming stage. Only Parachordeumium aphiurae 


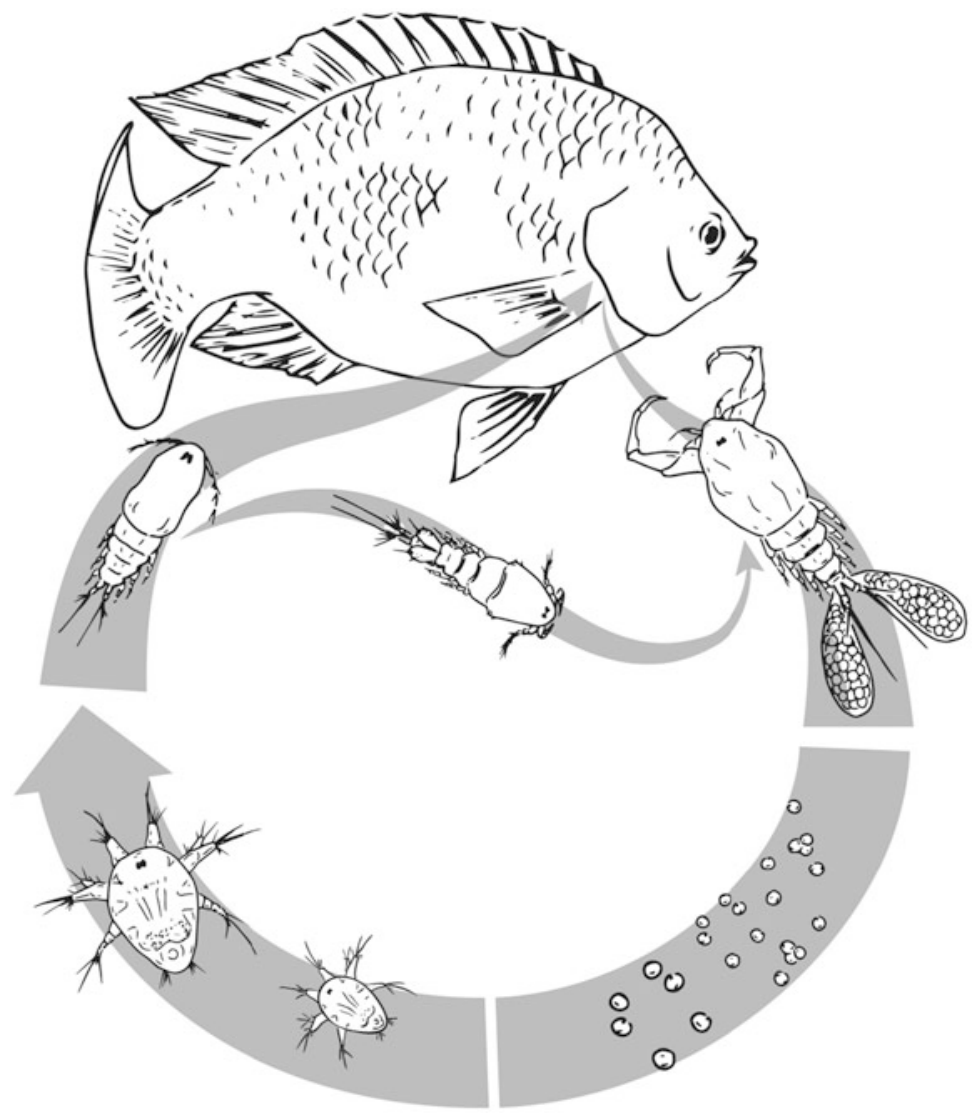

Fig. 5.2 The generalised life cycle of an Ergasilus von Nordmann, 1832, species showing the freeliving naupliar and copepodid stages as well as the parasitic adult female. Image from Smit and Hadfield (2018)

(Hérouard, 1906) and internal sea cucumber copepods have copepodid II hatching from their eggs (Martin et al. 2014). Copepodid I is in the typical crustacean form with two pairs of biramous swimming legs, each with 1-segmented rami. It begins free-living but is usually the infective stage. The copepodid stages provide a gradual transition from the copepodid body form to adult morphology, however transformed. In the more derived families, successive copepdid stages have increasing modifications in body form and limb structures. The fifth copepodid stage moults into an adult male or female. Following this moult, the female becomes sexually receptive.

\section{Further Life History}

Adult males may conduct precopulatory mate guarding and holding pre-adult females until the final moult. Males use an array of chemosensory aesthetics on their antennules to detect pheromones produced by females. Mating takes place soon 
after the female becomes sexually receptive and consists of mate detection, mate recognition, and mate capture and culminates in copulation. Sperm-containing spermatophore(s) are transferred to the female and usually discharged via copulatory pores, into seminal receptacle(s) within the genital region of the female. Sperm are stored for fertilization, which occurs as egg batches are laid. Females may produce several batches of eggs during her life. Most parasitic copepods extrude their eggs into paired egg sacs or uniseriate egg strings, although some are stored internally.

Copepods have a great diversity of invertebrate and fish hosts but are remarkably limited among other vertebrate groups with a single species on whales and dolphins, none on reptiles or birds, and only a very few, almost accidentally, on amphibians. Their simple life cycles may inhibit them from colonising more diverse vertebrates since their only mammal parasite has their most complicated life cycle. The life strategies of copepods suggest the simpler the host, the easier it is to parasitise.

\section{Additional Information}

Williams et al. (1996) reported, based on decades of research, that copepodids, chalimus, and immature adult copepods were very rare on Caribbean coral reef fishes but rather common on Western Pacific coral reef fishes (a 1-year study). One possible explanation for this difference is that Caribbean, small cleaner gobies (Elacatinus Jordan, 1904), are much more efficient in locating and removing these small, life cycle stages than are the larger Indo-Pacific cleaner wrasses (Labroides Bleeker, 1851). Thus, life strategies of Caribbean and Indo-Pacific parasitic crustaceans may operate under quite different selective pressures.

Brusca (1978) found adult cymothoid isopods of the genus Nerocila Leach, 1818, with damaged pleotelsons and uropods and speculated these injuries might represent predation by cleaner fishes. Williams and Williams (unpublished data) have found numerous injuries and missing parts of fish lice, fish-parasitic copepods, fish isopods, and gill worms (Monogenea) on, and in the gills, or mouths of fishes, and have observed copepods on fishes scurrying away from cleaner fishes, even though they were obviously too large to be removed. Cleaners may bite and injure crustacean parasites that are too large for them to remove (Cleaner nipping*). Cleaner nipping is a widespread, important, but hitherto unrecognised, life history peril for ectoparasites. Mahmoud et al. (2017) experimentally induced nipping and removal of fish parasitic isopods by portunid crabs. Cleaner shrimp similarly snip off the legs of small crustacean parasites to remove and eat them (Williams and Bunkley-Williams 1998b, unpublished data).

Copepod parasites of fish life cycles are little removed from those of their freeliving ancestors. They only have a few obligate intermediate hosts (pandarids, pennellids) and facultative intermediate hosts (lernaeids). The marine anchor worm (pennellid) intermediate hosts are pelagic squid and fishes, which required little modification for their planktonic larvae. A few adult females become embedded into host tissues but only to the point of mesoparasitism.

Many copepod parasites of invertebrates also have direct life cycles, but some have endoparasitic larvae and free-swimming adults, mesoparasitic larvae and 
ectoparasitic adults, and abbreviated or no larval stages. Some endo- and mesoparasitic forms can be quite modified.

\subsubsection{Cyclopoida: Short-Antenna Copepods*}

Most are small and free-living, but rarely planktonic, in marine and freshwaters. Some are commensal with invertebrates and only rarely damage their hosts (Williams and Wolfe-Walters 1990). Many parasitise molluscs, sea anemones, sea squirts, fishes, and a caridean shrimp (Conradi et al. 2012). The most well known is the anchor worm-an economically important fish pest, which was globally spread on goldfish and Asian carp and is now common worldwide. Species of the family Ergasilidae cause the most important problems in aquaculture and are distributed globally (Garcia and Williams 1985; Williams et al. 1994a, b, 1996; Thatcher and Williams 1998; Bunkley-Williams et al. 1999).

\section{Life Cycle}

Eggs are usually carried in paired or single sacs attached to first abdominal somite. However, some notodelphyids and Pectinophilus Nagasawa, Bresciani, \& Lutzen, 1988, store eggs internally. The full life cycle occurs in many copepods parasitising invertebrates and in ergasilid fish parasites. Ergasilids are also unusual in having naupliar stages feeding on unicellular algae. Thaumatopsyllids have a life cycle similar to that of the monstrilloids with parasitic nauplii inhabiting the gut of brittle stars and nonfeeding adults living in the plankton. The copepodid phase in Thaumatopsyllus paradoxus Sars, 1913 comprises the full five stages preceding the adult, and the entire phase from final nauplius to adult is completed without further food intake.

Parachordeumium amphiurae (Hérouard, 1906) hatches directly as an infective copepodid II, having passed through the first within the egg. In the tunicate parasite, Gonophysema Bresciani \& Lützen, 1960, the infective copepodid larva settles on the host and moults into an onychopodid larva, which is reduced to a simple elongate sac-like body provided with grasping antennae used for attachment. The onychopodid penetrates the skin of the tunicate and transforms into an amorphous, lobate adult (Rohde 2005).

The life cycle of anchor worms (lernaeids) has been described as direct with only one host, indirect with an intermediate host, or with a transfer host. The confusion lies in the apparent occurrence of all three cycles in the same species of anchor worm. The first copepodid usually attaches and develops through copepodid stages on the gills of a fish host. This may occur on the definitive host specimen, on a different specimen of the same species, or on a different species of fish. In the final copepodid stage, the female usually leaves the gills and attaches on the body of the same fish specimen (direct) or on a different one (indirect). Thus, a real intermediate host can occur, but this is not obligatory. Some of these species may be evolving towards an obligate intermediate host. This would represent a third method of 


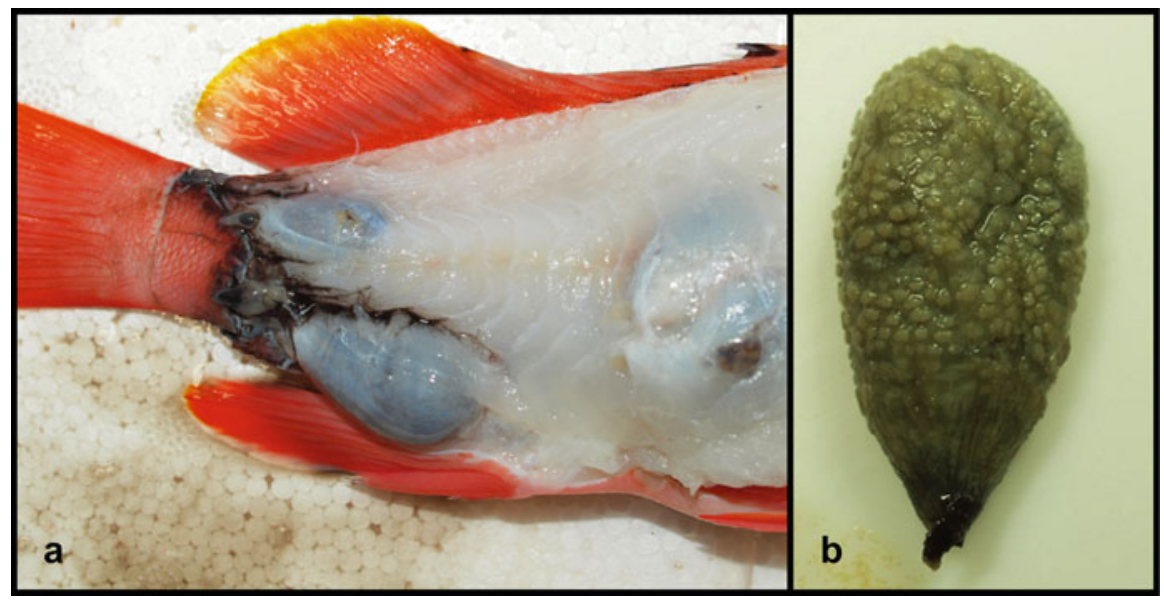

Fig. 5.3 Sarcotaces Olsson, 1872, from a blacktip grouper, Epinephelus fasciatus (Forsskal, 1775), collected in Okinawa. (a) embedded (skin has been removed to expose large, sack-like cysts), (b) removed large, sack-like cyst. Nagasawa et al. (2015) found eight cysts with females, males, naupli, and eggs in this host specimen. Images (C) Kazuya Nagasawa

developing, through an intermediate host, for which we propose the term parallel incorporation*.

Deep-sea copepods have been found resting and feeding on the mucus of gelatinous plankton (Humes 1985). Gasca et al. (2007) found mating males and females and early to late copepodid stages of Pseudolubbockia dilatata Sars, 1909, in the subumbrella cavity of deep-sea hydromedusae. We suggest this copepod is another protelean parasite in the short-antennae copepods.

\section{Further Life History}

Recent reports and descriptions of additional copepodids or of pre-adults in shortantenna copepods were probably growth stages, not moult stages (Martin et al. 2014).

\section{Additional Information}

The free-living stages in the life cycles of ergasilids and many of the copepod species parasitising invertebrates suggest that they have more recently evolved a parasitic lifestyle.

The most modified female of any of the fish-parasitic copepods are species of Sarcotaces Olsson, 1872. Osman et al. (2014) described and pictured the naupli of possibly a new species of Sarcotaces apparently host specific to a brownspotted grouper in the Arabian Gulf. Surprisingly, they found no females in six gall cysts, even though nauplii and males were present. Eggs were attached to the inner wall of the galls. Nagasawa et al. (2015) found eight cysts with females, males, nauplii, and eggs in a blacktip grouper (Fig. 5.3a, b) in the Ryukyu Islands.

Some short-antenna copepods occur in the musculature and sinus canals of fishes. Rosim et al. (2013) reported a new genus of ergasilid in the urinary bladder of fishes and considered the process of becoming an endoparasite. The muscle parasites are mesoparasites; however, their host positions do complicate their life cycles. 


\subsubsection{Harpacticoida: Wormlike Copepods*}

These are a very large group of mostly benthic copepods. Very few associate with other organisms, and almost none are known to be parasitic. In the family Tisbidae, 13 species parasitise deep-sea octopuses. Red Bug, an aquarium pest, has often been called a parasite of corals and is caused by the copepod Tegastes acroporanus Humes, 1981. Neoscutellidium yeatmani (Zwerner 1967) was also said to be a parasite of fish, and other wormlike copepods were noted to be parasites of whales, sea turtles, and manatees (e.g. Aznar et al. 2010). However, others have disagreed with these statements (e.g. Suárez-Morales et al. 2010a; Domènech et al. 2017). An apparent commensal species, the ochre copepod*, Balaenophilus manatorum (Ortíz, Lalana \& Torrez, 1992), has been observed in Caribbean manatees and sea turtles (Badillo et al. 2007; Williams and Bunkley-Williams unpublished data).

\section{Life Cycle}

Haracticoids probably follow the usual copepod life cycle of six naupliar stages and five copepodids found in their family. Dahms et al. (2000) discussed all that is known about the naupliar stages in Tisbidae. No development stages of parasitic forms had ever been found until López-González et al. (2000) described copepodids III and V. They suggested similar copepodid stages occurred internally (actually mesoparasitic) for the 12 other adult forms found in other octopuses. Therefore, their discovery completed the life cycle of these parasites (see Additional Information below). They hypothesised copepodid I was the infective stage and all these occurred internally. They did not discuss the naupliar stages, but these are expected to be the usual, six, free-swimming forms.

\section{Further Life History}

Adult males have only been found in four of the known haracticoid species. They may not live very long, not stay on the host very long, or even move to new hosts to copulate with other females.

\section{Additional Information}

The more complete life cycle suggested by López-González et al. (2000) is interesting and possibly correct. The only problem is that it is in disjunct halves. Until the external portion is matched with the internal portion in a single species, Ockham's razor would suggest these are portions of two different life cycles of tisbids on octopuses. The complete life cycle is thus still unresolved.

Ogawa et al. (1997) suggested Balaenophilus Aurivillius, 1879, species on sea turtles spend their entire life cycle on one host and cannot swim, like whale lice. Domènech et al. (2017) experimentally found nauplii can only crawl, but copepodids and adults can swim, albeit only for short distances.

Zwerner's (1967) discovery of Neoscutellidium yeatmani in the gills of Antarctic eelpout has been uncritically repeated so many times that it appears to be widely believed. However, this form has never been reported again. He found a mere seven specimens in the gills of 92 fish. These numbers are too low to sustain a viable life cycle for a parasite. This was very likely an accidental infection. This deep-water fish 
is known to eat molluscs, and 13 species of parasites in this family infect the gills of deep-water octopuses. These copepods could have spilled from an octopus to the fish consumed (see Prey Predator Transfer). More specimens with this association, with higher numbers per host, would need to be observed before this species could be confidently regarded as a fish parasite.

Many authors, even very recently (e.g. Aznar et al. 2010), have called the ochre copepod on sea turtles and manatees an ectoparasite, but it appears to be only a commensal. Suárez-Morales et al. (2010a) found that it was a harmless epibiont. This copepod formed ochre-coloured patches on the skin with no positive precursor relationship with barnacles or algae. Badillo et al. (2007) explored the possibility of parasitism of wormlike copepods on whales, sea turtles, and manatees in detail and believed that they ate keratin. They therefore claim this makes them commensals of whales, yet ectoparasites of turtles. This interpretation does not appear convincing, and we assert that they are all commensals.

Suárez-Morales et al. (2010a) also dismissed, another harpacticoid, Harpacticus pulex Humes, 1964, associate. It had been reported on a manatee only once, in captivity, and appears to be a non-associated predacious species.

Thus, we surmise wormlike copepods do not parasitise vertebrates or corals (Red Bugs). Some may be obligate commensals. Some may also harm vertebrates in captivity but are not parasites.

\subsubsection{Monstrilloida: Larval Parasitic Copepods*}

Larval parasitic copepods are wholly parasitic and occur worldwide (tropical, temperate, polar) in marine waters and infect benthic gastropod and bivalve molluscs, polychaete worms, and sponges (Martin et al. 2014). Approximately 166 species are known in five genera in a single family. Monstrilla Dana, 1849 (Latin for monster) is the best-known genus. They are not abundant anywhere but more often found in coastal and coral reef areas. Their biology and ecology are poorly known. The only mortalities attributed to larval parasitic copepods was a partial die-off of cultured brown mussels (Suárez-Morales et al. 2010b) caused by copepodids, the most damaging stage.

\section{Life Cycle}

Suárez-Morales (2011) reviewed the diversity, as well as the life cycles of larval parasitic copepods. They have a protelean life history unique among metazoan parasites (Martin et al. 2014). The first naupliar stage is free-living, but the rest are endoparasitic. All the copepodid stages are parasitic. Copepodid V, called subimago by Suárez-Morales et al. (2014), is the emergent stage. It moults rather quickly into an adult after it leaves the host. The adults are nonfeeding, free-swimming, reproductive, and pelagic. Most copepods produce egg sacs or spawn freely in the water column, but larval parasitic copepod females attach their eggs on their long, ovigerous spines with mucous secreted by the terminal part of the oviduct. Egg masses are produced iteratively corresponding to when the ovigerous spines grow. 
Eggs hatch into lecithotrophic nauplii that locate a mollusc or polychaete host and burrow into its tissues. They metamorphose into sac-like naupliar stage in the host's blood system. Two antero-ventral root-like processes absorb nourishment from the host. This stage is like no other crustacean larvae. Development continues endoparasitically until the last copepodid escapes from the host and undertakes a single moult into a reproductive adult. Suárez-Morales et al. (2014) described the first copepodids (III, IV, V) in detail, finding copepodid V to be pre-emergent and emergent.

\section{Further Life History}

Adults spend very little time in the plankton; therefore, they are rarely found and usually in low numbers. Suárez-Morales (2001) described one mass aggregation in the Caribbean Sea off Mexico.

Pelagic adults lack all cephalic appendages except antennules. The known hosts include pyramidellid and vermetid prosobranch gastropods, bivalves, and polychaete worms. Pairing the same species of free-swimming males and females morphologically has been difficult. The few morphological characters have also made taxonomic work difficult and often inconclusive, and descriptive standards have only relatively recently been upgraded (Grygier and Ohtsuka 1995). Suárez-Morales (2011) summarised the morphologies of the group to aid in identifying adults and life cycle stages.

Suárez-Morales et al. (2010b) were the first to find a monstrilloid in a commercial bivalve mollusc and to document the consequent harm and mortalities.

\section{Additional Information}

A radical placement of the larval parasitic copepods within the sea lice, based on SEM data, and antenna and caudal rami morphology, was proposed by Huys et al. (2007). The differences Suárez-Morales et al. (2014) found between these groups' copepodids suggested such a combination would be incorrect. Their life histories are also completely different in almost every respect.

A subimago refers to a pre-adult mayfly with wings, but no functional genitalia. It can fly, but cannot mate, and can be morphologically very similar to the adult. It moults into an adult. The copepodid V from Suárez-Morales et al. (2014) does not appear sufficiently different to warrant the use of this borrowed term. Kuris et al. (2005) suggests larval parasitic copepods are parasitoids. They do have a life cycle similar to parasitoids; however, we believe they are parasites because they do not kill their hosts.

Only 21 species $(\sim 18 \%)$ descriptions are based on both sexes, 63 on females only, and 32 on males. Molecular studies might help pair females and males of the species (Suárez-Morales 2011).

\subsubsection{Siphonostomatoida: Siphon-Mouth Copepods*}

Siphon-mouth copepods have siphon-like mandibles and a frontal filament that attaches to the hosts. These attributes have contributed to their great diversity 


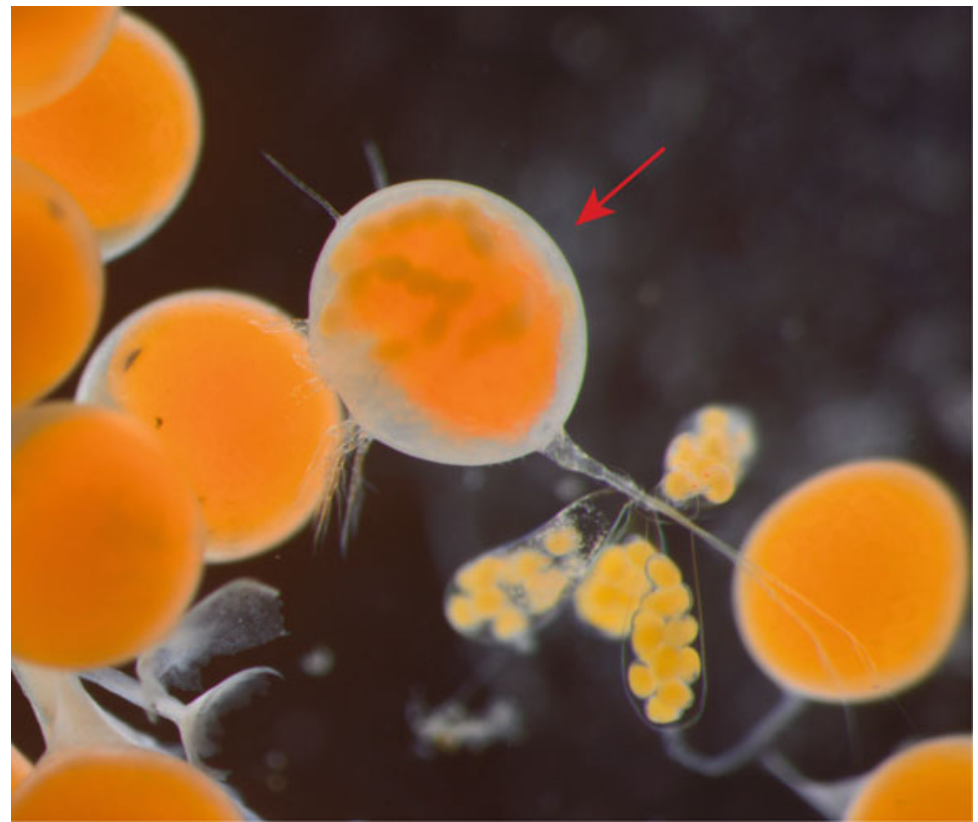

Fig. 5.4 Cuckoo copepods (nicothoids) parasitise the eggs of lobsters and spider crabs in Asia and Brazil. They mimic the eggs of their host and are not removed from the host's eggs, which they eat. The copepod (arrow) has egg strings. See life cycle in Otake et al. (2016). Image (C) Kaori Wakabayashi

( 2233 species in 39 families) and success. Sea lice (caligoids) are well known fish copepods and are very damaging to fishes in cage culture, salmon being particularly damaged by the salmon louse. Cuckoo copepods*, or nicothoids (Fig. 5.4), are the most famous of this group of parasites of invertebrates that harm commercially important lobsters and spider crabs.

This order holds $75 \%$ of the known copepod parasites of fishes (1544 species in 17 families). Most species are marine, but a few are freshwater (Garcia and Williams 1985; Williams et al. 1994a, b, 1996; Williams and Bunkley-Williams 1996; Bunkley-Williams et al. 1999).

\section{Life Cycle}

The full copepod life cycle occurs in many families of siphon-mouth copepods, especially those utilising invertebrates as hosts, such as asterocherids and cancerillids. In parasitic copepods, the infective larva is, with rare exceptions, the first copepodid, and life cycles are direct, involving only a single host. In fish parasites, the nauplius phase is reduced to two lecithotrophic stages and has uniseriate egg strings in which disc-shaped eggs are closely packed into one row extending the length of the string; and most nauplii have a single pair of modified caudal setae known as balancers (function unknown). Related families with 
multiseriate egg strings, such as lernaeopodids, sphyriids, and two genera of hatschekiids, have nauplii lacking balancers. In some lernaeopodids (Allela LeighSharpe, 1925; Clavella Oken, 1815; and Nectobranchia Hesse, 1863), the nauplius phase is reduced to one stage. In other lernaeopodids and some pennellids (Salmincola Wilson, 1915; Cardiodectes Wilson, 1917; and Peroderma Heller, 1865), it is lost completely, and eggs hatch directly into the infective first copepodid. Life cycle abbreviation also occurs in some parasites of invertebrates. The Herpyllobiidae and the genus Trochicola Dollfus, 1914, have only two naupliar stages, and only one nauplius is known for Gonophysema Bresciani \& Lützen, 1960, and for some genera of nicothoids. In other genera of nicothoids, some chordeumiids, and cucumaricolids, there is no nauplius stage. Izawa (2010) experimentally showed that there could be five naupliar stages in Gangliopus pyriformis Gerstaecker, 1854. In most fish parasites, the first copepodid secrets a chitinous frontal filament from an anteriorly located gland, soon after it settles on the host. This filament anchors the developing chalimus larva securely to its host (Rohde 2005).

The life cycles of sea lice have been the topic of much research and debate of late. This attention is due to the damage that they cause cage cultured fishes, particularly of salmonids (Lafferty et al. 2015). Knowing the correct life cycle is critical in determining when to treat for the damaging stages. Caligid sea lice were thought to have four chalimus stages and one or two pre-adult stages. Several recent papers have challenged this scenario (e.g. Hamre et al. 2013; Venmathi Maran et al. 2013). They found that the typical caligid life cycle comprised eight stages: two naupliar, one copepodid, and four chalimus stages preceding the adult in Caligus Müller, 1778, but with the four chalimus stages represented by two chalimus and two pre-adult stages in Lepeophtheirus Heegaard, 1943. This is a profound change with significant implications for the aquaculture industry. As the typical caligid life cycle may not exist, it may be necessary to determine the life cycle of every species of damaging sea louse. Again, only 3.8\% (17) of life cycles are known for 450 caligid species (Venmathi Maran et al. 2013).

The new Stingray Laser Gun has only been used to shoot adult sea lice (Bevanger 2016). Considering the flexibility and accuracy described for the gun, it could probably be used to shoot multiple life cycle stages.

Pre-adults also secrete a frontal filament during moulting but soon detach and become motile. Frontal filaments and chalimus larvae occur in most fish parasites for which the larvae are known, but none occur in the lernanthropids. Nicothoids use a similar filament to attach their developing larva to the exoskeleton of a crustacean host. The basic copepodid stages, as primitively retained in Cancerilla Dalyel, 1851, comprise five stages plus the adult. One pre-adult stage in Caligus clemensi Parker \& Margolis, 1964, or two pre-adult stages in sea lice, as true moult stages, have been added to the basic life cycle. The general trend in parasites is to simplify or reduce ancestral free-living life cycles. These additions are quite unusual and have only been found in this order.

Pennellids (marine anchor worms*) differ from all other copepods by needing (obligate) intermediate hosts (fish, squid, pelagic gastropod) in order to develop. The copepodid larva becomes a chalimus larva stage on the intermediate host. Some male 
and female chalimus individuals mate on this host. Others leave the host and mate in the water column. Males soon die; females have a short planktonic period, find a final host, and metamorphose into an adult (Poulin 2011a). Brooker et al. (2007) reviewed the literature and thoroughly described the life cycle and life history of the famous pennellid copepod Lernaeocera branchialis (Linnaeus, 1767).

Not all marine anchor worms have intermediate hosts. Okawachi et al. (2012) suggest Peniculus minuticaudae Shiino, 1956, has a direct life cycle, unlike most pennellids, because copepodids, chalimi, adult males, premetamorphic adult females, and post-metamorphic adult females of the parasite were all found on a single fish. They also describe adult male, copepodid I, and late chalimus stages and redescribe post-metamorphic and premetamorphic adult females.

Ismail et al. (2013) described a complete, direct life cycle of a pennellid, Peniculus minuticaudae Shiino, 1956. The hatching stage was an infective copepodid followed by four chalimi and adult instars. Males associated with various pre-adult females, but copulation only occurred between adults. Fertilised premetamorphic adult females carrying spermatophores may detach from the host and settle again before undergoing massive differential growth into the post-metamorphic adult female. Many marine anchor worms (pennellids) have intermediate hosts. This is the first life cycle of the group in which the female remains in the same position on the same host specimen (Ismail et al. 2013).

Otake et al. (2016) had named a new cucukoo copepod* in 2013 and described its abbreviated nicothoid life cycle of free-living nauplius I (NI) observed hatching from female egg sac, copepodid I (CI) found on body of host, and copepodid II+ (CII+) and adults found on host eggs. They surmised NI develops into infective CI in the water column, CI settles on the body of host, and CI moults to CII, migrates to host egg masses, and develops into CII+ and then adults. Adults mate on host egg masses.

Brazenor and Hutson (2013) examined the effects of temperature and salinity on the life cycle of Lernanthropus latis Yamaguti, 1954, on the euryhaline barramundi in Australia. Nauplii hatched best at $30-32{ }^{\circ} \mathrm{C}$ and 35\%. None hatched in freshwater and only a few in brackish water. Lernanthropus latis is euryhaline, but freshwater can be used to break its life cycle.

Økland et al. (2014) described two new rhabdovirid viruses, which occurred in all life cycle stages of the salmon sea louse in Norway. The viruses caused tissue necrosis in adult copepods but did not infect fish. They speculate the copepod injects the virus in the fish to confuse its immune system as part of its purposeful life cycle strategy. We find their suggestion interesting but rather astonishing. Copepods do not purposely use viruses; theirs was not the first report of copepod viruses but the fifth; many other fish-parasitic viral vector mutualists* exist to the benefit of crustacean infective stages; and we designated the first viral crustacean mutualists*.

\section{Further Life History}

Sea lice are notorious for causing problems in marine aquaculture, particularly of salmonids (e.g. González and Carvajal 2003; Lafferty et al. 2015). The contamination of the environment by salmon sea lice from fish farms is a politically and economically important question that has received recent attention. Serra-Llinares 
et al. (2016) found that farms increase the infection of local, wild salmonids. They also noted Thorstad et al. (2015), and others strongly suggested the transmission of lice from farm salmon to wild salmonids in systems where the fish occur in close vicinity. These adult caligids can freely swim between hosts (host hop*) and build up in fish cages. Few parasitic copepods have this life-history advantage (serial parasites). The filtering effect of cages tends to concentrate sea lice. Adult male and female caligids are frequently found in plankton samples (Venmathi Maran and Ohtsuka 2008). They must spend considerable periods free-swimming off hosts. Some species have even been described only from the plankton, and their hosts remain unknown.

Ohtsuka et al. (2011) previously described a dajid isopod and a nicothoid copepod parasitising the marsupial lumen of a mysid in Japan. The adults eat mycid eggs and drastically reduce the population of mysids. Infective stages of the copepod penetrate host body tissues, feed, and grow. Infective isopods penetrate the space between the carapace and the dorsal tergites. Remarkably, isopods and copepods rarely occur together, but alternately, albeit continuously, parasitised the same host at different times of the year. This life history association is unique in parasitology. We will call it alternate host sharing*. This allows both parasite species to use all available resources of the host.

\section{Additional Information}

Three species of copepods are known to fully encyst in intermediate host fish tissues. Only one has been named. Lewis (1964) found the first pandarids to encyst in the fins of bony (teleost) fishes in Hawai'i. Lewis only found male copepodids and immature males, which he tentatively identified as Nesippus cf. costatus Wilson, 1924.

Amaterasia amanoiwatoi Izawa, 2008, was described from female copepodids I, III, IV, and V and a female escaping from a copepodid V. Izawa found 5, 13, 16, and 41 copepodids in fin galls on a single striped triggerfish from the Eastern Pacific (Izawa 2008). A new species of Amaterasia Izawa, 2008, was found in individual cysts, as Lewis (1964) had found, not galls, on the body and dorsal fin of 14 species of fishes in Puerto Rico (Williams and Bunkley-Williams unpublished data).

Tang et al. (2012) found that Lewis' (1964) younger early encysted stage was a copepodid IV, the older early encysted stage was a copepodid V, and the lateencysted and recently excysted stage was an immature adult male. Izawa (2008) and Tang et al. (2012) speculated about the life cycle of their species but made no descriptions. Tang et al. (2012) suggested encystment could be protection from coral reef cleaners.

We propose a new life cycle for these encysted copepods*: there are five planktonic nauplii (Izawa 2010) and a first copepodid stage. The CI is infective (found in galls; Izawa 2008) and settles from the plankton onto a host and forms a cyst or gall under the skin on the fins or body of a variety of different bony, coral reef fishes. Lewis (1964) found surgeonfishes (acanthurids) were preferred in Hawai'i. However, parrotfishes were preferred in Puerto Rico (Williams and Bunkley-Williams unpublished data). The cysts are open posteriorly for respiration (mesoparasite). After feeding, developing, and moulting through CI-CIV, the fifth copepodid emerges from the cyst leaving a moulted 
exoskeleton behind. Lewis (1964) found these forms were soft and pliant, which he interpreted to be of value in leaving their cysts. It was actually because they had recently moulted. The $\mathrm{CV}$ then swims out and searches for a shark definitive host. There could be some predator transfer involved since the copepodids are in hosts preyed upon by sharks. The encysted copepod life cycle* is the only mesoparasitic life cycle known in parasitology and only the second obligate intermediate host life cycle discovered in copepod parasites of fishes. Many tapeworm (cestode) shark parasites have bony fish intermediate hosts, but this is the first crustacean one ever discovered.

The evolutionary usefulness or necessity of pennellid intermediate hosts has never been explained (Poulin 2011a; Martin et al. 2014). We can discern at least seven, nonmutually exclusive explanations:

1. Easier to Find - the open sea is a vast 'desert' with very few final hosts, but intermediate hosts are far more common (Williams and Bunkley-Williams 1996).

2. Easier to Infect - intermediate hosts are generally smaller, slower, and have better attachment sites.

3. Longer Survival - feeding and resting on the immediate host extends the parasite life cycle and replenishes their energy.

4. Bigger is Better-adult females are stronger and attach better than larval forms.

5. Ride to Final Host-intermediate hosts are often food for, or associated with, the final hosts. Even when eaten, prey-predator transfer can occur (Williams and Bunkley-Williams 1996).

6. Faster Attachment - when the female settles on the final host, water currents, host movements, and sometimes host cleaning or cleaner organisms make her stay perilous (loose on the host). Nutrients from the intermediate host can be used to permanently attach without waiting to feed on the final host and digest.

7. Widen Host Range - the only crustacean parasite to infect mammals cannot do so without an intermediate host.

Kik et al. (2011) found Lepeophtheirus acutus Heegaard, 1943, was a potentially dangerous sea louse of elasmobranchs in captivity. Not only did it damage sharks and rays but could complete its life cycle in an aquarium.

Muñoz et al. (2015) found early and late copepodids of two species of Caligus, two of Trifur Wilson, 1917, and two of unknown families, on juvenile fishes. They examined thousands of nearshore, planktonic fishes, found 3\% infected, and $1 \%$ infected by multiple species. They thus opened a completely new dimension into parasitic life strategies, which we have termed planktonic juvenile fish infection*. Juveniles of a single host species have sometimes been examined for parasites (e.g. Nielson et al. 1987; Herrera 1990), but masses of juveniles have seldom been studied (e.g. Herrera 1984; Felley et al. 1987; Cribb et al. 2000). Muñoz et al. (2015) concluded these juvenile fishes were intermediate hosts for these copepods. However, caligids are not known to have intermediate hosts, and pennellid intermediate hosts are adult fish or squids. They had also concluded the copepods would mature too soon to develop with the host fishes. However, we believe the hosts and the parasites will grow up together in these cases. Alternatively, these may be small predators* feeding on juvenile fishes as a part of their life cycles (Table 5.1). Whichever is the case, this 
Table 5.1 Crustacean life cycles with predation phases

\begin{tabular}{l|l|l}
\hline Name & Predator/host & Examples \\
\hline Micropredator & $<1 / 1000$ & No crustaceans, microbial organisms \\
\hline Minipredator & $>1 / 1000<1 / 100$ & Fish gnats, serial parasites, jelly parasitoids \\
\hline Smaller predator & $>1 / 100<1 / 10$ & Copepodids, fish gnats, fish isopods, fish lice \\
\hline True predator & $>1 / 10$ & Some fish isopod juveniles \\
\hline
\end{tabular}

extends and prolongs life cycles further than we had imagined. Interestingly, only copepods are taking advantage of this resource, not only among crustacean parasites but also among all parasites. Muñoz et al. (2015) also searched for internal parasites and found none.

Venmathi Maran et al. (2013) clarifications of sea lice life cycles are important for timing the treatment of these damaging parasites in cage culture. As noted above, of the 450 species of caligids, only 17 complete life cycles are known in three genera (Caligus, Lepeophtheirus, Pseudocaligus [=Caligus]) (Venmathi Maran et al. 2013). Thus, and similar to many other parasitic Crustacea, we know very little about them.

Cuckoo copepods are named after the nest-parasitic birds by that name (Cuculidae). These copepods parasitise the eggs of lobsters and spider crabs in Asia and Brazil. They mimic the eggs of their host (Fig. 5.4) and are thus not removed by the host, as they resemble the real eggs, which they eat. Otake et al. (2016) called these copepods 'associates'. Kuris et al. (2005) calls them 'symbiotic egg predators'. However, we consider them to be true parasites, damaging and feeding off their hosts, with adults that never leave the host.

Flyingfishes are food for many large offshore predators, which host Pennella spp. Flyingfishes were probably a downward incorporated intermediate host for a Pennella spp. at one point. Eventually, a former intermediate host speciated into Pennella exocoeti (Holten, 1802) on flyingfishes.

\subsection{Cirripedia: Barnacles}

Høeg et al. (2009) found that cypris larva morphologies of the barnacles reinforced the concept that this larva was a prerequisite to the tremendous success of that taxon. The evolution of parasitism, obligatory in three major taxa, was the result of convergent evolution. Thecostraca was distinct from Tantulocarida (Sect. 5.10) because they differed in the life cycle stages that penetrated their hosts (Høeg et al. 2009). 


\subsubsection{Acrothoracica: Burrowing Barnacles*}

Burrowing barnacles (burrowing crustaceans of Kolbasov 2009) have 70 species in 12 genera, 4 families, and 2 orders, but many species have probably not been discovered. They have been called parasites of molluscs, echinoderms, and corals (anthozoan cnidarians) by many authors (e.g. Williams et al. 2011) but are not.

\section{Life Cycle}

These very small, naked barnacles bore into calcareous material such as animal shells and inanimate hardgrounds. Burrowing barnacles produce a slit-like hole in the surface known by the trace fossil name Rogerella Saint-Seine, 1951. They feed on plankton (Kolbasov 2009). They do not feed on their associates. Burrowing barnacles are only found in their hosts' shells and never touch their flesh, except possibly in the case of corals. They are not obligates, perfectly happy living on inanimate hard ground, and do not harm their hosts. We do not understand how they can be called parasites?

\section{Additional Information}

Williams et al. (2011) called a burrowing barnacle a parasite and showed that it fed on its host hermit crab's eggs. However, this was predation, not parasitism. Murphy and Williams (2013) suggested burrowing barnacles in hermit crab shells were 'transient parasites' because they somehow consumed hermit crab eggs and preferred female hermit crab shells. In our opinion, burrowing barnacles are not parasites, as least when considering the current available information.

\subsubsection{Rhizocephala: Parasitic Barnacles*}

The parasitic barnacle is the 'poster child' for gross modification of parasitic forms. Adults are unrecognisable as crustaceans, let alone barnacles. Only their larval forms resemble those of normal barnacles (see Sect. 5.6.3). They are also famous for controlling the behaviour and morphology of their hosts. They damage commercially important crustaceans. About 288 species are known, about a quarter of all barnacle species. They infect crustaceans, mostly true crabs (brachyuran) and anomuran crabs (hermit crabs, squat lobsters, etc.). A few parasitise caridean shrimp, mantis shrimp, peracarids, and even other barnacles. We worked on the button-crab parasite* on the blue crab in the Gulf of Mexico but have not found such obvious parasitic barnacles in the Caribbean.

\section{Life Cycle}

Unlike most barnacles, parasitic barnacles have separate sexes. Adults are sessile, with females consisting of a sac attached to the crab host (externa) (Fig. 5.5) with rootlets of tissue flowing cancer-like through the host's body (interna) and dwarf males inside the female. Some females sequentially only produce male larvae from large eggs, female larvae from small eggs or mixed sexes. They have the usual 


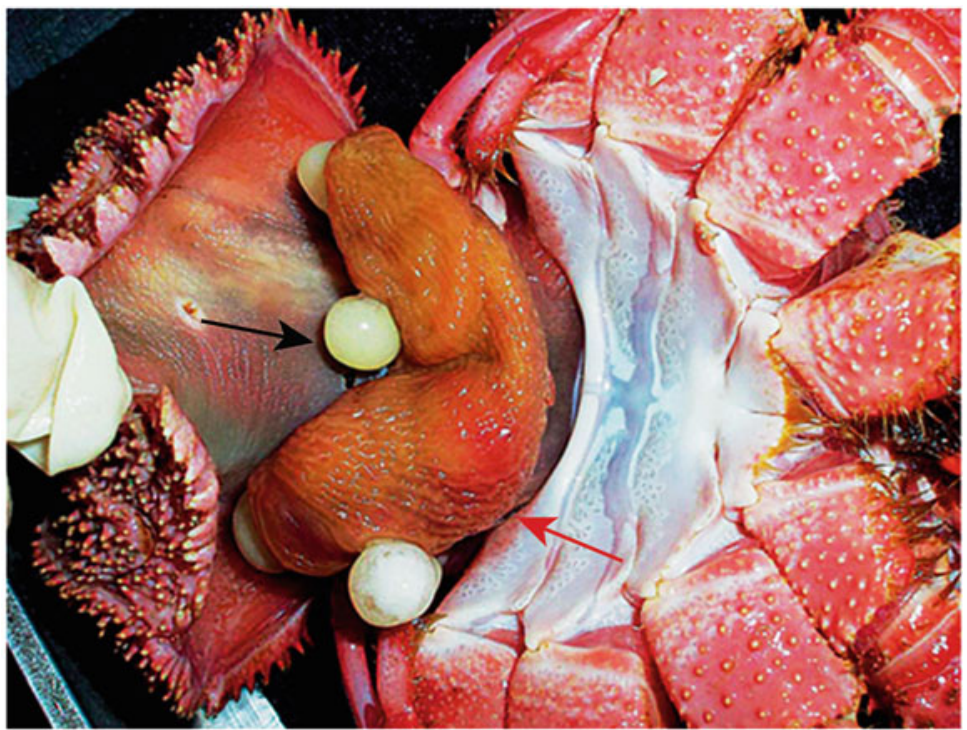

Fig. 5.5 Ventral surface of the false king crab, Paralomis granulosa (Hombron \& Jacquinot, 1846), parasitised and sterilised by Briarosaccus callosus Boschma, 1930 ("greater than" symbol-shaped mass - red arrow), externa of this rizocephalan parasitic barnacle, which, in turn, was hyperparasitised and rendered sterile by four Liriopsis pygmaea (Rathke, 1843) (pearl shapes-black arrow) epicarid parasitic isopods (Cryptoniscidae). A different black-and-white photograph of these associations was in Lovrich et al. (2004). Associates in this present colour photograph have been misidentified in several popular sites online. Image (C) Gustavo A. Lovrich

naupliar instars and infective cyprid; however, in some species, embryos develop directly into cypris larvae before adult females release them. The nauplii are smaller than those found in other barnacles, which may be necessary to produce them in much greater numbers. The larvae are lecithotrophic. The cypris are usually at least 2 days old before they settle on a host. In kentrogonids, male cyprids are larger than female ones. Some have a naupliar eye, and others have compound eyes. Injection of the vermigon (the migratory internal stage) happens within 1-3 days after settlement. When many male larvae exist, only the fastest and strongest will succeed. When there are few males, the female remains receptive longer. When a virgin is found, the male cyrid must settle close to the orifice, enter the brood chamber, and inject a trichogon stage. The trichogon looks like a verogon, except with a spiny collar. It becomes a dwarf male and reaches one of two male receptacles. Once established, the dwarf male undergoes spermatogenesis and is nourished by the female parasite for the duration of its life (cryptogonochorism). The male cypris of akentrogonids penetrate the host or the virgin female with their antennules and without a kentrogon or trichogon. A single male can fertilise all the broods of the female. A female externa produces several batches of larvae and drops off the host just before the host moults. A new, young externa is produced from the interna and emerges from the host body (Waiho et al. 2017). 


\section{Further Life History}

The externa takes the place of the crab egg sac. The host's behaviour is chemically altered causing sterilisation and only moults when the aged externa drops off. The host treats the externa as if it were its egg sac. Male crabs, which would never have carried eggs, care for the externa. They are even more affected since their tail shape changes to the female configuration to better protect the externa (feminization). An externa may last for several years.

\section{Additional Information}

These life cycles show parasitic barnacles are the most parasitic of the crustaceans. They totally penetrate all the tissues of their host, control the behaviour of the host, and are drastically modified for the parasitic existence.

Glenner and Hebsgaard (2006) made a comprehensive phylogenetic analysis of the evolution of life history strategies in parasitic barnacles. They found they were monophyletic with a filter-feeding barnacle-like ancestor. The host-infective kentrogon larva, inserted in the life cycle of Kentrogonida, was ancestral, and a homologue of the juvenile thoracican barnacle. The host inoculation in Akentrogonida (last pelagic larval stage directly injects into haemolymph) is derived and has evolved only once within the parasitic barnacles. The ancestral host is anomuran (hermit crabs, squat lobsters, etc.).

Alverez et al. (2010) described the externae of the button-crab parasite in detail. Unlike most parasitic barnacles, they found only a single male receptacle but two implanted males. They questioned what sorts of male-male competition occurs when they are not separated.

Glenner et al. (2010) used light and SEM microscopy of cypris larvae to supplement molecular data showing that parasitic barnacles, thought to be the most primitive, were actually the most advanced, along with many evolutionary extrapolations.

These parasitic barnacles are sometimes hyperparasitised by cryptic isopods (Fig. 5.5). Just as the barnacle sterilises its crab host, the hyperparasite sterilises its fellow parasite. There are some indications that swimming decapods, which must remove epibionts, are more resistant to the attachment of settling crustacean parasites; however, no experimental evidence exists (Boyko and Williams 2009). In the reverse, Li et al. (2015) found a species of crab parasitised by a rhizocephalan had many more barnacles, and other epibionts, than those not parasitised. This is an example of our positive precursor*.

Several authors have recently suggested parasitic barnacles could be host-specific control agents for nonindigenous crabs, such as the problematic green crab. However, parasites seldom make effective controls, and well-intended introductions have often been disastrous.

\subsubsection{Thoracica: Normal Barnacles*}

This group containing the normal acorn and gooseneck barnacles has four parasitic species in three families and three genera. The shark barnacle* is little modified for 
parasitic existence except for the loss of its shell and adding a tough tegument. Polychaete barnacles* are moderately modified. The jellyfish barnacle* is the least modified with small, thin plates. The cirri (feeding legs) are still used for obtaining food. These free-living-to-parasitic transitionals are, of course, of great scientific interest (Rees et al. 2014). The shark barnacle is famous for promoting Charles Darwin's interest in barnacles.

\section{Life Cycle}

They are hermaphroditic with all individuals possessing a penis, and no dwarf males are known in shark barnacles and polychaete barnacles. Adults are receptive as females for fertilisation after moulting. They use their penis to copulate with an adjacent individual as other hermaphroditic free-living barnacles. Barnacles have the longest penises, relative to body size, in the Animal Kingdom. Oddly, dwarf males have been found attached to larger hermaphrodites in some species (androdioecy; Sawada et al. 2015).

The fertilised egg hatches into a standard, barnacle nauplius, a one-eyed, pearshaped larva with a head, a naupliar eye, a pair of horns, and a telson. Nauplii are usually brooded by the parent and released after the first moult swimming freely with setae. Towards the end of the sixth instar, they begin to develop compound eyes and a globular shape. They undergo 6 months of growth, passing through five instars, before transforming into the cyprid stage, which has a carapace, is torpedo-shaped and is the stage before adulthood. It does not feed and only searches for a host. This may last for a period of days to weeks. It explores potential hosts with modified sensory antennules. Once it finds a host, it undergoes metamorphosis into a juvenile barnacle. Shark barnacles are usually found in pairs near the dorsal fin of their shark host; therefore, the cypris larvae must not only find a host but also a partner (see founder pair*).

\section{Further Life History}

Shark barnacles breed through the year and live on their host for at least a year. Both genera feed on the host by roots formed from their peduncles. They mostly infect small specimens of sharks $(10 \%)$, and incidence is reduced $(2 \%)$ in large ones. Gonads of infected sharks never develop (nutritional sterilisation*).

\section{Additional Information}

Williams et al. (2010) reported a prey-predator transferred isopod in a lantern shark but found no barnacles. Some epiphytic normal barnacles attach to hosts or parasites (e.g. Williams 1978; Williams and Williams 1986b; Mignucci-Giannoni et al. 1998), and the sea turtle barnacle has been found on the carapace of a speckled crab at Dauphin Island, Alabama (Williams and Bunkley-Williams unpublished data).

Shark barnacles parasitise at least seven deep-sea lantern sharks and dogfish (Ommundsen et al. 2016). Furthermore, two species of polychaete barnacles and a jellyfish barnacle are known (Yusa et al. 2015). The jellyfish barnacle is an obligate associate of jellyfishes, and Pagès (2000) found it attached in an area with few nematocysts near the gonads of the jellyfish host. We believe the lack of stinging cells may have originally attracted the barnacle infective stage to this area, and the 
gonads became a convenient food source later. A simple development of parasitism is still in progress.

\subsection{Facetotecta: Y-Parasites*}

The 11 species in the larval genus Hansenocaris Îto, 1985 of y-parasites remain a mystery in parasitology. Y-larvae have been known for 129 years, but their assumed parasite adult forms and hosts have never been found. These parasites are both everywhere and nowhere. They must be both parasitologically and ecologically very important, but how remains a mystery.

\section{Life Cycle}

Y-nauplii are egg-shaped, with a faceted cephalic shield and carapace (reticulated cuticular ridges, forming plates), from which the group derives its name, and a relatively long, ornamented abdomen. They have a characteristic bobbing motion when swimming that makes them easy to distinguish in plankton samples. The function and homology of the naupliar horn pores and dorsocaudal organs have been much debated but remain uncertain. They are either planktotrophic or lecithotrophic. Only lecithotrophic nauplii have been raised through all five instars. Planktotrophic nauplii have food visible in their stomachs. Unlike barnacle larvae, the y-cyprid is constantly swimming. This larva is distinctively the costracan. The y-cyprid has a univalved carapace that only partially covers the larval body and resembles an inverted boat but with elongated sharp posterior ends (Fig. 5.6). Paired compound eyes lie anteriorly in the body with antennules, labrum, paraocular processes, postocular filamentary tufts, and two pairs of rudiments of antennae and mandibles underneath (ventrally). The antennules have four segments. All larval stages are free-living and semitransparent. The cyprid does not feed. A number of species have been described based only on a y-cyprid $(N=7)$ or even a y-nauplii $(N=4)$. As with barnacles, the cyprid seeks a host to infect. It has compound eyes, is ambulatory with its antennae, and can produce an adhesive glue. Recently, possible juvenile forms have been produced by treating y-cyprid with the hormone 20-hydroxyecdysone to stimulate ecdysis and the transition to the next life cycle phase. The resulting slug-like, unsegmented, and limbless form was called 'ypsigon' (Fig. 5.6). It is formed in the cypris and escapes from its body (Glenner et al. 2008). This may be a juvenile. See Høeg et al. (2014) for more detailed descriptions, illustrations, and photographs.

\section{Further Life History}

Molecular studies support the present phylogeny of the y-parasites (Høeg et al. 2014). They remain mysterious parasites with unknown adults and hosts.

\section{Additional Information}

Glenner et al. (2008) suggest the ypsigon is the 'vermigon of the y-parasites'. Just like the barnacle vermigon, it is the injected form that will become the parasitic adult. This may be true, but just because formless structures are produced by similar 


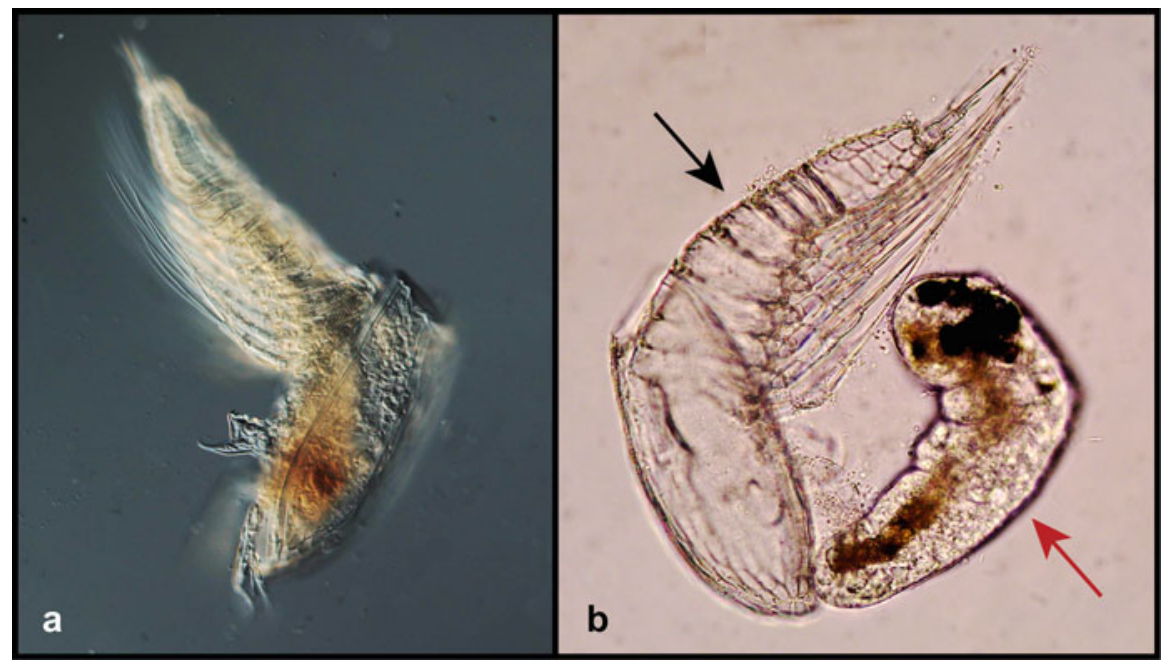

Fig. 5.6 Facetotecta (y-parasites). (a) Free swimming y cyprid: showing the carapace, the thorax with six pairs of natatory legs and the segmented abdomen, (b) an ypsigon (red arrow) within minutes of leaving the empty cuticle of the spent y-cyprid (black arrow). The cuticles of the carapace, thorax, appendages and abdomen are clearly visible, but no tissues remain in the spent y-cyprid. The worm-shaped ypsigon exits by amoeboid bending and peristalsis movement of the body and is believed to be the initial parasitic stage that enters into the tissue or body cavities of a still unknown host. Details in Glenner et al. (2008). Images (C) JT Hoeg, M Grygier, Y Fujita, H Glenner, J Olesen

methods and appear similar does not make them the same. Their notion is courageous, albeit premature.

Glenner et al. (2008) found that 40+ morphological types of y-larvae occurred very abundantly around Sesoko Island in Okinawa. This unusual situation may indicate a centre of origin or, possibly, a diversity hot spot. Yet, the adults remain unknown. The 'phantom' adults are neither too rare to discover, nor in some obscure unexamined hosts, nor in some restricted localities. The larvae are just too abundant, widespread, and diverse for such restrictions. This is an adult that parasitologists may be encountering all the time but just cannot recognise. The adult y-parasites may be morphologically similar to another parasite, with which they are confused, or so morphologically indistinct as to be unrecognisable as a parasite. Glenner et al. (2008) came to a similar 'highly simplified structure' conclusion. 


\subsection{Ascothoracida: Copebarnacles*}

These are uncommon parasites that cause little damage and infect non-commercially important hosts. Copebarnacles are a small group of $\sim 107$ species in 23 genera, 6 families, and 2 orders, which are ecto-, meso-, and endoparasites. They occur from the intertidal to the deep sea around the world.

\subsubsection{Laurida: Coral Copebarnacles*}

Coral copebarnacles are ecto-, meso-, and endoparasites of corals (Scleractinia, Zoantharia, Antipatharia and Alcyonacea) and ectoparasites of crinoids (Waginella). The suggested common name is based on their bodies that are similar to copepods but are related to barnacles.

\subsubsection{Dendrogastrida: Echinoderm Copebarnacles*}

Echinoderm copebarnacles are meso- and endoparasites of echinoderms (Asteroidea, Echinoidea and Ophiuroidea).

\section{Life Cycle}

Sexes are separate except for the hermaphroditic petrarcids. Sex determination is genetic, and some male and female larvae differ in the armature of chemosensory aesthetascs (as in most parasitic barnacles). A-nauplii have an oval, bowl-shaped head shield, which is broader anteriorly, and setiform frontal filaments. A-cypris have a bivalve carapace and antennules with hooked claws. Echinoderm copebarnacles brood their larvae and only release a-cypris, while coral copebarnacles release nauplii. Usually, six naupliar instars (sometimes two brooded) are followed by one to two cypris-like stages (a-cypris, ascothoracid larvae) (similar to the cirripede single cypris and the y-cypris of y-parasites). Many are lecithotrophic, but some species are planktotrophic. Coral copebarnacles a-cypris occur in the plankton. The a-cypris (ascothoracid-larva) attaches by grasping antennules rather than by glandular secretions as in cirripede cyprids. When two a-cyprid instars occur, the second is the settlement stage. Many species have an abbreviated ontogeny, and the entire naupliar phase is sometimes brooded or embryonised. No complete life cycle is known for any copebarnacle. Neither host infection, nor copulation has ever been observed. Most females have seminal receptacles on their legs, but not in dendrogastrids. Some male a-cyprids have testes with mature sperm and possibly fertilise the females through the pore in the host. Some dwarf males sit close to the aperture, and others live in the mantle cavity of the female. The transition from a bivalved stage to a sac-like carapace is suspected to occur in one moult, but this remains unresolved. A 'post-larval' stage of females and males has been discovered, and second-stage a-cyprids, ready to moult to 
the male stage, have been observed. The cypris for the modified, enlarged female, and dwarf males of Gorgonian copebarnacles (Gorgonolaureus Utinomi, 1962) are not known. The complete life cycle is equally not known (Kolbasov et al. 2015). Threefive naupliar instars occur. Gorgonolaureus muzikae Grygier, 1981 has been noted to be frequently infected by hyperparasitic cryptoniscoid isopods (Kolbasov et al. 2015).

\section{Further Life History}

Some ectoparasitic males and females can swim from host to host. Others are semipermanently glued in place. Some are endoparasites in galls in corals and sea stars. Others even start as an endoparasite but eventually create an opening to the outside and become mesoparasitic. Parasites of cnidarians occupy individual polyps or nodules formed from several polyps. Many of those in echinoderms sterilize their hosts. Feeding methods are uncertain. Many have piercing-sucking mouthparts, and the cuticle of at least one species seems capable of absorptive feeding (as in parasitic barnacles). Hyperparasitism of ascothoracidans by cryptoniscid isopods is not uncommon, occurring in four of the six families. Some sterilise their copebarnacle hosts. In a spectacular case, a copebarnacle, which had sterilised its host, was, in turn sterilised by an isopod. Their body is enclosed by a bivalve carapace often modified and enlarged for brooding and possibly food absorption in females.

\subsection{Subclass Tantulocarida: Minute-Crustacean Parasites*}

Minute-crustacean parasites are a highly specialised, small (36 species in 23 genera and 5 families) group of minute $(<0.3 \mathrm{~mm})$ ectoparasites on small benthic crustaceans (copepods, isopods, tanaids, amphipods and ostracods). They occur from the subtidal to the abyssal, widespread in the southern and northern hemispheres, and in both cold and warm waters. They claim the fame of the world's smallest arthropod $(76 \mu \mathrm{m})$.

\section{Life Cycle}

Minute-crustacean parasites have asexual and sexual life cycles. The first is when a parthenogenetic female develops from a tantulus larva and remains permanently attached to its larva, and the host, as sort of a 'Frankenstein' female. It feeds off the host and produces numerous eggs. This adult female has a large, sac-like trunk attached by the larval head. The larval trunk is sloughed leaving a scar, but no complete moult occurs. Eggs develop within the trunk sac and hatch directly into the infective tantulus larval stage.

The second life cycle occurs when a free-living semelparous female is produced by an attached tantulus larva, escapes from the larva, and swims away to copulate with a similarly produced free-swimming male. These minute-crustacean parasite life cycles are unique. Instead of the standard moulting cycle of all other crustaceans, the mature adults develop in the attached parasitic tantulus larva. The extreme brevity of early ontogeny seems to be an adaptation to parasitism in situations where a high dispersal ability is not advantageous. 


\section{Further Life History}

Minute-crustacean parasites have a dramatic reduction in body form compared to other crustaceans, with an unsegmented sac-like thorax and a much reduced abdo men. The attached larvae and parthenogenetic females are permanently attached to their host by the oral disc with an adhesive. In the centre of the disc, they make a minute puncture, through the host integument, with their cephalic stylet. This is their only access to the body fluids of the host.

The free-swimming, nonfeeding adults lack cephalic appendages but possess two clusters of aesthetascs on its anterior margin. They are free swimming and have six pairs of large thoracopods without endites. The first two thoracic somites are incorporated into the cephalothorax. The male abdomen bears a posteriorly directed, median stylet and intermittent organ. It originates on the first abdominal somite. The parthenogenetic females live longer than their sexual doppelganger and are responsible for the majority of the reproduction of their species.

\section{Additional Information}

Knudsen et al. (2009) described tantulus larvae, developing males, parthenogenetic females, and only the third developing sexual female ever found. They noted that the taxonomy of the group is based mainly on the tantulus larvae, which is quite an unusual role for a larval life cycle stage. Some suggest these minute crustacean parasites, with no larval stages, are the adults of the orphan mysterious y-parasites (facetotectans), which have no known adults, only larvae. There are myriad reasons why these life cycles are, unfortunately, unlikely to fit together.

\subsection{Amphipoda: Scuds}

Scuds are a minor group of known parasites, but they have many species commensal on ascidian, bryozoan, cnidarian, echinoderm, mollusc, sponge, and crab hosts. Many of these may be parasitic or at least well on their way to parasitism. They are called commensals because we just do not know enough about most of them to make a proper categorisation. Whale lice and jelly parasitoids are known to be parasitic, and we believe a bivalve scud is also an unrecognised parasite.

\subsubsection{Cyamidae: Whale Lice}

There are 32 species in 6 genera and one family (Cyamidae) of whale lice. They have no carapace, and their bodies are dorsoventrally flattened instead of laterally compressed as in other amphipods. They are one of the few aquatic crustaceans that cannot swim in any part of their life history. Molecular studies of whale lice have determined the evolution of their host whales (Kaliszewska et al. 2005). Infections can be heavy on whales and other marine mammals (Mignucci-Giannoni et al. 1998; 
Colón-Llavina et al. 2009), and superinfections can harm whales. Whale lice will also attach to humans handling whales.

\section{Life Cycle}

There is an easily discernible life cycle. Eggs are held in the marsupium of the female. Females produce more eggs in each brood as they age. A quarter to half of the eggs die in the marsupium. The eggs hatch directly into a juvenile form with no larval stages, similar to fish isopods and all Peracarida. They have clawed pereopods and immediately attach to the cetacean skin. Sexual maturity is usually reached after six moults. Some eat their exuvia (exoskeleton remains) after moulting. The complete life cycle may take 8 or 9 months.

\section{Further Life History}

Whale lice parasitise cetaceans (whales, dolphins, porpoises). Since whale lice cannot swim, they can only be spread by direct contact among hosts such as during mating, nursing or care giving. They feed on dead cetacean skin and algae and are attracted to wounds on hosts but more for attachment than actual feeding. They may even clean up wounds and so speed up healing. Whale lice also like creases, crevices, and barnacles for attachment. By eating algae, they control its growth on their host. In general, slow swimming whales have more whale lice, than fast swimming whales. Some suggest that host jumping or breaching is done in order to knock off whale lice. Some online videos show human divers easily brushing whale lice off whales with only their fingers. Heavy infections reportedly harm humpback and gray whales. We found a heavy infection on a sperm whale that may have contributed to its death (Mignucci-Giannoni et al. 1998).

\subsubsection{Melitidae: Bivalve Scuds*}

Melita anmyeonensis Shin, Coleman, \& Kim, 2013, is found between the gills and mantle cavity of the broad angel wing bivalve, Barnea dilatata (Soulelet, 1843), in South Korea. Scuds in six families associate with bivalve mollusc hosts but never in high numbers of adults. Shin et al. (2013) found no damage to the host. Kretzler (1984) could not detect obvious physical damage to sea urchins even by very heavy infections of scuds. They could not determine if the association was obligate. They called it commensalism. We feel the high prevalence (100\%) and intensity [1-169 (av. 28.8)] in the broad angel wing, and the lack of free-living collections suggests that it is an obligate parasite. This bivalve is no stranger to crustacean parasitism having two species of parasitic copepods. Shin et al. (2013) noted host abandonment* of $M$. anmyeonensis from damaged and captured broad angel wings. Host abandonment is a frequent strategy of crustacean parasites for finding another host. 


\subsubsection{Hyperiidea: Jelly Parasitoids*}

They are often called parasites or parasitoids (Lafferty and Kuris 2002; Kuris et al. 2005 ) but are not exactly parasites either. We term them serial parasitoids*. In various parts of their life histories, they may be free-living, kleptoparasites, minipredators*, parasitoids, serial parasitoids, or a mix. They have an obligatory association with jellies (salps and jellyfishes) as a nursery for their young (parasitoidism), often rest on jellies (phoresis), but spend most all of their lives as minipredators (see Table 5.1). Jelly parasitoids have $\sim 283$ species in 22 families.

They damage and kill some gelatinous zooplankton but have no known ecological or commercial importance. Now that jellyfish are held and reared in major aquaria, jelly parasitoids have become a problem. Effective chemical treatments have been developed (e.g. Boonstra et al. 2015).

\section{Life Cycle}

Mating occurs on a host jelly, males depart, and ovigerous females remain on the host while brooding the eggs. Brood sizes range from 50 to several hundred eggs. The eggs are relatively small for amphipods. Larval stages are in the female marsupium. The first stage is the pantochelis larva with four cheliform pereopods and unsegmented and limbless metasoma and urosome. The pantochelis stage metamorphoses into a 'protopleon' larva (often divided into three sub-stages), having a segmented metasome and imperfect pleopods. In many species, there is no pantochelis stage, and the egg hatches directly into a first protopleon stage. The last (or only) protopleon stage gives rise to the first juvenile stage (a miniature adult) and marks the demarsupiation or the deposition by the female of the larvae (in rare cases the juveniles) into a host. During demarsupiation, the gravid female swims out to find a host and deposits one or a few larvae upon the host specimen (depending on host size and capacity). She continues infecting one host after another. Some females penetrate a host, split a gonad with its mouthparts, and inserts the larvae deeply into the organ. As they grow, the juveniles leave the gonad and start feeding on the prey trapped by the host. Some females deposit pantochelis larvae on the surface of salps with their specialised seventh pereopods. When the larvae moult a few hours later, the ensuing protopleon larvae enter the branchial cavity and eat its wall or feeds on the collected suspended matter. Once the host can no longer support the young as they mature, they leave it for another salp in the chain. Species of phronimids excavate solitary salps or pyrosomes into 'barrels' open at both ends and in which they hide and use as a nursery. The larvae are demarsupiated into the barrel where they soon bunch together into a tight cluster that slowly moves around on the inner barrel wall. The female stays with the barrel and prevents the young from passing to the outer surface. At intervals, she makes short excursions into the water and returns with prey to feed her brood. The pereopods are used to maintain the position of the animal within the barrel, and beating of the pleopods propels the combined barreljelly parasitoids through the water (bio-jet ski). 


\section{Further Life History}

Some adults feed on small plankton, at least part of the time; others steal small plankton out of jellies; and some eat jelly tissues as minipredators. They certainly use jellies as places to rest. Jelly parasitoids seem immune to the stings of medusa. Males are better swimmers than females.

\section{Additional Information}

Gasca and Browne (2017) found ten hyperiid amphipods, a copepod, and a pycnogonid in jelatinous plankton in the Gulf of California. They also named a new species, Megalanceoloides aequanime Gasca, 2017, based on a redescription of M. remipes (Barnard 1932) in Gasca and Haddock (2016), distributions, sizes, and a few morphological differences. We name Megalanceoloides gascae $\mathrm{n}$. sp. based on the descriptions by Vinogradov (1964) and Vinogradov et al. (1996) of 'M. remipes'. We also distinguish $M$. gascae from $M$. remipes on the basis of geographical distributions in the northern Indian Ocean (Vinogradov 1964) vs southwest Atlantic (Barnard 1932; USNM 301871, 1090231), south-east Pacific (USNM 1090233, 1090237), and Antarctic Ocean (USNM 1090236). The former three records represent two new locality records. The two species are further distinguished based on the sizes of females, $19 \mathrm{~mm}$ female (Vinogradov 1964) vs $40 \mathrm{~mm}$ male (Barnard 1932), and morphological differences discussed by Gasca and Haddock (2016). The holotype is the specimen collected by Vinogradov (1964: 114-117, by monotypy ICZN 1999: Art 73.1.2) and also in illustrated ions by Vinogradov (1964: Figs. 4, 5) and Vinogradov et al. (1996: Fig. 26) (ICZN 1999: Art 72.5.6, 73.1.4). The new species is the third in the Megalanceoloides remipes species complex and in genus Megalanceoloides Zeidler, 2009.

\subsection{Isopoda: Isopods}

\subsubsection{Anuropidea: Jelly Isopods*}

Jelly isopods are giant, blind isopods that occur in all oceans except the Indian Ocean (to date) and parasitise large scyphozoans in the deep sea of the Eastern Pacific and Japan (Ohtsuka et al. 2009). Ten species in one genus, Anuropus Beddard, 1886, are known, but only two have been associated with scyphozoans. They live in and feed on their host, but very little else is known (Ohtsuka et al. 2009). Our lack of knowledge may be an artefact of destructive net collections (Gasca and Browne 2017).

\subsubsection{Cymothooidea: Fish-Associated Isopods*}

Fish-associated isopods are relatively large as adult parasites, in comparison with most other parasitic Crustacea, and are often seen by divers on the outside of marine-reef fishes (Figs. 5.7 and 5.8) and by fishermen in the mouths and gill chambers. Fish gnats* 


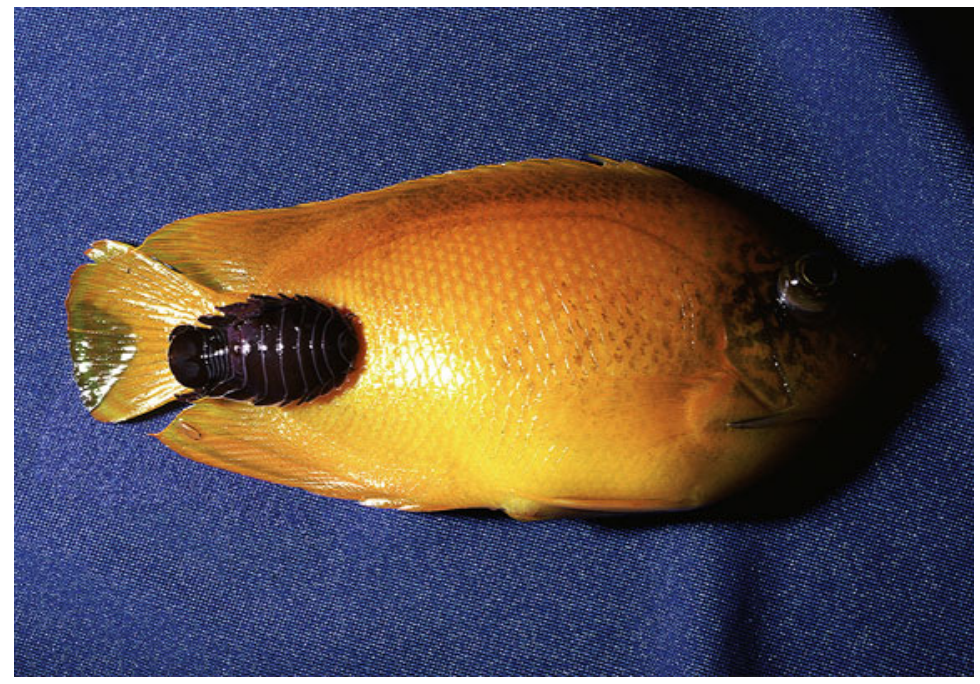

Fig. 5.7 Yellow angelfish, Centropyge heraldi Woods \& Schultz, 1953, with female Renocila kohnoi Bunkley-Williams \& Williams, 1987, attached to the caudal peduncle from Ishigaki Island, Japan. Image (C) Lucy Bunkley-Williams

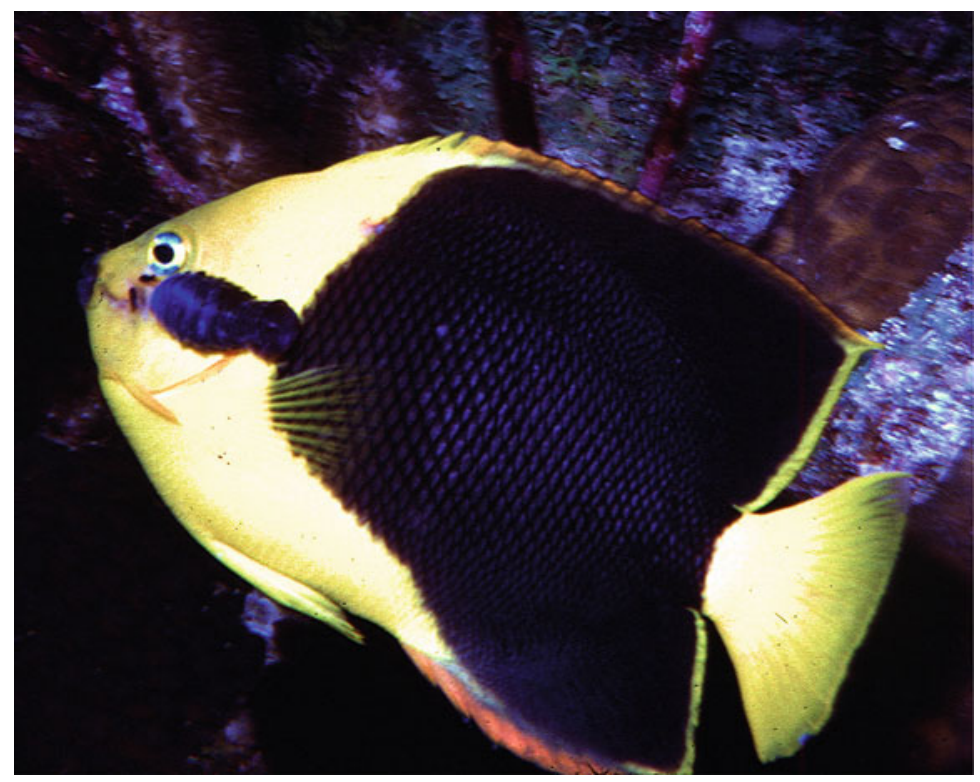

Fig. 5.8 The most spectacular Caribbean Anilocra Leach, 1818, is this black female Anilocra holacanthi Williams \& Williams, 1981, on the yellow face of the rock beauty, Holacanthus tricolor (Bloch, 1795). There are two micro-males just anterior to the female. Image $\odot$ Lucy BunkleyWilliams (taken at the insular shelf edge off La Parguera, Puerto Rico) 
(see below) are much smaller (1-3 mm) and highly mobile ectoparasites on marine and estuarine fishes (Smit and Davies 2004; Tanaka 2007). Fish gnats are not true parasites but serial parasites. Four other families have been variously stated to have parasitic species. No cirolanids are parasites, some corallanids may be parasites (GentilVasconcelos and Tavares-Dias 2015), and, very likely, some salve bugs (Aegidae) and nasal isopods* (Tridentellidae) are parasites (e.g. Bruce and Wong 2015).

The life cycles of fish-associated isopods and fish gnats are so completely different that their sharing a superfamily seems incongruous. Fish-associated isopods are permanently parasitic as adults and fish gnats only as juveniles. Fishassociated isopods hold their eggs in a marsupium and fish gnats in pouches in the female body. Fish-associated isopods attach with their pereopods and fish gnats by their mouthparts.

\subsubsection{Corallanidae: Serial Fish Isopods*}

We have collected these isopods on fishes but have not considered them to be true parasites, because so little is known about their associations. Some species do feed on fish blood.

Gentil-Vasconcelos and Tavares-Dias (2015) considered Excorallana berbicensis Boone, 1919, to be a parasite of South America freshwater fishes and E. tricornis (Hansen, 1890) a facultative parasite of many marine fishes. They may be correct about E. berbicensis, but we are not ready to accept $E$. tricornis as a true parasite (Bunkley-Williams and Williams 1998a). We would call it a serial parasite. Very little is known about any life cycles of Excorallana Stebbing, 1904.

\subsubsection{Cymothoidae: Fish Isopods*}

The most famous cymothoid is the so-called tongue-replacement isopod (Brusca and Gilligan 1983), which was also featured as the monsters in the horror movie 'The Bay' (2012).

Fish isopods may cause some problems in aquaculture (Williams 1974; Woo 2006). They drastically affected fisheries in a large lake in Egypt (Mahmoud et al. 2017). Juveniles may kill juvenile fishes, and adults may seriously stunt and slow the growth of hosts (Bunkley-Williams and Williams 1998a; Mladineo 2003). Fish isopods have also been shown to increase swimming drag and metabolic demand of their hosts (Östlund-Nilsson et al. 2005).

More than 369 species of fish isopods exist in 43 genera (see Chap. 3). They occur in and on fishes around the world, but mostly in the tropics and subtropics, in coastal waters, with some in freshwaters largely in South America with a few species in Africa and Asia (Bunkley-Williams and Williams 1998a; Smit et al. 2014), and even the deep ocean (Quattrini and Demopoulos 2016; Williams and Bunkley-Williams 2003). Some almost complete life cycles are known (e.g. Williams and BunkleyWilliams 1994; Aneesh et al. 2015). 
Klompmaker and Boxshall (2015) listed many fossil fish parasitic isopods but dismissed all due to insufficient evidence. Nagler et al. (2017) claimed the oldest fossil parasitic isopod based on sucking mouthparts and legs suited for attachment, but these could be just as indicative of a minipredator. We are also in the process of describing a parasitic fossil isopod (Williams and Bunkley-Williams 2008, unpublished data), which may prove equally disputable.

\section{Life Cycle}

Fish isopods may go through four parasitological life cycle stages: free-living, smaller*, serial parasite, and true parasite (see Table 5.1). Brood pouch development may include egg, oblong embryo predator, curled embryo with enlarged cephalic end and tapered posterior, uneyed embryo, eyed embryo, pre-manca, and manca juvenile (Williams and Williams 1985a, b). Embryology is often neglected in species descriptions and even in life cycle studies. Embryos in brood pouches number from 37 to 1600 (Adlard and Lester 1995) but are usually in the low to mid-hundreds. Larger and older supra-females have more offspring. Although some brood mortality is expected, Bakenhaster et al. (2006) found none in Glossobius hemiramphi Williams \& Williams, 1985.

Pre-manca in the marsupium of some species are larvae. Mancae in, and escaping from, the marsupium are juveniles. To avoid confusion, we here refer to this as a manca juvenile*. Once the manca juvenile begins to form the seventh pair of legs in 1-4 moults, we consider these instars juveniles. The few juvenile stages that we know spend the daytime in the surface plankton. They descend at night, finding transfer or definitive hosts. The first to settle on a definitive host develops through the male stage and directly into a female. The second becomes a male. This was the traditional infective assumption based on little data. However, they may actually be infected by founder pairs.

Mladineo and Valic (2002) and Mladineo (2003) found only two Ceratothoa oestroides (Risso, 1816) manca infected each annular sea bream even when more mancae were available. They attached to the fish body and migrated under the operculum, rather than being swallowed as previously suspected (e.g. Bunkley-Williams and Williams 1998a).

Supposedly, a few complete life cycles of fish isopod are known, but none are complete. First, a natural release of mancae has only been closely observed once (Williams and Williams 1985c). A female on a brown chromis in a coral reef reared her posterior from the surface of the host and released a juvenile from the rear of her marsupium, slowly lowered back down, and reared up again to release another. This process was slowly and methodically repeated, although the complete release was not observed. Adlard and Lester (1995) found it took 1-3 $\mathrm{h}$ in the lab. The juveniles swam upwards towards the surface. Some authors have mistaken our burst release (Williams and Williams 1985c) with the normal release process. Burst release occurs when a host is caught or struck. All juveniles are released at once even if they are not quite mature (pre-manca and manca; Williams and Williams 1985c). Adlard and Lester (1995) caused this response in the lab with pressure on the dorsal surface of a female and found it took 1-2 min. 
The second problem with most 'complete' life cycles is they do not include the free-swimming juvenile stages. We have found up to six stages (Williams and Bunkley-Williams 1994; and see below). The fish isopod manca juvenile has six pairs of legs. Most manca juveniles are much more setose than later juvenile stages. The final juvenile has seven pairs of legs. Intermediate juveniles may have 6.25-, 6.5-, and/or 6.75-leg pairs. Some suggest escaping mancae require a free-swimming period before they can attach to hosts; however, Thatcher (2000) found they were ready to attach to fishes as soon as they left the brood pouch, and Williams and Williams (1985c) reported that Anilocra chromis Williams \& Williams, 1981, and Cymothoa oestrum (Linnaeus, 1758) could attach immediately. Large samples of all post-manca juvenile stages $(C$. oestrum $)$ have only been examined by Williams and Bunkley-Williams (1994). Juveniles are positively phototaxic and can be captured in light traps at night. They swim to the surface light when released from the female. They can also be captured with surface plankton nets during the day. They thus appear to avoid the diurnal planktivores on the reef. Adlard and Lester (1995) found they rested at the surface of the water with their hooks (dactyls) through the day, but this was demonstrated in aquaria and not in the field. They descend back to the reef at night and can be caught near the bottom with diver-towed plankton nets. Some have suggested juveniles must feed within 1-2 days to survive (Lester 2005). However, manca juveniles, unfed, for more than a week, are still capable of infecting hosts. Adlard and Lester (1995) reported that only half of the mancae were infective after 8 days. Juveniles of Glossobius hemiramphi and Livoneca ovalis (Say, 1818) use resting hosts before locating their final hosts. Cook and Munguia (2015) found mancae of Cymothoa excisa Perty, 1833 had a window of 7 days to infect hosts. Juveniles of $L$. ovalis are micro-males since an adult male has never been found. Resting hosts are commonly used by many species (Thatcher 2000) and may be a part of the normal life cycle. This predisposes them to becoming micro-males.

Thatcher (2000) described an interesting life cycle strategy. A manca juvenile swimming right-side up (dorsal up), stops swimming, falls to the bottom landing upside-down (ventral up), and does not move. When a small fish comes near to investigate or eat it, the manca springs to life and attaches to the hapless fish. The isopod now has either a resting host to feed on or a final host on which to mature. This 'dead bug' or 'playing opossum' behaviour, we will call the opossum attack*. Thatcher (2000) found mancae could feed on and kill up to four small fishes in $24 \mathrm{~h}$. This behaviour was in freshwater isopods.

Mancae attach all over the body of the host and move to the normal attachment site (Adlard and Lester 1995) as we have seen (Williams and Bunkley-Williams unpublished data). Legrand (1952) suggested mancae of Anilocra physoides (Linnaeus, 1758) were attracted to the motion of fish fins. Some mancae fall off when they attempt to move to the normal attachment site (Williams and Bunkley-Williams unpublished data). Cook and Munguia (2015) found that manca of Cymothoa excisa located hosts by visual and chemical clues.

The number of juvenile moults have not been determined for most species; however, Williams and Bunkley-Williams (1994) reported finding six post-manca juveniles in Cymothoa oestrum (Fig. 5.9). A juvenile attaches to a host and begins to 


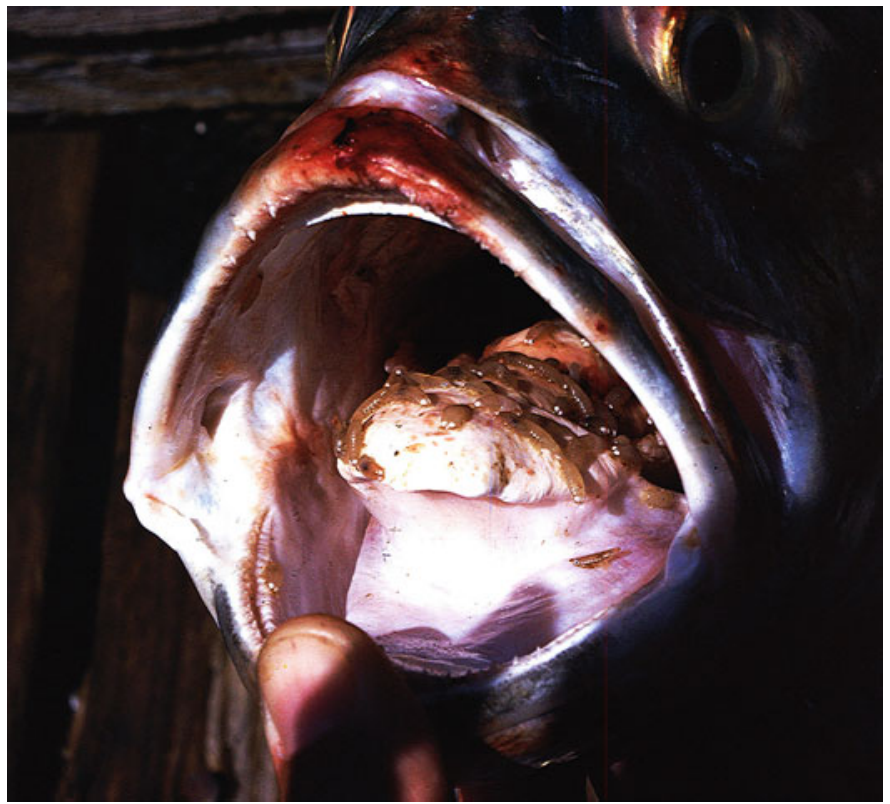

Fig. 5.9 Superinfection of juvenile Cymothoa oestrum (Linnaeus, 1758) on a Crevalle Jack, Caranx hippos (Linnaeus, 1766), incapacitated in a fish trap on Mona Island, Puerto Rico. Image (C) Lucy Bunkley-Williams

develop through a series of instars: juvenile-male transitional, immature male, male, male-female transitional, immature female, virgin female (no oostegites), and ovigerous female. The second juvenile that arrives will cease developing and remain as a male, with development hormonally controlled by the female. If the female dies, the associated male resumes developing into a female. Anilocra Leach, 1818, juveniles replace solitary dead females. Williams and Bunkley-Williams (unpublished data) have often seen a juvenile attached in the attachment scar where a female was formerly located. Micro-males may be attracted to dying females and begin to develop into females protected underneath the 'cougar' (old female). Williams and BunkleyWilliams (unpublished data) have reared juvenile Anilocra haemuli Williams and Williams, 1981, to females and A. chromis to male-female transitionals, on their natural hosts, in the lab.

Adlard and Lester (1995) found Anilocra pomacentri Bruce, 1987, recruited from July to December, with a peak in September to October, at Heron Island, Great Barrier Reef. They never saw males with females despite intense efforts in the field and laboratory. One of their hypothetical scenarios is essentially our micro-male life cycle.

Aneesh et al. (2015) gave the 'complete' life cycle for Cymothoa frontalis Milne Edwards, 1840. However, they have the same problems discussed above: (1) omitting how the manca are naturally released (demarsupiation) and (2) omitting the number of free-swimming juvenile stages. They did recognise six female stages. 
However, their stages Fs-1 to Fs-3 appear to be within the first female instar, which is confusing. Furthermore, size alone does not determine supra-stages or instars (see size discussion below). Their Fs-4 would be our vegetative* supra-female (Sf-2). Their Fs-5 to Fs-6 would be the second marsupial stage (Sf-3). Overall, this does agree with our assertation that females have more than one brood with feeding vegetative stages in between. However, we think most fish isopods have more than two broods.

When all brown chromis hosts with Anilocra chromis on seven $100 \mathrm{~m}$ segments of a linear coral reef were eliminated, and recovery followed for a year, the hosts recruited evenly from the plankton, but the isopod recruitment was significantly higher on the ends of the linear reef adjacent to areas still populated with isopods. The same result was obtained in a subsequent year (Williams and Bunkley-Williams unpublished data). Thus, the swimming juvenile stages only appear to disperse over very short distances.

\section{Further Life History}

Several studies on cymothoid-host associations have examined impacts of Anilocra on components of host fitness (reviewed in Chap. 10). Adlard and Lester (1995) found that Anilocra pomacentri reproductively compromised its female host. Fogelman et al. (2009) found A. apogonae sterilised its female host. Other studies have shown an apparent effect of cymothoid infection on drag associated with swimming (Östlund-Nilsson et al. 2005), and oxygen consumption (e.g. Binning et al. 2013), and on host movement and migration (Meadows and Meadows 2002; Welicky and Sikkel 2015). Brown chromis males infected with Anilocra chromis appear unable to maintain a spawning site (Williams and Bunkley-Williams unpublished data). Contrastingly, Meadows and Meadows (2002) and Robinson (2005) found little to no effect on host mating success or fecundity.

A tenet in the strategy of fish isopod infection has always been that the first manca juvenile to arrive becomes a female and the second remains a male (epigametic sex determination). Mladineo and Valic (2002) and Mladineo (2003) found a pair of Ceratothoa oestroides manca juveniles became established simultaneously together in the mouth of a host and excluded all other mancae. Aneesh et al. (2015) found something similar with Cymothoa frontalis. Possibly almost all fish isopod juveniles infect hosts in juvenile pairs, which we will call founder pairs*. This may change all cymothoid infection methods.

Life strategies sometimes consistently 'deposit' the male and the female of a pair on different sides of a host. Williams and Williams (1982) have described these duplex arrangements for males and females in opposite gill chambers and on different sides of a fish caudal peduncle (Williams and Williams 1987). This allows space for larger females and larger brood pouches, allows smaller fishes to be parasitised (Williams and Williams 1982), prevents double parasitism, and separates areas of isopod feeding and damage. Female hormonal fixing of their male appears to remain intact over these distances. Thatcher (2000) found this arrangement with Anphira xinguensis Thatcher, 1995, in the gill chambers of the beaked pacu. 
Occasionally, site-specific isopods are found in a different location on their hosts, and they do not migrate to their normal site. When these parasites are kept from their site because of preoccupation, we call them displaced parasites*; when their normal sites are available, we say they are accidental attachments*. For example, we have seen normally under-eye Anilocra attach above the eye or on top of the head when both of their normal sites were occupied. These are the normal attachment sites for other species of isopods and may help to explain how utilisation of different sites evolved. We found 13 longsnout bullhead sculpins*, most with female Elthusa sp. isopods in their gill chambers and males underneath the females. However, we also found three males, of the same size and species, attached in two of the same hosts on the body near the opercular openings (Fig. 5.10). The evolution of gilldwelling isopods into external attaching isopods has been previously hypothesised (Brusca 1981) but never demonstrated. These normal female-male gill-chamberdwelling isopods with externally attaching cohorts represent the first ever observation of an example of this event (Fig. 5.10).

When two reproductive sets of the same species occupy the same host, when normally only a single set occurs, we call it double parasitism. This often occurs with the micro-male life cycle. It is common in Anilocra chaetodontis Williams \& Williams, 1981, but less so in other Anilocra spp. We found it was detrimental with A. brillae Welicky, Hadfield, Sikkel \& Smit, 2017 on red hinds and coneys, and with Livoneca redmanii Leach, 1818 in Cero (Williams and Bunkley-Williams unpublished data). It is rare in gill-chamber isopods, and, of course cannot occur in oral cavity ones. The duplex arrangement also prevents this situation.

As is typical of isopods generally, adult females continue to grow and moult on the host. Older, larger females can be quite different morphologically from males and immature females (supra-females, Bunkley-Williams and Williams 2003). These differences have caused many taxonomic problems. Adult females moult on the host in two parts. This is probably necessary to have some hardening of the pereopods to maintain attachment on the host. We have seen this many times on Anilocra spp. where the posterior part is shed usually posterior to the 3rd pereon,

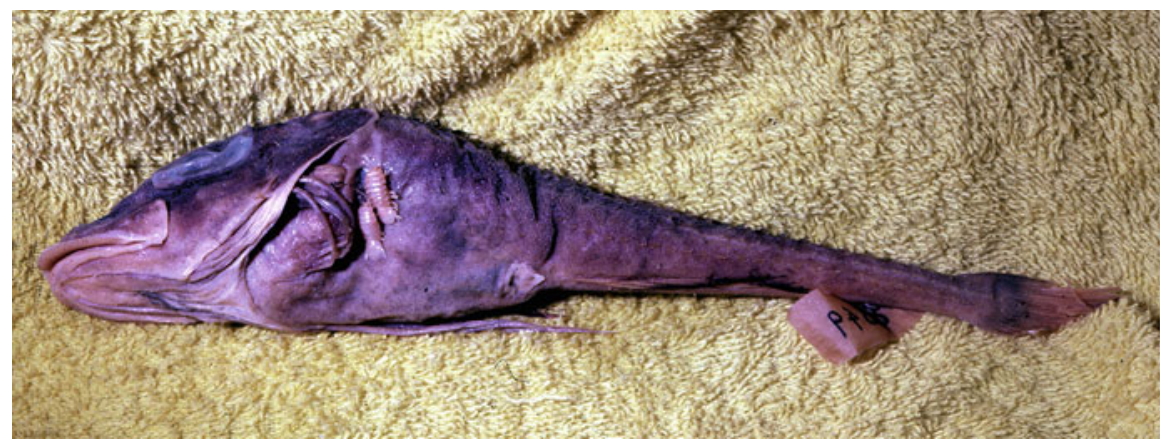

Fig. 5.10 Normally gill-dwelling Elthusa Schioedte \& Meinert, 1884, attached externally under pectoral fin and near the gill openings on longsnout bullhead sculpins, Ereunias grallator Jordan \& Snyder, 1901, in Japan. Image (C Lucy Bunkley-Williams 
sometimes the 4th. There must be a considerable delay between moult halves, or we would have never seen so many. We call these mid-moult stages. The delay allows the new hooks (dactyls) to harden before the last anterior segments are shed. We have seen mid-moult stages with a large posterior body and a much smaller anterior body (Williams and Bunkley-Williams unpublished data). We have also seen mid-moult stages in four wild Cymothoa oestrum juveniles (Williams and Bunkley-Williams 1994).

Discerning the different juvenile stages of cymothoids is most difficult. Mid-moult specimens clearly mark the lower size range of each juvenile stage. When enough specimens exist to find mid-moults, the complete juvenile life cycle can be discerned. Four mid-moults in C. oestrum allowed us to discern six postmanca juvenile stages (Williams and Bunkley-Williams 1994; Williams and Bunkley-Williams unpublished data). As far as we are aware, this is first time all juvenile stages have been identified in the wild.

Post-juvenile mid-moults allow the elucidation of what changed in the moult and to positively identify instars. Some supra-females regain their marsupium in one moult. Spectacular, mid-moult stage half-female/half-male forms have been observed (Williams and Bunkley-Williams unpublished data), as have supra-females with half formed marsupiums, indicating two moults are needed to form a marsupium (Williams and Bunkley-Williams unpublished data). As noted above, isopod effects on hosts often cannot be measured with fish condition factors. We studied 120 specimens ( 85 infected) of doctorfish with $0-8$ specimens of two species of adult isopods and noted there was no difference in condition factors (Williams and Bunkley-Williams unpublished data). The isopods cause the host to grow more slowly, but they remain proportional (proportional stunting). Östlund-Nilsson et al. (2005) also found no conditional factor difference and summarised the literature on this topic. A malefemale pair of Livoneca redmanii in each gill chamber of mackerel will cause a decline in condition factor and often kills the host (Williams and Bunkley-Williams 1996). Lanzing and O'Connor (1975) also found host condition was only reduced in multiple isopod infections. However, Robinson (2005) found a reduced condition in bicolor damselfish infected with single Anilocra partiti Williams \& Williams, 1981 females, and Sala-Bonzano et al. (2012) found no condition factor effect of Ceratothoa italica Schioedte \& Meinert, 1883, on sand steenbras in a protected area, but severe effects in a similar overfished (unprotected) area. The prevalence of infection was also different (30 vs $47 \%$, respectively). Obviously, the life cycle success rate was improved by stresses on the host, particularly when the lower abundance of host specimens should have had the opposite effect.

The sizes of gill- and mouth-dwelling cymothoids are closely correlated with their host size due to space constraints; externally attaching ones are slightly less coordinated. However, isopod and host sizes are related suggesting they grow simultaneously. This also suggests most hosts are infected young, by young parasites, and the host and parasite grow up together.

Some have suggested that females only have one brood and others that they have one brood immediately after another. In many cases, the so-called virgin female (no oostegites) was the largest of the female specimens collected (Williams and 
Williams 1982, 1986a). Obviously, these females are in a feeding (vegetative) stage between broods. The number of adult moults and their morphological stages are not known for any cymothoid. However, Aneesh et al. (2015) found six adult female stages corresponding to two of our supra-females, including a vegetative one (see above).

Adlard and Lester (1995) found spent (demarsupiated) females could moult, feed, rejuvenate, and lay new eggs, all in one instar. No intervening vegetative instar was necessary. Evidence exists to support two life cycle portions in these fish isopods: simple and complex rebrooding. Simple rebrooding* with relatively small brood sizes, where the female internal organs are only flattened by the marsupium, not atrophied, and no vegetative moult is necessary to re-establish feeding. Complex rebrooding* with large brood sizes, where female internal organs are atrophied, a moult to a vegetative supra-female is necessary to re-establish feeding, and a second moult is necessary to re-establish a supra-female with a marsupium. Simple rebrooding is more economical and faster but limited numerically in offspring. Complex rebrooding is slower and uses more resources but produces many more offspring. Adlard and Lester (1995) found simple rebrooding in an externalattaching isopod. Williams and Williams (1982) found complex rebrooding in a gill chamber-dwelling isopod, Williams and Williams (1986a) in an externally attaching isopod, and Aneesh et al. (2015) in a buccal cavity-dwelling isopod. Isopods producing larger broods may require the energy resources afforded by vegetative supra-female instars. Of course, many other, undiscovered, reproduction scenarios probably exist.

External isopods do not live as long as their hosts, as evidenced by empty attachment scars. Additionally, some isopods become covered with encrusting organisms. These are likely old isopods which have ceased moulting and are about to die.

Bakenhaster et al. (2006) found that Glossobius hemiramphi live for a year in south Florida (USA). Adlard and Lester (1995) found Anilocra pomacentri lived for a maximum of 13.5 months. Bakenhaster et al. (2006) found monthly 4.6-18.2\% (ave. 10.1\%) prevalence throughout a year, in 2928 ballyhoo with the highest prevalences in the summer, with small, young-of-the-year hosts. With larger hosts, the prevalence exponentially declined.

Adlard and Lester (1995) found Anilocra pomacentri changed the behaviour of the Great Barrier Reef chromis making them not migrate with uninfected cohorts. We (Williams and Bunkley-Williams unpublished data) observed a similar phenomenon in brown chromis infected with Anilocra chromis. The infected adults stay under coral heads with the juvenile brown chromis, while the uninfected adults go out above the reef slope to feed on plankton. Meadows and Meadows (2002) similarly found foureye butterflyfish infected with Anilocra chaetodontis stayed in low-energy areas where their offspring were more available to young potential hosts. The diel migratory reef fish, French grunt, usually migrates from reef to seagrass habitat at dusk. Those infected with Anilocra haemuli were less likely to migrate than their uninfected schoolmates (Welicky and Sikkel 2015).

Adlard and Lester (1995) interpreted this as a depression of the host reproductive response to move to spawning areas on the reef slope. We interpret the observed behaviour of brown chromis to be because the infected adults cannot feed and 
survive in open waters (Williams and Bunkley-Williams unpublished data). Meadows and Meadows (2002) suspected this was also a host behavioural change caused by the isopod. Welicky and Sikkel (2015) were not certain if infected fish had less energy to migrate or if uninfected cohorts harassed them. However, all four behaviour modifications, caused by the isopods, accomplished the same availability of manca juveniles to infect juvenile and young fishes. We will call this effect nursery hiding. These are newly recognised life cycle innovations caused by parasite modification of its host behaviour.

\section{New Life Cycle: Micro-male Life Cycle}

Among the nine species of Anilocra described by Williams and Williams (1981) and two from Japan (Williams and Williams 1986a), no males have been reported. After juveniles were found in apparent copula with females, we assumed that juveniles were functioning as males. To test this assumption, individual juveniles were raised on their host, periodically preserved, sectioned, and stained. The infective, 6-leg juvenile was a functional male as were all intermediates up to and including the 7-leg juvenile. However, as soon as a juvenile began to obtain an adult shape (juvenile-male transitional), it began to lose its male characters. Only juveniles were reproductive males. This resolved the 'mystery of missing males'. We refer to this reproductive juvenile as a micro-male. Juveniles with full male characters have been found in several species, but these have never been suspected to be sexually active. Many species are known to use paratenic hosts (Thatcher 2000; Bakenhaster et al. 2006), which may predispose them to becoming micro-males.

Six-legged manca juveniles are released from the marsupium (Williams and Williams 1985c), swim to the surface in the daytime, and descend near the bottom at night. They find small hosts, which do not go to cleaner fish or shrimp (blennies, gobies, cardinalfishes), attach, feed, and moult once, or several times, into 7-legged juveniles. In off-reef areas in Venezuela, these juveniles were found on adult glasseye (Bunkley-Williams et al. 2006). They may sense the pheromones of receptive females, leave this micro-male host, swim to the female, crawl under her, and mate belly-to-belly. We have observed them in copula and found a semen string when they were separated. They may hide under the female either before or after copulation, return to their micro-male host, or find another small host. They may eventually locate a juvenile of their definitive host and develop into a female as their host develops. No adult male stage exists. Juveniles develop directly into juvenile-female transitionals, immature females, and females.

We sometimes found juveniles under females or very close to females on the final host, but usually we found them on cardinalfishes, gobies, and other small fishes (Williams and Bunkley-Williams unpublished data). Adlard and Lester (1995) found Anilocra pomacentri juveniles on the final host, blennies, and cardinalfishes. They apparently spend most of their time attached and feeding on resting hosts and only visit the female to mate.

This life cycle is unique, not just among isopods, but in parasites in general. We are not aware of anything similar. It is a modification of juveniles on resting hosts probably driven by cleaner pressure. It seems to be widespread and highly successful. 


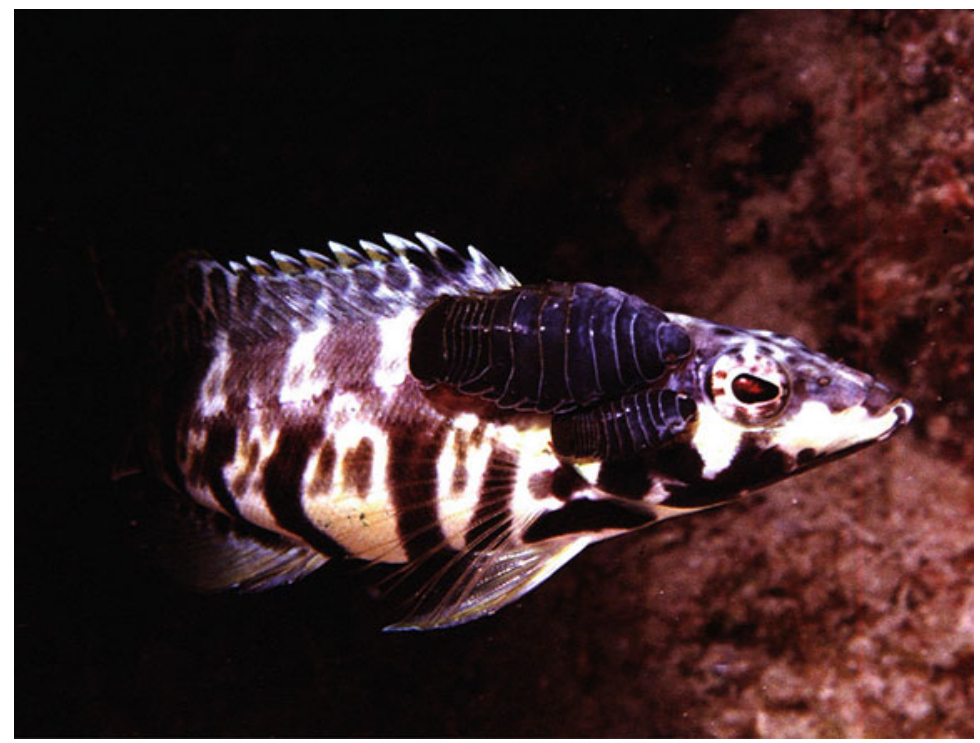

Fig. 5.11 Female-male pair of Renocila bowmani Williams \& Bunkley-Williams, 1980, on harlequin bass, Serranus tigrinus (Bloch, 1790), in the Dominican Republic. Image (C) Lucy Bunkley-Williams

While we have not seen males associated with many other Anilocra, some Anilocra do have associated males. Possibly, this life cycle and other host specificity differences will place the micro-male Anilocra in a different genus. We are exploring this possibility. Other cymothoids share this life cycle, e.g. Livoneca ovalis (Williams and Bunkley-Williams unpublished data), Anilocra apogonae (see Fogelman and Grutter 2008), and A. pomacentri (see Adlard and Lester 1995).

The advantages of this live cycle have allowed Anilocra spp. to be the only large, external cymothoid isopod of larger Caribbean coral reef fishes (Fig. 5.8). Nerocila spp. occur around but are unable to penetrate any distance into the Caribbean (Bunkley-Williams et al. 1998; Bunkley-Williams and Williams 1999); and Renocila spp. only infect a few small species (Fig. 5.11; Williams and Williams 1980). The apparent advantages of this life cycle include the following:

1. It allows the female to grow larger on the host because no resources are used by a male partner (Fig. 5.8).

2. Two females may be supported by a host, instead of a male-female pair (Fig. 5.11).

3. Larger females produce more offspring and two females twice as many.

4. It protects vulnerable juveniles from cleaners.

5. It produces greater genetic diversity as many micro-males are available at different times to fertilise each female, instead of one permanent male partner. 
6. The abundance and close proximity of numerous micro-males solve the problem of finding a mate.

7. Micro-males form a quick reserve available for developing new females.

8. Micro-males become sexually mature quicker than true males.

9. The energy necessary for a female to hormonally control a male partner is unnecessary.

10. Larger-growing females quickly become too large for cleaner organisms to threaten.

11. Micro-males can parasitise smaller hosts that do not seek out cleaner organisms.

12. Micro-males can easily change host specimens and/or species and are thus more flexible and resilient.

13. Micro-males could potentially use up the resources of one host and just move to another with little effort or danger.

14. The lack of host specificity in micro-males allows them to exploit a broader and more available food supply and to be more flexible and resilient.

15. The time a planktonic reproductive form has to locate a final host is almost infinitely extended by being able to exploit a broad range of more available smaller fishes.

16. Copulation while on the outside of a fish host is easier and safer with a tiny micro-male than with a larger and more bulky 'true' male.

17. This life cycle also resolves the classic question of the expense of sexual reproduction, since all adults produce eggs.

18. It maintains, or even multiplies, the advantage of diversity in sexual reproduction while not sacrificing the productivity advantage of asexual reproduction.

\section{New Life Cycle: Prey-Predator Transfer Life Cycle*}

Many intriguing questions regarding the cymothoid life cycle still exist. These include the following: how can little, slow, juvenile fish isopods (cymothoids) possibly chase and infect fast-swimming pelagic fishes? Why do juvenile isopods infect and develop into non-swimming forms in the mouths of fishes too small for them to develop into adults? Juvenile isopods may not chase large, fast hosts, but rather rest and wait for small, slow ones. Are little hosts dead-ends or 'bait'?

Apparent prey-to-predator transfer has been observed in king mackerel (Williams and Bunkley-Williams 1994), shortfin smooth lanternshark (Williams et al. 2010), and red lionfish (Aguilar-Perera et al. 2018). Connors et al. (2008, 2011) experimentally showed sea lice would abandon their host, when it was attacked by a predator $(\sim 70 \%$ of the time $)$, and reattach to the predator.

Juvenile isopods infect the mouths of common, small, easily infected, 'bait' fishes. They feed and pass through moults from the 6-leg juvenile to a post-juvenile, non-swimming stage on this transfer host. At any point during this development, if the host is eaten by a predator, they flee their (prey) host and attach in the mouth of the predator host (final host). The first isopod to arrive becomes the female and the second a male, as was once thought to happen in all other cymothoids (Mladineo and Valic 2002; Mladineo 2003; Aneesh et al. 2015). 
Isopods in trap, net, and trawl fisheries are well documented to frequently abandon their host and sometimes enter a different fish host. Three cases of natural prey-to-predator isopod transfers have been described (Williams and BunkleyWilliams 1994; Williams et al. 2010; Aguilar-Perera et al. 2018), and adult and juvenile isopods have successfully, experimentally, been transferred between the same and different host species (e.g. Williams et al. 1982). The attack of a predator or its feeding action may dislodge an isopod from a transfer host or the isopod may abandon the host. Swallowing a single prey fish may be too fast for a transfer, but with a mouthful of prey fishes, adequate time may exist for a transfer. All transfers need not be successful, just enough.

Cymothoa spp. are quite common ( $\sim 5 \%)$ in the two most abundant bait fishes in the Caribbean and in five small species of cardinalfishes in Okinawa. Can all these juveniles be 'wasted' in dead-end hosts? They cannot develop into adults in these small fishes, and they can no longer swim. We have collected these juveniles from the plankton and found they attach to any available fish in aquarium experiments. Is this a desperate survival mechanism or something more? We have described burst release (Williams and Williams 1985c), which is female isopods reacting to predator attack by dumping, and thus saving all her juveniles in her marsupium. These juveniles immediately attach to anything including humans. If juveniles react this way to attack, and adults are known to switch hosts, why would juveniles in a prey host not transfer to a predator?

In field experiments, we found juvenile isopods first attached all over host fishes and then crawled to their adult positions. Transferring juveniles could attach anywhere in the mouth or throat of predators and then crawl to their adult position. In contrast, adult transfers attach wherever they can and do not migrate (Williams and Bunkley-Williams 1994; Williams et al. 2010; Aguilar-Perera et al. 2018).

Infecting small, slow-swimming, schooling, abundant fishes seems rather easy as evidenced by $\sim 5 \%$ success rate. Infecting fast-swimming, pelagic fishes seems almost impossible. We have observed many diverse cases where the isopods appeared to slow down their hosts and make them more susceptible to predation. In this case, it is a benefit for the completion of the parasitic life cycle and another form of a parasite modifying the behaviour of its host.

The proposed life cycle occurs in Cymothoa spp. and Livoneca ovalis and may also occur in others. It may also occur as a supplemental life cycle to isopods that also have normal life cycles and could explain some of their unusual hosts. Isopods of most predacious fishes infect juvenile hosts and mature with them. Only a few older host specimens are infected. These could have been parasitised by preypredator transfer.

This life cycle is unique, not just among isopods, but in parasites in general. We are not aware of anything similar, although Pascual et al. (2002) reported an accidental prey-predator transfer in decapod isopods. The transfers may have begun as accidents and then gradually evolved into an important pathway. This allowed isopods to infect a variety of hosts that they could not have possibly otherwise reached. 


\subsubsection{Gnathiidae: Fish Gnats*}

Fish gnats are small (1-3 mm) ectoparasites on marine and estuarine fishes (Smit and Davies 2004; Tanaka 2007). As protelean parasites, they are only parasitic as juveniles and, due to their typically brief associations with hosts, may best be termed 'micropredators' (e.g. Lafferty and Kuris 2002). Fish gnats are perhaps best known as the main food of cleaner fishes on coral reefs (Grutter 1997).

Approximately 226 species of fish gnats (most in Gnathia Leach, 184) in 12 genera and a single family are known around the world from the marine shallows to the deep sea. They occur at all latitudes but are more diverse and abundant in the tropics. The study of fish gnats has had a 'split personality' until recently, with benthic ecologists studying the adults and parasitologists the juveniles. Only recently has the morphology of juveniles been included in the taxonomy (Hadfield et al. 2008; Farquharson et al. 2012). However, the life cycles of six species are known (Smit et al. 2003; Tanaka 2007; Hadfield et al. 2009; Hispano et al. 2014).

\section{Life Cycle}

Even the most basic life cycle of fish gnats has only very recently been discovered (Fig. 5.12; Smit and Davies 2004). Zuphea are the first juvenile stage of fish gnats that leave the female, find a host, gorge and swell up with blood, and become the second stage called 'praniza'. The praniza eventually drops off the host and finds a secluded place on the bottom to develop into the next zuphea (Z2). Z2 swims up, finds a host, and repeats the cycle (P2). Zuphea feeding times vary from a few hours to a few days with Z3s taking the longest. They can be as short as an hour on coral reef fishes. Zuphea may attack, feed off (snack*), and kill larval or juvenile fishes as smaller predators*. Eventually, P3 moults into an adult (Fig. 5.12). In some species, in genera Elaphognathia Monod, 1926, Gnathia, and Paragnathia Omer-Cooper \& Omer-Cooper, 1916, this occurs in one moult. In one species in genus Caecognathia Dollfus, 1901, the first moult results in a pre-adult, which later moults into an adult. We call these feeding and metamorphing units serial parasites, which is somewhat similar to the life cycle found in ticks (arachnids). Praniza may only stay on bony fishes for a few hours but on sharks and rays for weeks. Complete life cycles vary from short to lengthy, directly in relation to seawater temperature: polar ( 4-5 years), temperate $(\sim 2$ years males, $\sim 1$ year females), and tropical ( 2 months) (Smit et al. 2003). Life cycle fluctuations appear to be seasonal in most species but could be dependent on host availability in some. Adults are benthic, nonfeeding, and semelparous.

Global warming could make them more successful and more damaging (Hispano et al. 2014). Some Z1 have mouthparts too small to swallow blood cells and must feed on lymph. At Z2, they can feed on blood (Hispano et al. 2014).

Ota et al. (2012) appear to have solved the mystery of why P3 (praniza III) were only found on elasmobranchs. They collected hundreds of praniza I and II of Gnathia trimaculata Coetzee, Smit, Grutter, \& Davies, 2009 on bony fishes (teleosts) and hundreds of praniza III only on sharks. This host switch seems to be the life 


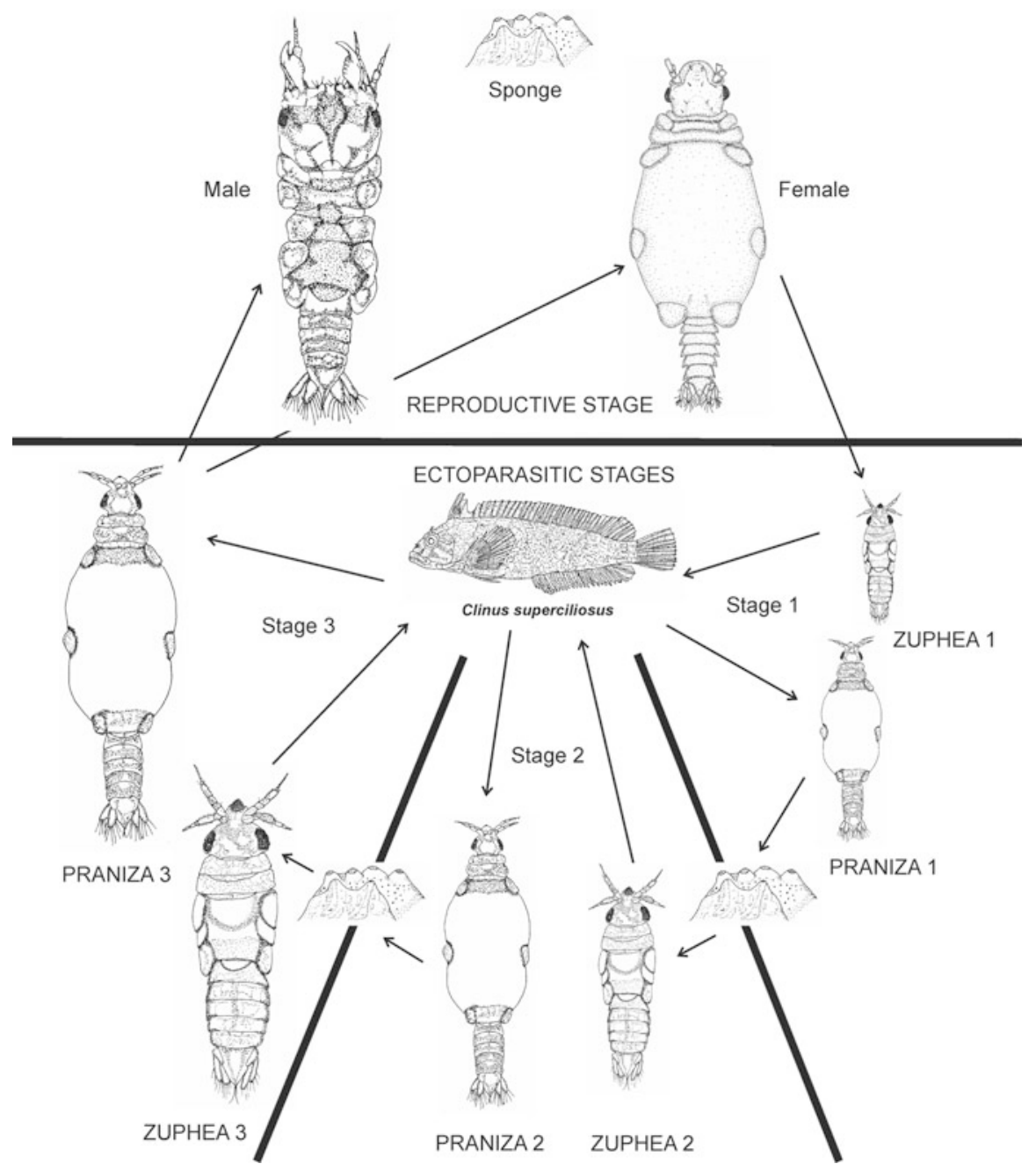

Fig. 5.12 Schematic representation of the life cycle and life stages of Gnathia africana Barnard, 1914 on its host fish, Clinus superciliosus (Linnaeus, 1758). Image from Smit et al. (2003)

strategy of all fish gnats so far found on sharks and rays. Praniza III takes the most time to feed. Attaching to an elasmobranch protects this stage from cleaners.

Several recent studies on Australian and Caribbean recently settled, larval, coral reef fishes found gnathiid micropredation [= our smaller predator] damaged and/or killed them (Artim et al. 2015, and references therein). This can have great importance in fish recruitment (Artim et al. 2015). Sikkel et al. (2017) suggested gnathiids are micropredators $[=$ our minipredators $*$ ] but act like parasites by not leaving the host during each larval life cycle instar (protelean). 
Fish gnats are also implicated in the spread of a parasitic protozoa such as Haemogregarina bigemina Laveran \& Mesnil, 1901, between hosts (Smit and Davies 2004). Juvenile fish gnats on fishes often cannot be identified morphologically as the taxonomy is based on adult males, although this is beginning to change in recent studies (Jones et al. 2008). Fish gnats on coral reefs appear most active at night (Sikkel et al. 2006), although this may not be the case in other environments. At least in the eastern Caribbean, diel activity appears to be related to both life history stage and sex (Sikkel et al. 2006). Fish gnats appear to be generalists. They are known to parasitise 61 families in 18 orders of fishes; however, some fishes are infected more often and more heavily (Tanaka 2007; Coile et al. 2014). This could be attributable to some combination of preference, host susceptibility, and/or host behaviour. Fish gnats may even appear on pelagic fishes (Williams and BunkleyWilliams 1996). For example, amberjack (Carangidae), which fed near the bottom, have been infected with fish gnats, and fish species which did not feed near the bottom were free of gnathiids (Williams and Bunkley-Williams unpublished data). Coile et al. (2014) found fish gnats, which fed on more susceptible hosts, produced larger, presumably more successful offspring.

Fish gnats can attach all over the body of fishes. Smit et al. (2003) suggested where they first attach is where they stay. Some studies suggested site preferences, but whether this is by selective settlement or migration is unknown. Fish gnats are repelled from the skin of toxic gobies by their poison glands but do attach to their fins. It seems likely that they also avoid the toxic skin of trunkfishes (ostraciids, fishkill toxin) and also puffers (tetraodontids, fugu toxin).

\section{Further Life History}

Adult fish gnats do not feed. Males attract females, usually young females with pheromones, and there are some reports of males defending or acquiring harems of females (Smit and Davies 2004). In reality, of the few relationships known, in only two species have males been reported with many females. Males do appear to fight with the big, impressive, giant mandibles, at least not under lab conditions. Brood sizes vary from a few to almost 200 and may vary by female size and environmental conditions (Coile et al. 2014 and citations).

\section{Additional Information}

We suggested that another reason mudskippers leave the water during low tides was because fish gnats are concentrated in the remaining, small, tide pools (Williams et al. 2007). The small Atlantic cleaner gobies, with small mouths, swallow fish gnats whole. In contrast, the bigger, Indo-Pacific cleaner wrasses, with larger mouths, appear to bite them into pieces (Williams et al. 1996). Some of these cleaners selectively feed on larger gnathiids (Grutter 1997). With implications for our understanding of cleaning symbioses, cleaner fishes often do not eat the fish gnats that are not gorged with blood. Is this because the blood-swollen ones are more easily found? Or is this due to preference by cleaners for fish blood rather than gnats without blood? 


\subsubsection{Epicaridea: Crustacean Isopods*}

The category 'epicardeans' was formerly considered a suborder but is now an infraorder placed in suborder Cymothoida. It contains 704 described species of crab isopods and cryptic isopods. Crustacean isopods are almost unique in using crustaceans as their intermediate and final hosts, with the exception of a few corallanids and a cirolanid (Bruce pers. comm.).

Williams and Boyko (2012) call them partial castrators because reproduction is often not completely blocked. This is nutritional sterilisation, not hormonal sterilisation. Boyko and Williams (2016) reviewed the methods to find, collect, and preserve crustacean isopods.

\subsubsection{Cryptoniscoidea: Cryptic Isopods*}

Cryptic isopods are poorly studied, but interesting, with most of their species hyperparasitic on other isopods in their own order, or in parasitic barnacles (Fig. 5.5). They also parasitise a variety of free-living crustaceans. There are 146 species in 51 genera and nine families. They are of little commercial interest, except as potential hyperparasitic controls for other crustacean parasites.

\section{Life Cycle}

Adult female cryptic isopods usually have neither pereopods nor oostegites. Their epicaridian larvae must develop within the female since there is no marsupium. Her body ruptures to free the larvae. They find and attach to copepods, and their life cycle is the same as in decapod isopods, except the males stay in the cryptoniscus larval form.

\section{Further Life History}

Cryptic Isopoda are ecto-, meso-, or endoparasitic. Liriopsids are hyperparasites of parasitic barnacles and parasites of other symbiotic crustaceans. Lovrich et al. (2004) found Liriopsis pygmaea (Rathke, 1843) (Fig. 5.5) infected 36.5\% of the externa on the parasitic barnacle, Briarosaccus callosus Boschma, 1930, parasitising false king crabs in Argentina. These were mostly (208 of 238) cryptonicus larva. This suggests to us that most of the infective larvae, even finding a correct host, fail to infect the host. Larvae were highly aggregated with $92.7 \%$ inside empty externae, suggesting these sites attracted cryptonici. Only a few early subadult females, late subadult, and one late subadult were found along with 18 adult females. Parasitic barnacles recovered from hyperparasitic sterilisation once the cryptic isopods died.

Cabiropsids, with 34 species, are parasitic on free-living isopods and hyperparasitic on other crustacean isopods. The family may also include a few parasites of cumaceans. Hemioniscids (barnacle isopods*), with eight species, are parasites of barnacles. Dajids (backpack isopods*), with 56 species, are external parasites of krill (euphausiids and mysids) and midwater shrimp; however, Ohtsuka et al. (2011) found an endoparasitic species alternate host sharing with a copepod (see copepod section above). The 
parasites look like backpacks on their hosts and are often mistaken as fleshy growths or tumours. A few occur in the gills. Cyproniscids, with 30 species, are hyperparasitic on parasitic barnacles (some formerly liriopsids), occasionally directly parasitic on decapod hosts, and parasites (hypersymbiotic) on symbiotic crustaceans. Podasconids (amphipod isopods*), with four species are parasites of amphipods. Asconiscids only have a single species parasitic on a mysid. Crinoniscids, with three species, also only have one species on a cirripede barnacle. They are parasitic on sessile and pedunculate thoracican barnacles. Entophilids, with two species, are endoparasitic in callianassid shrimp and munidid squat lobsters.

Other cryptic isopods, besides the one we found (Williams and Williams 1987), hyperparasitically infect the brood pouches of isopods. Stone and Heard (1989) found a new cryptic isopod in the serial fish isopod* Excorallana delaneyi Stone \& Heard, 1989. Many species of cryptic isopods remain undescribed.

\subsubsection{Bopyridae: Decapod Ectoparasitic Isopods*}

There are more than 651 species of decapod isopods (Bopyroidea). Members of families Bopyridae and Ionidae cause a noticeable swelling of the gill chamber or carapace (Boyko and Williams 2016). The bulges they cause in the carapace of decapods make them among the most impressive and distinctive crustacean parasites. The deformities named Kanthyloma crusta Klompmaker, Artal, Van Bakel, Fraaije, \& Jagt, 2014 (ichnotaxa-trace fossil evidence), date these parasites in the fossil record back to the lower Jurassic (182.7-174.1 million years ago; Klompmaker et al. 2014), and they have been found in 92 species of fossil decapods (Klompmaker and Boxshall 2015). They slow the growth and nutritionally sterilize some commercially important crabs and can cause the collapse of a population but have also been used as bioindicators (Williams and Boyko 2012).

\section{Life Cycle}

Eggs develop into free-swimming larvae within a ventral brood pouch (marsupium) formed of lamellar outgrowths of the female pereopodal coxae (oostegites). Larvae of a single brood mature synchronously and are released simultaneously as microniscan larva (epicaridium, microniscus or microniscid). The microniscan attaches externally to a pelagc calanoid copepod, pierces its cuticle to feed on its blood, and undergoes six moults and becomes a cryptoniscan (cryptoniscus and cryptoniscid). When it drops off its copepod host, it seeks a crab or shrimp definitive host in the earliest post-larval stage. On the host, it develops into a juvenile (bopyridium) and then into a female. The first cryptoniscan arriving at a host becomes a female and the second, a male (epigametic sex determination). The female attracts a male with pheromones and hormonally controls it to remain a male similar to cymothoids. The female grows large, while the male remains a dwarf attached to the female. 


\section{Further Life History}

They are ectoparasites. Females look nothing like isopods, except for some vague segmentation. Males look more like isopods. They attach in the branchial chamber of their hosts. Some adults do not moult to grow. Partial or complete sterilisation of hosts is due to energy loss from parasitic feeding, not hormonal control as in parasitic barnacles. It is temporary and reversible once the parasite is gone.

Williams and Boyko (2012) summarise the papers following the introduction of a nonindigenous decapod isopod, a drastic population decline of a mud shrimp, and possible collapse of a north-west Pacific ecosystem. Williams and Boyko (2016) found double parasitism of two species in the gills and abdomen of a specimen of hermit crab in Indonesia.

\subsubsection{Ionidae: Ghost Shrimp Isopods}

Only eight species are known and are ectoparasitic on the gills or under the abdomen of ghost shrimp. Similar to bopyrids, they cause a noticeable swelling of the gill cavities. In most respects, they are like the decapod ectoparasitic isopods (above).

\subsubsection{Entoniscidae: Crab Mesoparasitic Isopods*}

There are 40 species of crab mesoparasitic isopods. They are mesoparasites in the haemocoel of brachyuran and anomuran crabs. They make a small, chiselled hole through the host's exoskeleton to communicate with the environment.

\section{Life Cycle}

They release larvae, through an exit pore near the base of the fourth pereopods of the host, which follow the typical bopyrid life cycle. Apparently, this also involves a copepod intermediate host, and they presumably settle as cryptoniscid larvae in the branchial chamber and then penetrate their hosts. They first become endoparasitic and later mesoparasitic. However, their life cycle is poorly and incompletely known (Williams and Boyko 2012).

\section{Further Life History}

Females produce a posterior stalk that extends to the external environment of the host through the branchial region or eyestalks. As in bopyrids, females look nothing like isopods, except for some vague segmentation. Males look more typical. Some adults do not moult to grow. Partial or complete sterilisation of hosts is due to energy loss from parasitic feeding, not hormonal control as in parasitic barnacles.

\section{Additional Information}

They have been suggested as biological control agents for introduced crabs (Williams and Boyko 2012). Kuris et al. (2005) suggested Portunion maenadis (Giard, 1866) could be used as a biological control of the green crab. 
Squid are intermediate hosts for marine anchor worms and have been reported to attract many forms of crustacean parasites accidentally. Pascual et al. (2002) surmised a prey-predator transfer of larval isopods when patagonian squid ate the intermediate host copepods. Their cryptoniscus larvae successfully penetrated and colonised the squid. They were entirely embedded in the oral bulb at the beginning of the oesophagus of two female squid. They suspected this was only accidental parasitism; however, this could represent a strategy for host switching, new resting host, or even eventual speciation. A shift of phyla in hosts is always of interest.

\subsection{Tanaidacea: Tunnelling Tanaids*}

Tanaids are a large, free-living group with only one species, Exspina typica Lang, 1968, often found in the intestine and body cavity of deep-sea holothurians, assumed to be a parasite (e.g., Kudinova-Pasternak 1987). Alvaro et al. (2011) confirmed it was a parasite. Many species associate with invertebrates and Hexapleomera robusta Moore, 1894, even with sea turtles and the Caribbean manatee from which we have collected it.

\section{Life Cycle}

Most are similar to fish cymothoid isopods with a free-swimming manca leaving from the marsupium. Two manca life cycle stages of one species were found in the gut of a deep-sea polychaete in the Florida Straits (Suárez-Morales et al. 2011). These stages are probably endoparasitic.

\section{Further Life History}

The adults show few modifications to a parasitic life. However, the full reduction of maxillule setation only occurs in E. typica, and the bifurcated and sharply tipped dactyli in the pereopods is probably a parasitic adaptation for anchoring the crustacean in the soft tissue of the host (Alvaro et al. 2011).

\section{Additional Information}

The unmodified life cycles would suggest a parasitic mode of life is in the early developmental stages. Many tanaidacean species make sand tunnels. This behaviour could have predisposed them to making tunnels in the body wall of holothurians.

\subsection{Decapoda}

Several families of shrimp are well known as associates of other invertebrates, notably sponges and corals, also bivalve molluscs and echinoderms. These species are generally categorised as commensal and not considered parasites as such. A review of these taxa is beyond the scope of the present work. 


\subsubsection{Palaemonidae, Alpheidae, and Atyidae: Sponge Shrimps*}

Shrimp that inhabit sponges are usually referred to as commensals largely because very little is known about their habits. Only a few parasitic species have been determined from two superfamilies; however, many more species are parasitic and probably not just in sponges.

\section{Life Cycle}

Small, eusocial Synalpheus Spence Bate, 1888, carry one to a few dozen large eggs that hatch directly into benthic juveniles (Duffy and Macdonald 1999). Large, malepaired Synalpheus sp. females release several hundred small, planktonically dispersing nauplii from a clutch (Duffy and Macdonald 1999). Eggs hatch into nauplii, which are feed on yolk reserves (lecithotrophic larvae), and metamorphose into zoeae. Zoeae feed on algae (planktotrophic larvae) and metamorphose into myses, which look like tiny adults, and feed on algae and zooplankton. The final instar is post-larvae.

Typton carneus Holthuis, 1951, form heterosexual pairs and exclude conspecifics and other shrimp (negative precursor). Duffy et al. (2000) found Synalpheus regalis Duffy, 1996, excluded heterospecific shrimp. He also demonstrated this species had a colony hierarchy with only one reproductive female and hundreds of helpers. This was the first case of eusociality noted in a marine animal. Six more, probably parasitic, species in the same genus have been found to practice eusociality. We suggest these are the first known eusocial parasites*.

\section{Hyperparasites}

Williams and Boyko (2012: Fig. 1a) illustrated a crab isopod, probably Bopyrella harmopleon Bowman, 1956, on a sponge shrimp, Synalpheus fritzmuelleri Coutière, 1909, from Panama. This may be a hyperparasite, but we cannot be certain. We do not know if the shrimp was collected from a sponge and this shrimp species is not an obligate parasite. Anker (2016) published a photograph of a decapod isopod on Synalpheus brevicarpus (Herrick, 1891), which is definitely a hyperparasite. Several other species of sponge shrimp have hyperparasitic decapod isopods.

\section{Additional Information}

Duffy et al. (2000) showed that shrimp of the Synalpheus gambarelloides group, and S. regalis, in particular, were sponge parasites. Duriš et al. (2011) studied Typton carneus in Caribbean fire sponges in Belize and found it was parasitic. They also examined two other species of Typton Costa, 1844, and three species in three other genera of palaemonids (Pontoniinae) from the western and eastern Atlantic and Indo-Pacific and one alpheid from the Indo-Pacific and found them to be parasites. Their results suggested parasitism by sponge shrimp was widespread.

Zitzler and Cai (2006) reported the first obligate sponge shrimp*, Caridina spongicola Zitzler \& Cai, 2006, in freshwater. This spectacularly coloured, now popular aquarium, shrimp infects an undescribed spongillinid sponge in an ancient 
lake in Indonesia. We believe it is also the first obligate parasitic sponge shrimp reported from freshwater. Zitzler and Cai (2006) only found diatoms in six shrimp stomachs and called them commensal. However, they have a life cycle like eusocial sponge shrimp [a few (12-18) black eggs directly develop and are released as immature adults with no planktonic phase]. Have numbers (up to 137/host) like eusocialists. We doubt diatoms alone would support any shrimp, much less this many. All marine obligate sponge shrimp, studied thus far, are parasitic.

\subsubsection{Brachyura: True Crabs}

True crabs do not make very good parasites. We would call them semi-parasites or kleptoparasites, at best. We believe this is because their basic adult structure is so very unsuited for parasitic adaption and modification. Coral gall and pea crab parasites have a long fossil record but remain low in diversity. Their life cycles also show no adaption for parasitism. They mostly steal their host's food, may slow host growth, but do little, if any, physical damage to the host. Many reside at the uneasy border between parasitism and commensalism.

We have seen indicators of the potential for the development of 'better' parasitism, for example, a superinfection of crab zoea living in the gills of a gray angelfish at Mona Island, Puerto Rico, and adult burrowing crabs living in the gill chambers and feeding on the gill filaments of two gray snappers in Colombia (Williams and Bunkley-Williams 1994). However, these examples were rare, in incapacitated hosts, and proved impossible to duplicate.

\subsubsection{Cancroidea: Jelly Crabs}

Jelly crabs benefit by their life cycles associating with gelatinous plankton through protection, transportation, food, and development faster in warmer waters and saving energy (Towanda and Thuesen 2006). Their relationships with their hosts are more complicated. Ohtsuka et al. (2009) summarised the symbionts of gelatinous plankton. They found crab larvae were only associates, not parasites. However, at least four jelly crabs feed on their hosts, and they spend their entire life cycles on one host. This seems to us to be protelean parasitism. They also steal the food of their hosts, which seems to us kleptoparasitism. We know too little about most jelly crabs to determine their kind of symbiosis. Towanda and Thuesen (2006) closely studied one species, graceful rock crab, but did not diagnose their type of symbiosis.

\section{Life Cycle}

Not much is known. Adults are benthic and planktonic zoea search for and attach to jellyfish. The megalopae and juveniles develop on the host. Eventually, the cypris drops off the host and develops into adults. Sometimes hundreds of megalopae occur 
on the host. Fewer juveniles are seem, which might suggest some cannabilism occurs (Towanda and Thuesen 2006).

\section{Further Life History}

Jelly crabs steal food and eat tissues of their hosts; however, they eat jelly parasitoids, which greatly benefit their hosts. Is parasitism rated as a proportion of good vs evil? We do not think so. This is mutualistic parasitism*.

\subsubsection{Cryptochiroidea: Coral Enveloped Crabs}

Klompmaker et al. (2016) objected to the existing common name 'Gall Crab' because so few actually form real galls. Whether these crab are parasites or commensals, if they damage corals, and even what they eat remains unknown (Vehof et al. 2016). There are 53 species in 21 genera and a single family, which form galls in shallow reef corals and in some deep-water corals (Castro 2015). We have seen these crabs on coral reefs all over the world.

\section{Life Cycle}

They have separate sexes, different internal fertilization, and mate belly-to-belly. Mating takes place just after the female has moulted and is still soft. Females only mate once and store the sperm to fertilise all their batches of eggs. The eggs are released onto the female's abdomen, below the tail flap, secured with a sticky material, and protected there during embryonic development. Females with eggs are called 'berried' (as are all egg-carrying decapods) because the eggs resemble round berries. When development is complete, the female releases the newly hatched larvae into the gall; they pass out into the water and become part of the plankton. Zoea have a tall dorsal spine and may have additional spines for predator deterrence. The zoea of most species must find food (planktonic), but some crabs provide enough yolk in the eggs that the larval stages can live off the yolk (lecithotrophic). Larval development is scarcely known for coral enveloped crabs but is thought to consist of at least five, and possibly seven, planktonic larval stages (Van Der Meij 2014). Different species may have various numbers of zoeal stages, separated by moults, before they change into a megalopa stage. This last larval stage resembles an adult crab, except for having the abdomen (tail) sticking out behind. Megalopae settle in hole, cracks, or creases in living corals. After one more moult, the crab is a juvenile. The coral grows around the crab, and somehow the crab forms a gall to its particular specifications. Females become sexually mature after the 4th instar in the gall but continue to enlarge until the 7 th instar. They somehow manage to enlarge the gall. They produce multiple broods of eggs fertilised by the first mating.

\section{Further Life History}

Many feed on mucus secreted by the corals, inadvertently a little coral tissue, and detritus. Some filter feed. Males are smaller than females. Females cannot leave their gall, but males can. Sometimes pairs live together in one gall, in adjacent galls, or 
even in interconnected galls. They cause no real harm to corals. These crabs form their gall to their own size and design. Related crab species form similar galls; therefore, the galls have phylogenic importance (Wei et al. 2013). Some galls are too closed to be accessible to males. These females copulate before the gall closes, store sperm, and produce up to eight broods over the next 10 months (Vehof et al. 2016). They found evidence of recent mating of females in more open galls.

\section{Additional Information}

Castro (2015) discussed all the publications concerning the food habits of gall crabs. They were largely based on supposition, and Castro concluded, like Vehof et al. (2016), that we still do not know what they eat. He also found the question of their types of symbiosis unresolved. Badaro et al. (2012) observed mucus feeding in the laboratory and suggested all enveloped crabs fed this way and that they are not parasites. We disagree with Badaro et al. (2012) because corals are their obligate hosts and they feed off coral-produced products, if not tissues, which the corals need. That they cause little harm to corals may be true but is not relevant to their type of symbiosis.

\subsubsection{Pinnotheridae: Bivalve Pea Crabs}

The most famous species in this group is the oyster pea crab. They are cosmopolitan, but more common in the tropics and subtropics, and speciose with 322 species in 57 genera and 2 families. They are tiny soft-bodied crabs that live parasitically largely in the mantle of bivalve molluscs and in a few large gastropods, sometimes inside sand dollars and sea urchins, in the rectum of sea cucumbers, tubes of parchment worms, burrows of mud shrimp, and gills of sea squirts (Castro 2015). Some have been reported commensally in, on, or in tubes or burrows of various invertebrates. Many of these relationships are not well studied, and some may be parasitic. They retard the growth of some commercial molluscs by $30 \%$ causing serious problems and millions of dollars in losses in aquaculture (Trottier and Jeffs 2015).

\section{Life Cycle}

Many males venture out of their hosts to visit females in other hosts, mostly at night. This is because hosts are more active and sensitive during the day and can squash males. Trottier and Jeffs (2015) observed males being crushed. Additionally, they are subject to predation less in the dark, than in the light of day. However, we documented the first record of predation on a male, and probably at night, since it was by a cardinalfish, on a coral reef in Okinawa (Williams and Williams 1986c). Pea crabs find females by their pheromones. Male crabs sometimes must rub, or tickle, bivalve mollusc hosts for hours to make them open up (Trottier and Jeffs 2015). Once in the host, they copulate with the female, who never leaves the host. Thus, females can become relatively larger (still only pea-size) to produce eggs, while the polygamous males are smaller and flatter to sneak in and out of hosts. In hosts with more roomy 
accommodations, males may reside with females. Females carry egg masses attached to the pleopods, where they develop until they hatch into zoeae.

Usually, there are five zoeal stages, but some only have one. The zoeal and one megalopal stages are usually separated by only a few days. Hernández et al. (2012) found extended parental care and the suppression of the free-living megalopa in a species associated with western Atlantic ascidians. They undergo a complex metamorphosis during the post planktonic development. The male passes through two forms after the invasive stage, the pre-hard stage with a soft bare, carapace, and no swimming setae on the pereopods and the hard-stage with a hairy, hard carapace and natatory setae on some legs. The female goes through two very similar stages, only differing in the number of abdominal appendages, and five more feminine stages.

\section{Further Life History}

Population biology of few species has been studied, those in tropical and subtropical regions reproduced year round and in temperate regions seasonally during the summer. Reproduction and the presence of juveniles were not related to water temperature or salinity. The greatest abundance of juveniles (pleopods poorly developed) occurred just after the peaks of abundance in gravid females. Very few recruits (megalopal I) were found (Peiró and Mantelatto 2011); therefore, they must pass through this stage quickly. The female-juvenile correlation also suggests they do not disperse very far.

De Bruyn et al. (2011) examined Dissodactylus primitivus Bouvier, 1917, ectoparasitic on two spatangoid echinoid (heart urchins) hosts, Meoma ventricosa (Lamark, 1816) and Plagiobrissus grandis (Gmelin, 1791), which have the entire life cycle on $M$. ventricosa and only adults on $P$. grandis, but with more fecundity. Crabs detected hosts by olfactory cues. Crabs from $P$. grandis were more attracted by this host (where the entire life cycle can be fulfilled, possible imprinting). Crabs from $M$. ventricosa are equally attracted to either host. Host switching may explain asymmetrical infection rates and specialisation on $P$. grandis may be in progress.

Jossart et al. (2014) characterised pea crabs ectoparasitic on sea urchins at Discovery Bay, Jamaica, in which both sexes changed hosts, searched for sexual partners, and had a polygamous mating system. Most mate by polygynandry between large females and wandering small males, although some by monogamy, or temporary monogamy between adults of similar sizes, and a few by swarming of males (Castro 2015).

Ambrosio and Baeza (2016) found the pea crab, Tunicotheres moseri (Rathbun, 1918), did not attempt to infect previously, conspecific infected ascidian hosts, Styela plicata (Lesueur, 1823), to avoid conflict, even though this host was scarce and defence of the host was minimal. This is another variety of negative precursor. We wonder if defence of the host was once fiercer, incited this avoidance, and then faded with non-use.

\section{Additional Information}

Castro (2015) listed many damages attributed to pea crabs. The most common was slowed growth, and the most harmful, sterilization and sex reversal. He concluded 
that most associations were parasitic and only some more loosely associate forms in tube- or burrow-dwelling hosts might be commensal.

The California bay pea crab has the distinction of being one of only two marine crustaceans on the IUCN Red List (Wikipedia), and it is the only possible parasite on this list.

\subsection{Concluding Remarks}

The life strategies of most parasitic crustaceans are not very modified from their freeliving ancestors. With a few notable exceptions, their life cycles suggest they just do not make very good parasites. Most would seem to have recently evolved into parasitism, yet fossil evidence shows otherwise. The most grossly modified females still metamorphose from simple life cycles. Even the most successful group, the copepods, is still hindered in exploiting different classes of hosts by the simplicity of their life cycles.

The rigidity of their life cycles seems a major limitation of crustacean parasites. Part of this apparent situation may be a result of our lack of knowledge and understanding. Here we described four new and innovative life cycles, complex rebrooding, mesoparasite, micro-male, and prey-predator transfer; four instances of a new life cycle host behaviour modification, nursery hiding*; a common, but undescribed, life cycle form, mid-moult stage*; two instances of parasite intraspecies facilitation, positive precursor*; parasite intraspecies antagonism, negative precursor*; an ambush life cycle strategy, opossum attack*; doubling of the normal reproductive set on a host, double parasitism*; and separated male-female pairs, duplex arrangement* ${ }^{*}$. We also named and redescribed a known life cycle, simple rebrooding*. Possibly, many more life cycles and modifications remain to be discovered. However, these still represent rather minor modifications. Crustacean parasites lag far behind the other major parasite groups in both complexity and modification of their life cycles.

Mid-moult* individuals are an important new means to identify juvenile life cycle instars. They are also very useful in determining exactly what changes occur in a moult and can also be used to distinguish between supra-female instars. Our term displaced parasites* refers to life cycle forms which matured in the wrong locations on their host due to their normal sites being occupied. This is also linked to superinfections*, which are mass infections of many parasites on or in a host (often resulting in the death of the host and the parasites). These occurrences strain the fabric of normal parasite relations, and life cycles, often revealing unimagined changes and trends (Williams and Bunkley-Williams 1994; Madinabeitia and Nagasawa 2011; Ismail et al. 2013).

We used the term proportional stunting* to describe the slowing of growth in fishes caused by fish isopods (cymothoids). This cannot be evaluated by host condition factors, which have confused many into believing these parasites do little 
harm. Actually, they are quite detrimental and cause major economic loses to aquaculture and commercial fisheries.

The hypothesis of the first crustacean cymothoid being external attaching and then forms moving into the gills or mouth has not been supported by molecular phylogeny. The gill chamber appears to be a much more inviting and less hostile habitat for initial colonisation, as we have seen in two cases of unusual crustacean infections (Williams and Bunkley-Williams 1994). Our displacement cases seem to also suggest this scenario.

Schmid Hempel (2011) did not find well-adapted parasites became harmless but rather more efficient at countering the defences of their host. Many recent authors have suggested parasite evolution favours virulence. However, we report the first hyperparasite ever known to evolve into a mutualist and explain the pathway. Poulin (2011a) thought that parasites with few adaptions could revert to a free-living existence but cited few examples. He found no parasite reversals* to mutualism.

Predation has only recently been shown to occur within parasitic crustacean life cycles and cause damage and death of hosts. Parasitism and predation are difficult enough to distinguish when isolated, much more so within a life cycle. As we learn more details of life cycles, predation may become important phases. We attempt to define the types involved (Table 5.1 and Annotated Glossary (Sect. 5.15) below).

Cleaners feeding on fish gnats (gnathiids) may be accessory vampires. They may more easily find and/or select larger, swollen fish gnats filled with blood. Eckes et al. (2015) suggested cleaners benefited more from consuming fish mucus than fish gnats. We certainly believe they benefit more from eating blood-filled gnathiids, than ones without fish blood.

We found copepod pre-adult life cycle stages were common on Western Pacific fishes but very rare on Caribbean ones. This indicates that smaller cleaner gobies may be more efficient than larger cleaner wrasses and a factor in parasites completing life cycles.

Contrary to the literature, we find the wormlike copepod on sea turtles, manatees, and whales are not parasites. We described how Pennella exocoeti may have speciated. Flying fishes are food for many offshore large predators, which host Pennella species. Flying fishes were probably a downward incorporated intermediate host for Pennella spp. at one point. Eventually, a form became isolated and speciated into Pennella exocoeti on flying fishes.

Fish isopods (cymothoids) seem on the verge of evolving a real intermediate host. Fish gnats (gnathiids) may also be exploring intermediate hosts through micropredation. A new ergasilid copepod seems to be becoming an endoparasite.

Tongueworms are completely parasitic with no free-living stages, endoparasitic in an intermediate and a final host, and so modified to parasitism we cannot even equate their life cycle stages to free-living ones. All other parasitic crustaceans are incompletely parasitic in one way or another. Therefore, these life cycles suggest tongue worms are not crustaceans. They further suggest tongue worms are not even related to crustaceans, and this needs further investigation.

Fish lice and tongue worms have long been suspected to be related on the basis of their sperm morphology. Recent molecular work also finds them similar. Their life 
cycles are the same in having no free-living larval stages but are otherwise worlds apart. Fish lice are not even good ectoparasites, flitting around from host-to-host as juveniles and adults with females free-living off hosts. Tongue worms are good endoparasites every step of their way. The life cycles of fish lice and tongue worms suggest they have no phylogenetic relationship.

The few fossil 'tongue worms' only recently discovered are larval parasites of marine invertebrates. Equating these with tongue worms of present terrestrial vertebrates with no larval stages is impossible. These fossil tongue worms may be related to extant tongue worms, but they are not their ancestors. A parallel, and completely separate, evolution is more likely.

Octopus copepods (Harpacticoida) and tunnelling tanaidaceans (Tanaidacea) have similar life histories tunnelling through the tissues of octopuses and sea cucumbers, respectively. They also represent the rare parasitic forms in their largely free-living orders. Both also have commensal species on sea turtles and manatees. However, their life cycles are quite different (López-González et al. 2000; Alvaro et al. 2011), and they reside in different classes of crustaceans. Their modes of living and feeding must represent parallel evolution.

Anchor worms (lernaeids) and marine anchor worms (Pennellidae) are an astonishing example of parallel evolution. So much so that they were originally classified together in Lernaea Linnaeus, 1758. They are also the only copepods to make major host group switches: Amphibia and Reptilia by the anchor worm and Mammalia by the marine anchor worm. Even their life cycles are similar with intermediate hosts, except that it is not an obligate intermediate in the anchor worm. Furthermore, the anchor worm is freshwater, and marine anchor worms are marine, and they are classified in different orders.

Lafferty and Kuris (2002) recognised four life cycle strategies (a bit too simple) and ten trophic strategies. Poulin (2011b) arranged all parasites into six major life strategies (see Table 5.2). All categories, except vector transmission, apply to crustaceans. Poulin and Randhawa (2015) further defined and defended the categories but made little more use of them. Half were named for transmission methods and half for effects on the hosts, which seems confusing as they are not, necessarily, mutually exclusive. In order to standardise his terms, we rephrase parasitoid to 'adult injection transmitted', parasitic castrator to 'larval penetration/injection transmitted', and

Table 5.2 The original six major life strategies from Poulin (2011b) and our seven proposed transmission strategies

\begin{tabular}{l|l|l}
\hline & Original category name & New transmission-standardised names \\
\hline 1 & Parasitoid & Adult injection transmitted* \\
\hline 2 & Parasitic castrator & Larval penetration/injection transmitted* \\
\hline 3 & Directly transmitted parasite & Direct life cycle transmitted parasite \\
\hline 4 & Trophically transmitted parasite & Prey-predator transmitted parasite \\
\hline 5 & Vector-transmitted parasite & Vector-transmitted parasite \\
\hline 6 & Micropredator & Minipredator transmitted \\
\hline 7 & - & Inanimate transmitted \\
\hline
\end{tabular}


micropredator to 'micropredator transmitted' (see Table 5.2). We also add a seventh strategy. Most microbial parasites have no animate transmission agent. They contaminate potential hosts in incidentally shed host products or by long-lived free-living stages. Some symbionts on sea turtles and manatees spend their entire life histories on their hosts, never leaving, never transmitted. Poulin and Randhawa (2015) call their categories 'dead ends', but we do not believe micropredator is necessarily a parasitological dead end.

If we use the seven new transmission-standardised names to categorise crustacean parasites:

1. Adult injection transmitted - larval parasitic copepods (Sect. 5.5.3) have a life cycle similar to parasitoids but do not kill the host, and jelly parasitoids (Sect. 5.10.3) are almost parasitoids.

2. Larval penetration/injection transmitted - some parasitic barnacles (Sect. 5.6.2), some echinoderm copebarnacles (Sect. 5.8.2), and some crab barnacles sterilise their hosts. Sterilisation is not one strategy but two. Hormonal sterilisation is a permanent, parasite chemical control of a host. Nutritional sterilisation is a temporary parasite use of the host resources to the extent that host reproduction cannot occur.

3. Directly transmitted parasite - represents almost all of the crustacean parasites. Poulin and Randhawa (2015) found these forms were the simplest and least parasitically evolved of the parasites, which agrees with our analysis.

4. Trophically transmitted parasite - is only found in tongue worms (Sect. 5.3, which are probably not crustaceans). Marine anchor worms (pennellids) have this strategy, except the intermediate host is not eaten by the trophically higher predator. Our prey-predator life cycle follows this strategy, except the parasite juvenile only moults to an adult in a paratenic (not intermediate) host, before it is eaten.

5. Vector-transmitted parasite - does not occur in crustacean parasites.

6. Micropredator transmitted parasite-occurs in fish lice (Sect. 5.2), sea lice (Sect. 5.5.4, caligids), jelly parasitoids (Sect. 5.10.3) and some juvenile fish isopods (Sect. 5.11.2) that are micropredators.

7. Inanimate transmitted parasite-occurs in non-swimming fish lice (Sect. 5.2) and whale lice (Sect. 5.10.1).

Williams and Bunkley-Williams (1996) made the first, large-scale comparison of Caribbean and Western Pacific parasites of coral reef fishes using the same collection and examination techniques. In terms of crustacean parasites, they found less aegid associates and more tongue worms in the Pacific. Cymothoids, fish gnats, copepods, and barnacle associates were approximately equal. In contrast, non-crustacean parasites were less diverse and abundant in the Pacific than the Caribbean.

Fish lice, tongue worms, larval parasitic copepods, isopods, and whale lice lack larval dispersal stages. Fish lice and isopods have free-swimming juveniles to make up for this limitation, somewhat. Larval parasitic copepods, fish lice, and sea lice have free-swimming adults.

Many recent authors seem to equate, or even confuse, the complexity of parasitism with its severity. Sometimes these do go hand-in-hand, but they are different. 
Complexity makes parasites more resilient, adaptable, and in the case of marine anchor worms more able to switch major host groups. Severity is how voraciously and efficiently parasites use host resources to successfully reproduce the most. Some of the most severely parasitic crustaceans actually have rather simple life cycles (e.g. parasitic barnacles and Sarcotaces). The elaborate modification of adults is also sometimes equated to severity. Again, these may co-exist but are different.

Many crustacean parasites, in general, seem to infect young hosts and 'grow up' with them. This has been shown in many parasites where the younger hosts, even planktonic juveniles, are much more often parasitized than the larger, older ones. In addition, host tissues growing around their parasites indicate long-term association. Younger hosts are easier to find and infect often occurring in inshore schools. Our prey-predator transfer may be one of the only ways older host can be infected.

To evolve towards greater parasitism, the life cycle stages of crustaceans must be less and more. They must be less like the free-living crustacean stages (e.g. fish lice and fish isopods) and/or must add more parasitic stages in real intermediate hosts (e.g. tongue worms). They can either convert their free-living stages to parasitism or metamorphose new parasitic stages. Those few that have developed parasitic larval or juvenile parasitic stages are progressing. However, the free-living adults many retain must become parasitic. Adults must also become more modified and adapted to a parasitic existence. Crab barnacles have done a pretty good job of this, and a few copepod adults are well modified, but in general, crustaceans have done a terrible job of adapting to and exploiting parasitism.

Currently, we know only a minute fraction of the crustacean life cycles. Additional studies may turn what we think we know on its head, upside down, or throw it out the window. We are fooling ourselves that the little we know is typical. We expect most known group life cycles are not only unknown but probably false. Not only do we know few life cycles, but we also know few of the species in most groups, and these may have even different life cycles. Also, major groups are still springing into existence. Life cycle study is a field where magic is still awaiting discovery.

\subsection{The Future of Parasitology}

Crustacean and nematode parasites will soon dominate metazoan parasitology. We call the present dominating parasites (flatworms, tapeworms, thorny-head worms, etc.) as "Climax Parasites". They are ancient, stable, and perfect to take maximum advantage of the current conditions. Unfortunately, they are also practically unchangeable in having no free-living forms to become parasitic, no adults in invertebrates, major parasitic modifications, and low species abundance. We call crustaceans and nematodes (ecdysozoans) as "Transitional Parasites". They would eventually evolve into Climax Parasites but now possess just the opposite of the climax characters stated above. The Climax Parasites have traded flexibility and the ability to innovate for stability and the maximum parasite experience. They are rigid 
and vulnerable with exposed multiple hosts and complex life cycles, unable to make major host group shifts, life cycle reductions or additions, and too involved in, and dependant on, stability. Major global changes will leave them behind, at worse in extinction or, at best, in remnant triviality. Crustaceans and nematodes will inherit the new world of parasites.

\subsection{Annotated Glossary}

An astonishing number and variety of recent authors misapply and misuse common life cycle terms. This inaccuracy creates misunderstanding and undermines scientific precision. We here precisely define these terms.

Abandon host-when parasites evacuate a host that has been captured, injured, incapacitated, or poisoned.

Accidental attachment - (a) a host-specific parasite rarely attaching to an accidental host or (b) a site-specific parasite rarely attaching in a different position.

Accidental (incidental) host-(a) a host on which the parasite cannot complete its life cycle; (b) also used for very rarely infected hosts on which the life cycle can be completed.

Aegathoa-a juvenile genus used for Cymothoidae juveniles that could not be identified to genus and as such is a form genus. This should no longer be used, but inexplicably, recent uses exist.

Aesthetascs - chemosensory organs on the antennae and other structures of larval crustaceans used to locate appropriate hosts, virgin females, etc.

Aggregation - (a) usually refers to the distribution of parasites within hosts. Often, these are not uniformly distributed among host but aggregated in a few hosts;

(b) can also refer to a group of hosts or to a cloud of parasite infective stages.

Alternate host sharing - a life history strategy where two different species of parasites infect the same host, but not at the same time.

Ambushing - a manner of searching for hosts used by larvae and free-swimming adults, generally, resting still in the water column arched upwards at a $45^{\circ}$ body angle and then suddenly attacking an unaware host. Used in the daytime by some forms. Opossum attack is a form of ambushing. See cruising and hover and wait.

Androdioecy - having dwarf males and larger hermaphrodites. The small male is usually attached on or near a larger hermaphrodite.

Antennae - the second pair of antennae, usually longer than the first.

Antennulae - the first pair of antennae, which are usually shorter than the second.

Biological control — an agent killing or sterilising unwanted organisms.

Biphasic moult — a moult occurring in two posterior (first) and anterior (second) parts. This occurs in all Peracarida. See moult, mid-moult stage.

Body—is in three sections: the head (cephalon), thorax (pereon), and abdomen (pleon). See metasome and protosome.

Bopyridium (juvenile) - the third life cycle stage of epicaridian crustacean isopods. 
Brood mortality - loss of some individuals in developmental stages in the marsupium. This has only been measured indirectly with counts of different stages from different females.

Burst release-when a predator attacks a host and its parasite dumps out all its juveniles at once.

Capsule - a layer produced by a host to isolate a parasite. See cyst.

Castration-refers to removing male testicles. It has been classically misused in parasitology for sterilization. We change it to the correct term 'sterilization'. See hormonal sterilization, nutritional sterilization, partial sterilization, and sterilization.

Casual parasite—see periodic parasite, accidental host.

Cephalon - the head of the crustacean. See body.

Cephalothorax - the joined head and pereonal first somite (the maxillpedal somite). See body.

Chalimus - the third larval stages in sucker-mouth copepods (siphonostomatoids) between the infective copepodid stage and the adult. It is attached to the host by a filament and develops in a series of moults to the adult.

Cleaner nipping - a cleaner attacking a parasite, which is too large for it to remove, by biting or tearing off a piece or appendage.

Climax parasite (perfect parasite, advanced parasite)—one that has evolved to a 'perfect state' to take advantage of existing conditions and hosts to maximise its existence.

Clutch size - the number of eggs produced in one spawning event. See fecundity.

Commensalism - means living with, and benefiting from, a different species. Distinguishing commensalism from parasitism can be difficult. The trophic nature of many crustacean symbiotic relationships remains uncertain.

Complex life cycle (indirect life cycle)—one with two or more hosts.

Complex rebrooding - a series of marsupial reproductions with vegetative instars between marsupial stages. When a female is reproductive, the marsupium contents occupy all the body space with a large number of offspring. Her other organs atrophy, and she does not feed. See vegetative stage and simple rebrooding.

Copepodid - the second larval stage in copepods, between naupliar stages and adult. The first copepodid is free swimming. The others are on the host. See recently encysted and later encysted.

Cruising - a manner of searching for hosts used by larvae and free-swimming adults. Generally, it means swimming in the water column with an even keel.

Cryptogonochorism - a degenerative male form, attached and parasitic on a female, fertilising her eggs. Found in parasitic barnacles (rhizocephalans).

Cryptoniscan (cryptoniscus and cryptoniscid) - the second larval stage of epicaridian crustacean isopods.

Cypris stage (cyprid) (plural: cyprii, cyprids) - the second larval form in many crustaceans. There are usually one or two instars, and it is the infective stage.

Cyst - a parasite forming a protective coating or layer around itself generally inside a host, under its skin, etc. When the host forms a layer to isolate the parasite, this is 
called a capsule. In some cases, both contain a parasite. Some life cycle forms are encysted and/or encapsulated. See gall.

Definitive host (final host, primary host) — the usual, or normal, host of the parasite and the one on which it can complete its life cycle.

Demarsupiation - the releasing of the swimming or infective or reproducing stage from the marsupium (brood pouch).

Direct life cycle-involves a single host.

Direct develop larvae (crawl-away larvae) - larval stages that have very low dispersal potential and usually appear like the adult form of the animal. Fish lice (branchiurans) are crustacean examples. Non-swimming larvae of Chonopeltis are definitely crawl-away larvae.

Dispersal stage - free-living larval or adult stages that swim around, or are carried in water currents, to new areas.

Displaced parasites - when all the normal attachment sites are occupied forcing additional parasites to attach in unusual positions.

Double parasitism - when two reproductive sets of the same species occupy the same host, when normally only a single set occurs. See also multiple parasitism.

Downward incorporation-adding a new host after the original host with the new host becoming an intermediate host. Moving down the food chain. See parallel incorporation and upward incorporation.

Duplex arrangement - the separation of the male and female of a pair on opposite sides of a host.

Dwarf male-small male usually attached on or near a larger hermaphrodite (e.g. normal barnacles, Thoracica) or inside the female (parasitic barnacles, Rhizocephala). See androdioecy.

Ecdysis (moult) - the moulting of the cuticle and the transition to the next stage of development.

Ectoparasite - parasites that attach to the outside of their host. However, there is some disagreement about what is outside. We consider the brood chamber, eye orbit, gill chamber, mouth, nares, and open sinus cavities as external as their surface is ectoderm. See endoparasite.

Encapsulated-see cyst and capsule.

Encysted-see cyst and capsule.

Endoparasite-completely within the host. It has no opening to the environment as in a mesoparasite. We consider closed sinus cavities, lacunar canals, rectum, intestine and urinary bladder internal. See ectoparasite.

Epicaridium larva-see microniscan larva.

Epigametic sex determination-first infective life cycle stage arriving at a host becomes a female and the second, a male, e.g. decapod isopods (bopyrids) and fish isopods (cymothoids). See founder pair.

Epiparasite-see hyperparasite.

Eusociality - a colony system where only the queen is reproductive and is served and protected by relatives. Life cycles are direct lacking a planktonic stage. Sponge shrimp (carids) are the first known eusocial parasites. 
Exoskeleton-(a) the outer covering of crustaceans; (b) the old shell left after moulting or the exuviae.

Externa (plural: externae)— the outside, egg-, larvae-holding, sac of a female of parasitic barnacles (rhizocephalans).

Exuviae (formerly only plural, but exuvia is coming into use)—see exoskeleton.

Facultative intermediate host-infecting the host is not necessary to complete the life cycle.

Facultative parasite - may parasitise a host, but the host is not necessary to complete its life cycle.

Feeding stage-see vegetative stage.

Feminisation - parasitic barnacles (rhizocephalans) change the pleon configuration of male crabs they infcct into the female configuration to better protect their externa. Cryptic isopods (cryptoniscoids) residing in the marsupium of other isopods may control their host to retain this brood pouch.

Final host-see definitive host.

Founder pair - two infective stages attaching to a host together, excluding other cohorts, and successfully developing into a male and female pair (e.g. cymothoids).

Fugu toxin - tetrodotoxin (TTX) in puffers, which repels gnathiids from the skin of puffers, and we believe some other crustacean parasites.

Gall-a plant term. It is sometimes misused for large, parasitic cysts. Usually galls contain more than one parasite, often both sexes and life cycle stages. See cyst.

Good parasite - see true parasite and strict parasite.

Growth stage - a distinctly different morphological form not resulting from a moult. Some pre-adults may qualify. Many crustaceans have different growth stages as adults age or grow in size. See Supra-female.

Hover and wait-a form of ambush host seeking employed by fish lice (branchiurans) during the day. See ambushing.

Hormonal sterilisation-a permanent, parasitic chemical control of a host. See nutritional castration and partial sterilisation.

Host hopping - is adults, and/or larval life cycle stages, leaving one host and finding the same, or another, within a life cycle stage.

Host switching - can be (a) a long-term evolutionary change usually to quite a different kind of host; (b) part of the prey-predator transfer life cycle sequence; (c) casual parasite survival (e.g. Connors et al. 2008, 2011); or (d) even within a life cycle (Ota et al. 2012).

Hyperparasite (epiparasite) — a parasite parasitising another parasite.

Hypersymbiotic (episymbiotic) — a symbiont, usually a parasite, associating with/ infecting another symbiont, usually a commensal.

Immature - a young individual and another name for post-larva or juvenile.

Indirect life cycle-see complex life cycle.

Infective stage - the larval stage, which attaches to or injects infective material into a host. In many forms a cypris.

Infection-(a) parasitologically, a parasite or microbe invading a host (formerly referred only to endoparasites; see infestation); (b) medically, invasion of 
endoparasites; and (c) microbiologically, invasion of an organism that multiplies within the host (e.g. bacteria, fungi, protozoans, viruses).

Infestation-(a) parasitologically, ectoparasite on host can still be refer to parasites in the environment; (b) invasion of any parasite; (c) medically, sometimes used for ectoparasites; (d) medically, sometimes refers to the initial stage of parasite invasion followed by infection; and (d) common usage, aggregations of pests (e.g. mosquitoes, rats).

Inquiline - an animal living in another species of animal's nest, burrow, den, or resting place.

Instar-a larval stage between moults. For example, there are usually five naupliar instars.

Intermediate host - a host that a larval stage infects, feeds on, and undergoes at least one moult upon. See micro-male host, resting host, and transfer host.

Interna (plural: internae) - the internal and anastomosing part of a female parasitic barnacle (rhizocephalans).

Iteroparous - females have multiple broods, e.g. cymothoids.

Juvenile (immature, immature adult, post-larva) — a miniature adult. In cymothoids, the juvenile escaping the female marsupium has six pairs of legs (six-legged juvenile). See larva and manca.

Juvenile-like larvae-look like adults with four pairs of active thoracopods, but no suction disks. They are larvae of fish lice (branchiurans).

Kentrogon - an infective stage, metamorphosed from a crypis, of parasitic barnacles (rhizocephalans). The kentrogon injects a vermigon.

Kleptoparasites - steal the food or food stores of its host.

Larva (plural: larvae) —an immature greatly differing from the adult form, which must go through a metamorphosis to be an adult. Some authors use the terms juvenile and larvae interchangeably; however, these are different and distinct stages, which should not be confused.

Lecithotrophic larva - do not feed but use their yolk for nourishment.

Leg-see pereopod.

Lice (singular: louse) — technically phthirapteran insects; fish lice are branchiurans; and sea lice are either micro stinging jellyfish (since 1949), bird schistosomes (since 1928), or caligid copepods (since 1975 ); and whale lice are cyamid amphipods. Tongue-eating louse is an incorrect name for the famous tonguereplacing isopod.

Life cycle-development from conception until the organism produces its own offspring. Its study often emphasises stages of development. See life history.

Life cycle abbreviation - the brooding or elimination of normally free-living larval stages.

Life cycle truncation - the elimination of parasitic larval life stages.

Life history-reproductive strategies and traits plus other key events in the life of an organism. See life cycle.

Lifestyle - the mode of life. Habit (behaviour) and habitus (form). Mobility, feeding, nutrition, habitat, activity period, etc.

Major host group switch-parasitising a new class of host. 
Manca juvenile (plural: mancae) (Aegathoa, manca, micro-male, pullus II)-the post-larval juvenile of many pericardians (not amphipods), which leaves the brood pouch. See Aegathoa.

Marsupium (brood pouch)_formed of lamellar outgrowths of the female pereopodal coxae (oostegites). This pouch is under the ventral body surface of the female. See complex rebrooding and simple rebrooding.

Marsupium stages - various egg, embryo, and larva stages. This embryology is seldom considered in life cycle studies.

Megalopa-a post-larval crab. Extreme transformations occur in this stage.

Mesoparasite-(a) inside their host but retains a pore or hole connecting to the outside; (b) half-in-and-half-out as anchor worms (Lernaea); and, quite confusingly, (c) also used for parasites that enter host orifices (ear, nares, etc.). The latter might be less confusingly called Orifice Parasites.

Metanauplus (pleural: metanauplii)—see nauplius.

Metanauplus-like larvae - are similar to crustacean nauplii, but not metanauplii because of post-mandibular appendages and differentiated first thoracopods. They are larvae of fish lice (branchiurans).

Metasome (tail) - the posterior part of the protosome.

Micro-male - a 6-, 6.25-, 6.5-, 6.75-, 7-leg juvenile functional male of Anilocra spp., Livoneca ovalis, and possibly other cymothoids.

Micro-male host-a resting host for some juvenile fish isopods (cymothoids) on which moults from the 6-leg to 7-leg micro-male stage can occur. This is not an intermediate host because no larval stages are involved. The micro-male leaves this host to fertilise a female on the final host. It may return to this host specimen or another micro-male host.

Microniscan larva (epicaridium, microniscus or microniscid) — the first larval stage of epicaridian crustacean isopods.

Micropredator-like a mosquito; a small predator feeding on a big host and not spending much time with its macroprey. Predator less than 1000 times size of prey. See minipredator, smaller predator, and Table 5.1.

Mid-moult stages - a form of half delayed moulting found in some parasitic forms that must stay firmly attached to a host. The first half moults as usual, but the second half moult is delayed until the first half hardens.

Minipredator - a small predator that may, or may not, kill its prey and spends little time with it (feeds and leaves) but is greater than 1/1000 of its host's size, but less than 1/100 (e.g. gnathiids, cirolanids, some corallanids, some leeches). See micropredator, smaller predator, and Table 5.1.

Molt (apolysis, ecdysis) - the splitting of the outer covering (cuticle carapace, etc.) in order for a larger and/or different form to emerge in the life cycle. Outside the USA, the preferred British spelling is moult.

Multiple parasitism - when one host is infected with two, or more, different species of parasites representing, three or more reproductive sets. See double parasitism.

Mutualistic parasitism - when the symbiont is both harmful and helpful. Similar to sickle cell anaemia and malaria.

Mutualistic symbolism — when both host and associate benefit from the other. 
Natural history - the interactions of an organism with its environment that influence behaviour, forms, function, and abundance. See life history, life cycle, and lifestyle.

Nauplius stage (plural: nauplii)—is characterised by the use of the appendages of the head (antennae) for swimming. This first series of larvae has been shared by almost all crustaceans for the last half billion years.

Negative precursor - when one species of parasite or commensal infects a host first and causes a second species of parasite to be less successful in infecting the same host. See positive precursor.

Non-swimming larvae-the odd larvae of Chonopletis, a fish louse (branchiurans).

Nursery hiding - infected adult hosts staying with juveniles or young of the same species instead of migrating elsewhere with non-infected adults.

Nutritional sterilisation-is a temporary parasite use of the host resources to the extent that host reproduction cannot occur. See hormonal castration and partial castration.

Nymphs - are small 4-6-legged, larval forms of tongue worms (pentastomids).

Obligate parasite-is a species that must infect a particular host to complete its life cycle.

Onychopodid larva-replaces the on-host copepodid larva in Gonophysema gullmarensis Bresciani \& Lützen, 1960, a copepod parasite of a tunicate.

Oostegites (marsupium coverlets)—see marsupium.

Opossum attack - when a manca juvenile swimming dorsal side up, stops swimming, falls to the bottom, lands dorsal side down, and does not move. When a small fish comes near, the manca springs to life and attaches. See ambushing.

Orifice parasite - a term we prefer in place of mesoparasite for parasites living in natural orifices or openings in hosts.

Orthonauplius - a nauplius but has a shorter head, antennula, and two additional pairs of limbs.

Ova-eggs.

Overdispersed (aggregated, clumped) - in parasitology is a distribution with a higher variance than expected (e.g. when most hosts have a few parasites, but a few have many).

Pantochelis larva - the first larva of jelly parasitoids (hyperiideans) with four cheliform legs (pereopods) and an unsegmented and limbless metasome and urosome. It metamorphoses into a protopleon larva.

Parallel incorporation - adding a new host after the original host with the new host becoming an intermediate host. Begins with a resting host or transfer host becoming an intermediate host and eventually an obligate intermediate host. Moving sideways on the food chain. See downward incorporation and upward incorporation.

Parasite - takes benefits from the host it harms but very rarely kills it. True parasites or good parasites stay on their final host specimen never leaving.

Parasite Increased Trophic Transmission (PITT) - a parasite changing the behaviour of its intermediate host making the prey more likely to be eaten by the predator definite host.

Parasite reversal—a parasite becoming free-living. 
Parasitoid - an insect infecting another species of insect with its larvae. The larvae feed off the host and eventually kill it and escape as adults. Larval parasitic copepods (monstrilloids) have a similar life cycle, but do not kill their host.

Paratenic host (transfer host, transport host) - like an intermediate host, except the parasite does not go through any life cycle or larval stage on it.

Parthenogenesis - asexual reproduction by females without the need of males.

Partial sterilisation - a term used by Williams and Boyko (2012), as 'nutritional castration', where some reproduction still occurs.

Pereon - the thorax. See body.

Pereopod (leg, peraepod, pereiopod, thoracopod)_legs of the thorax (cephalothorax, pereon) of crustaceans.

Periodic parasite - acting like a facultative parasite, on a host for short periods of time, but free-living most of the time. Does not obtain most of its nutrition from a host or hosts. Not a serial parasite, temporary parasite, or true parasite.

Permanent parasite - is an obligate parasite, which spends more than one generation without leaving a host. See temporary parasite.

Planktotrophic larva-feeds on plankton. See lecithotropic larvae.

Pleon - the abdomen. See body.

Pleopods (paddle gills) — appendages underneath (ventral) the abdomen (pleon) of crustaceans.

Positive precursor-when the presence of one parasite facilitates infection by another. The interspecific form is fairly common; however, intraspecific forms are rare. This is when one species of a parasite or commensal infects a host first and causes a second species of parasite to be more successful in infecting the same host. See negative precursor.

Post-larva (plural: post-larvae) (immature, juvenile, pre-adult)—resembles the adult and characterised by the use of abdominal appendages (pleopods) for propulsion.

Praniza (formerly pranzia)—see zuphea.

Pre-adult - a stage after larvae and before adult.

Predisposition - (a) some hosts of crustacean parasites appear to be predisposed to the presence of parasites (Williams et al. 1982); (b) also may refer to a pre-existing condition or behaviour, which makes some process possible (e.g. speciation, life cycle change).

Preferred host-see secondary host and definitive host.

Pre-larvae (pre-zoae) - the first stage after an egg hatches. Usually held in a marsupium in isopods.

Pre-manca-the isopod brood-pouch stage after eyed embryo before manca and is less developed and has less setae.

Prevalence collection effect-when infected hosts are impaired by their parasites and are more readily to be collected (e.g. dip net, seine, trawl), or less likely to be collected (e.g. hook and line, baited traps), than uninfected ones.

Prey-predator transfer-Fish isopods (cymothoids) from prey fishes can transfer to the predators that eat them. See prey-predator life cycle and transfer host. 
Prey-predator transfer host (prey host) — a resting host for some juvenile fish isopods (cymothoids) on which moults from the six-legged manca juvenile to a post-juvenile stages can occur.

Primary host-see definitive host.

Proportional stunting - parasites slowing the growth of their host in a way that cannot be discerned in length-weight condition factors.

Protelean organisms - have larvae that are parasites, usually endoparasites, and free-living adults.

Protopleon larva - the second larval series of jelly parasitoids (hyperiids) with a segmented metasome and imperfect pleopods. It metamorphosed from a pantochelis larva and gives rise to a juvenile.

Pseudoparasite - our term for something that almost everyone accepts as, and calls, a parasite, but is not (e.g. most leeches).

Pullus II (plural pulli)—see manca larva.

Pupa - the unique, cigar-shaped, endoparasitic nauplii of larval parasitic copepods (monstrilloids).

Reproductive stage - see vegetative stage.

Recently encysted (copepodids 2-3)—pandarid copepodid stage (Lewis 1964). See late encysted.

Resting host - a host on which infective larvae or juveniles rest and feed. Larvae do not go through a metamorphosis on this host. See intermediate host, micro-male host, and transfer hosts.

Sea lice - caligoid copepods that infect marine aquaculture fishes, especially salmon. Many recent authors have called them fish lice, which is incorrect. See lice.

Secondary host - a host less often infected than the preferred host or definitive host but on which the parasite may complete its life cycle.

Semelparous - females that have only one brood.

Serial parasitoid — similar to a parasitoid in brooding its young in a host, but may use and kill more than one host as a nursery, and also may feed on, and kill, multiple hosts, as an adult.

Serial parasite - an obligate parasite that largely depends on host, or hosts, for nutrition. It is not simply a minipredator, because it associates with a host longer than to feed and leave and has one or more life cycle stages that exist multiple times potentially on and off the same or different hosts. See temporary parasite.

Simple life cycle-see direct life cycle.

Simple rebrooding - new marsupial reproduction after a single moult. The internal organs are only flattened by a brood pouch with a moderate number of off spring. The female can feed as soon as she moults. See complex rebrooding.

Site specific - when a parasite almost always attaches in the same position on or in a host. See accidental attachment.

Smaller predator - not a great deal smaller than its prey, attaches to, feeds on, and kills the host. It is an, hitherto, unrecognised life cycle phase (minipredator phase) in parasitic crustacean life. See micropredator, minipredator, and Table 5.1. 
Spillover - a term for the parasites, principally salmon sea lice, produced in fish farms, infecting native fishes. 'Spillover' suggests the pen is so full of free-swimming, infective parasites (copepodids) that a few are forced out. See filtering.

Sterilisation-the act of making an animal unable to reproduce. See partial sterilisation, hormonal sterilisation, and nutritional sterilisation.

Strict parasite-see true parasite.

Superinfection - a mass infection with about as many parasites that can fit on or in a host. This usually results in the death of the host and the parasites.

Supra-females (post-adult stages, supra-adult) — stages after the first adult female stage with size and/or morphological differences with the first adult and each other. These can be growth stages or instars and often occur in crustaceans.

Supra-males-see supra-females.

Tantulus larva - the only larval stage of minute crustacean parasites (tantulocarids) with a dorsal head shield, six-segmented thorax, and biramous urosome.

Temporary parasite - (a) a facultative parasite; (b) a parasite that survives for a time after ingestion by a host species other than its customary host; (c) a minipredator, associated with a prey item just long enough for it to be called a host but largely free-living and rarely found associate with a host; or (d) a parasite with any freeliving stage.

Thoracopod-see pereopod.

Transfer host (prey host) —a resting host for some juvenile fish isopods (cymothoids) on which moults from the 6-leg manca juvenile to a post-juvenile stages can occur. This is not an intermediate host because no larval stages are involved. See paratenic host, micro-male host, and prey-predator life cycle.

Transitional parasite - a crustacean or roundworm (Nematoda) in the clade Ecdysozoa. They are relatively new parasites with many free-living relatives and little evolved towards a climax parasite state. See climax parasite.

Transport host-see paratenic host.

Trichogon-injected into a female by a male crypis, of parasitic barnacles (rhizocephalans), and becomes a dwarf male.

Trophic transmission - see parasite-induced trophic transmission.

True parasite (good parasite, strict parasite)—a small organism, which feeds from and harms a larger organism. True parasites have a definitive host, which they never leave.

True predator (carnivore) —an organism that hunts, kills and eats other organisms (prey). See ambushing, opossum attack, and Table 5.1.

Underdispersed (uniform, regular)—-see overdispersed.

Upward incorporation - adding a new host after the original host with the former definitive host becoming the intermediate host. Begins with parasites surviving in a predator of the original host. Moving higher on the food chain. See downward incorporation and parallel incorporation.

Urosome-abdomen of arthropods.

Vector mutualists - when a disease or parasite transmitted to a host also benefits the vector. When crustacean parasites are vectors, the infective stage of the crustacean benefits by the invasive transferred organism confusing the immune system 
of the host and increasing infective crustacean survival. See viral crustacean mutalists.

Vegetative stage - is a term we borrowed from botany to describe a feeding and nonreproductive female stage of fish isopods (cymothoids) between stages with a marsupium. See complex rebrooding.

Vermigon - a migratory internal stage injected by the kentrogon stage of a parasitic barnacle (rhizocephalans).

Viral crustacean mutualists - a virus benefiting its crustacean host and doing little or no harm to the host.

Virgin female - a term used in the literature for an adult female lacking a marsupium.

A vegetative stage is a better term since these stages can occur both before and after stages with a marsupium.

Whale lice-see lice.

$Y$-cypris (plural: y-cyprii)—see y-nauplius.

$Y$-nauplius (plural: y-nauplii) — the first larval stage of y-parasites (facetotectans) and y-cypris the second.

Ypsigon-a slug-like, unsegmented, and limbless form, which may be the infective stage for y-parasites (facetotectans).

Zoea stage (plural: zoeas or zoeae) - the first larval stage of a decapod characterised by the use of the thoracic appendages for swimming and a large dorsal spine.

Zuphea-the first juvenile of fish gnats (gnathiids) with obvious segmentation, which leaves the female, finds a host, feeds, and becomes the second stage, a praniza $(\mathrm{P} 1)$.

\subsection{Common Names}

Common names are listed alphabetically in bold with and family names in square brackets:

American Alligator, Alligator mississippiensis (Daudin, 1802) [Alligatoridae]; Anchor Worm, Lernaea cyprinacea Linnaeus, 1758 [Lernaeidae] also used as a group name for the genus and/or family; Antarctic Eelpout, Lycodichthys dearborni (DeWitt, 1962) [Zoarcidae]; Atlantic Salmon, Salmo salar (Linnaeus, 1758) [Salmonidae]; Ballyhoo, Hemiramphus brasiliensis (Linnaeus, 1758) [Hemiramphidae); Barramundi, Lates calcarifer (Bloch, 1790) [Latidae]; Barrier Reef Chromis, Chromis nitida (Whitley, 1928) [Pomacentridae]; Beaked Pacu, Ossubtus xinguense Jégu, 1992 [Serrasalmidae]; Bicolor Damselfish, Stegastes partitus (Poey, 1868) [Pomacentridae]; Blacktip Grouper, Epinephelus fasciatus (Forsskal, 1775) [Serranidae]; Blue Crab, Callinectes sapidus Rathbun, 1896 [Portunidae]; Blue Runner, Caranx crysos (Mitchell, 1815) [Carangidae]; Bluespotted Ribbontail Ray, Taeniura lymma (Forsskål, 1775) [Dasyatidae]; Broad Angel Wing, Barnea dilatata (Soulelet, 1843) [Pholidae (angel wings)]; Brown Chromis, Chromis multilineata (Guichenot, 1853) [Pomacentridae]; 
Brown Mussel, Perna perna (Linnaeus, 1758) [Mytilidae]; Brownspotted Grouper, Epinephelus chlorostigma (Valenciennes, 1828) [Serranidae]; Burrowing Crab, Raninoides lamarcki Milne-Edwards \& Bouvier, 1923 [Raninidae]; Button-Crab Parasite, Loxothylacus texanus Boschma, 1933 [Sacculinidae]; California Bay Pea Crab, Parapinnixa affinis Holmes, 1900 [Pinnotheridae]; Caribbean Fire Sponges, Tedania spp. [Tedaniidae]; Caribbean Manatee, Trichechus manatus manatus Linnaeus, 1758 [Trichechidae]; Cero, Scomberomorus regalis (Bloch, 1793) [Scombridae]; Common Fish Louse, Argulus foliaceus (Linnaeus, 1758) [Argulidae]; Coney, Epinephelus fulvus (Linnaeus, 1758) [Serranidae]; Cressey's Sea Louse, Caligus rogercresseyi (Boxshall \& Bravo, 2000) [Caligidae]; Crevalle Jack, Caranx hippos (Linnaeus, 1766) [Carangidae]; Doctorfish, Acanthurus chirurgus (Bloch, 1787) [Acanthuridae]; Dolphinfish, Coryphaena hippurus (Linnaeus, 1758) [Coryphaenidae]; Epaulette Shark, Hemiscyllium ocellatum (Bonnaterre, 1788) [Hemiscyliidae]; False King Crab, Paralomis granulosa (Hombron \& Jacquinot, 1846) [Lithodidae]; Foureye Butterflyfish, Chaetodon capistratus Linnaeus, 1758 [Chaetodontidae]; French Grunt, Haemulon flavolineatum (Desmarest, 1823) [Haemulonidae]; Glasseye, Heteropriacanthus cruentatus (Lacepede, 1801) [Priacanthidae]; Goldfish, Carassius auratus (Linnaeus, 1758) [Cyprinidae]; Graceful Rock Crab, Metacarcinus gracilis (Dana, 1852) (Cancer sometimes still used) [Cancridae]; Harlequin Bass, Serranus tigrinus (Bloch, 1790) [Serranidae]; Japanese Louse (also Goldfish Louse), Argulus japonicus Thiele, 1900 [Argulidae]; Jelly Isopod, Anuropus spp. [Anuropidae]; Jellyfish Barnacle, Alepas pacifica (Pilsbry, 1907) [Heteralepadidae]; Gray Angelfish, Pomacanthus arcuatus (Linnaeus, 1758) [Pomacanthidae]; Gray Snapper, Lutjanus griseus (Linaeus, 1758) [Lutjanidae]; Gray Whale, Eschrichtius robustus (Lilljeborg, 1861) [Eschrichtidae]; Green Crab, Carcinus maenas (Linnaeus, 1758) [Portunidae]; King Mackerel, Scomberomorus cavalla (Cuvier, 1829) [Scombridae]; Largemouth Bass, Micropterus salmoides (Lecepede, 1802) [Centrarchidae]; Longsnout Bullhead Sculpin, Ereunias grallator Jordan \& Snyder, 1901 [Ereuniidae]; Marine Anchor Worm, Pennella spp. [Pennellidae]; Non-swimming Fish Lice, Chonopeltis spp. [Argulidae]; Ochre Copepod, Balaenophilus manatorum (Ortíz, Lalana, \& Torrez, 1992) [Balaenophilidae]; Oyster Pea Crab, Zaops ostreus (Say, 1817) [Pinnotheridae]; Patagonian Squid, Loligo gahi (Orbigny, 1835) [Loliginidae]; Peacock Bass, Cichla ocellaris (Bloch \& Schneider, 1801) [Cichlidae]; Pink Salmon, Salmo gorbuscha (Walbaum, 1792) [Salmonidae]; Polychaete Barnacles, Rhizolepas annelidicola, Day, 1939, and R. gurjanovae Zevina, 1968 [Rhizolepadidae]; Red Bug, Tegastes acroporanus Humes, 1981 [Tegastidae]; Red Hind, Epinephelus guttatus (Linnaeus, 1758) [Serranidae]; Red Lionfish, Pterois volitans (Linnaeus, 1758) [Scorpaenidae]; Rock Beauty, Holacanthus tricolor (Bloch, 1795) [Pomacanthidae]; Rock Hind, Epinephelus adscensionis (Osbeck, 1765) [Serranidae]; Salmon Sea Louse, incorrectly called 'Salmon Louse', Lepeophtheirus salmonis (Krøyer, 1838) [Caligidae]; Scud [amphipods]; Sea Firefly, Cypridina hilgendorfii (Müller, 1890) [Cypridinidae]; Sea Lice, Caligus 
and Lepeophtheirus [Caligidae]; Sea Turtle Barnacle, Chelonibia testudinaria (Leach, 1817) [Chelonibiidae]; Shark Barnacle, Anelasma squalicola (Lovén, 1844) [Anelasmatidae]; Shortfin Smooth Lanternshark, Etmopterus joungi (Knuckey et al. 2011) [Etmopteridae]; Smooth Hammerhead, Sphyrna zygaena (Linnaeus, 1758) [Sphyrnidae]; Speckled Crab, Arenaeus cribrarius (Lamarck, 1818) [Portunidae]; Sperm Whale, Physeter macrocephalus Linnaeus, 1758 [Physeteridae]; Sponge Shrimp, various species [Palaemonidae, Alpheidae, etc.]; Striped Triggerfish, Xanthichthys lineopunctatus (Hollard, 1854) [Balistidae]; Tongue-replacing Isopod, Cymothoa exigua (Schioedte \& Meinert, 1884) [Cymothoidae]; Toxic Gobies, Gobiodon spp. [Gobiidae], trunkfishes [Ostraciidae]; Yellow Angelfish, Centropyge heraldi Woods \& Schultz, 1953 [Pomacanthidae].

Acknowledgement We thank Drs. Kaori Wakabayashi and Kazuya Nagasawa, Laboratory of Aquaculture, Hiroshima University, for photographs of their parasites (Figs. 5.2 and 5.3); Dr. Gustavo A. Lovrich for the image used in Fig. 5.4; Prof. Jens T. Høeg for the images in Fig. 5.5; Dr. Carlos Muños, Department of Biology, for photographic assistance; and the many authors who provided us reprints of their papers. Further thanks to $\mathrm{ABC}$ Taxa and Folia Parasitologica for permission to use the images in Figs. 5.1 and 5.11, respectively. We appreciate the Calvert Marine Museum, Solomons, Maryland, allowing us to examine their fossil crustaceans.

\section{References}

Adlard RD, Lester RJG (1995) The life-cycle and biology of Anilocra pomacentri (Isopoda, Cymothoidae), an ectoparasitic isopod of the coral-reef fish, Chromis nitida (Perciformes, Pomacentridae). Aust J Zool 43:271-281

Aguilar-Perera A, Quijano-Puerto L, Carrillo-Flota E, Williams EH Jr, Bunkley-Williams L (2018) First record of the snapper-choking isopod Cymothoa excisa (Isopoda: Cymothoidae) parasitizing invasive lionfish Pterois volitans (Scorpaeniformes: Scorpaenidae). J Mar Biol Assoc UK 98(8):2095-2097. https://doi.org/10.1017/S0025315417001576

Alvaro MC, Błażewicz-Paszkowycz M, Davey N, Schiaparelli S (2011) Skin digging tanaids: the unusual parasitic behaviour of Exspina typica in Antarctic waters and worldwide deep basins. Antarct Sci 23:343-348

Alverez F, Bortolini JL, Høeg JT (2010) Anatomy of virgin and mature externae of Loxothylacus texanus, parasitic on the dark blue crab Callinectes rathbunae (Crustacea: Cirripedia: Rhizocephala: Sacculinidae). J Morphol 271:190-199

Ambrosio LJ, Baeza JA (2016) Territoriality and conflict avoidance explain asociality (solitariness) of the endosymbiotic pea crab Tunicotheres moseri. PLoS One 11(2): 0148285

Aneesh PT, Sudha K, Helna AK, Anilkumar G, Trilles J-P (2015) Cymothoa frontalis, a cymothoid isopod parasitizing the belonid fish Strongylura strongylura from the Malabar Coast (Kerala, India): Redescription, description, prevalence and life cycle. Zool Stud 54:42

Anker A (2016) Synalpheus brevicarpus (Herrick, 1891). http://alpheidae.myspecies.info/taxon omy/term/386. Accessed 31 Oct 2018

Artim JM, Sellars JC, Sikkel PC (2015) Micropredation by gnathiid isopods on settlement-stage reef fish in the eastern Caribbean Sea. Bull Mar Sci 91:479-487

Aznar FJ, Badillo FJ, Mateu P, Raga JA (2010) Balaenophilus manatorum (Ortíz, Lalana and Torres, 1992) (Copepoda: Harpacticoida) from loggerhead sea turtles, Caretta caretta, from Japan and the western Mediterranean: amended description and geographical comparison. J Parasitol 96:299-307 
Badaro MF, Neves EG, Castro P, Johnsson R (2012) Description of a new genus of Cryptochiridae (Decapoda: Brachyura) associated with Siderastrea (Anthozoa: Scleractinia), with notes on feeding habits. Sci Mar 76(3):517-526

Badillo FJ, Puig L, Montero FE, Raga RA, Aznar FJ (2007) Diet of Balaenophilus spp. (Copepoda: Harpacticoida): feeding on keratin at sea. Mar Biol 151:751-758

Bakenhaster MD, McBride MRS, Price WW (2006) Life history of Glossobius hemiramphi (Isopoda: Cymothoidae): development, reproduction, and symbiosis with its host Hemiramphus brasiliensis (Pisces: Hemiramphidae). J Crustac Biol 26:283-294

Banerjee A, Poddar S, Manna S, Saha SK (2016) Mutualistic association of rotifer Philodina roseola with the branchiuran fish ectoparasite Argulus bengalensis at its embryonic stage. Biol Lett 12(3):20151043

Barnard KH (1932) Amphipoda. Discov Rep 5:1-326

Bennett MB, Heupel MR, Bennett SM, Parker AR (1997) Sheina orri (Myodocopa: Cypridinidae), an ostracod parasitic on the gills of the epaulette shark, Hemiscyllium ocellatum (Elasmobranchii: Hemiscyllidae). Int J Parasitol 27:275-281

Benz GW, Bullard SA (2004) Metazoan parasites and associates of chondrichthyans with emphasis on taxa harmful to captive hosts. The elasmobranch husbandry manual: captive care of sharks, rays, and their relatives. Ohio Biological Survey, Columbus, OH, pp 325-416

Bevanger L (2016) Norwegian fish farms fight sea lice with 'Star Wars'. DW. http://www.dw.com/ en/norwegian-fish-farms-fight-sea-lice-with-star-wars/a-19029019

Binning SA, Roche DG, Layton C (2013) Ectoparasites increase swimming costs in a coral reef fish. Biol Lett 9(1):20120927

Boonstra JL, Koneval ME, Clark JD, Schick M, Smith M, Stark AL (2015) Milbemycin oxime (Interceptor) treatment of amphipod parasites (Hyperiidae) from several host jellyfish species. J Zoo Wildl Med 46(1):158-160

Boyko CB, Williams JD (2009) Crustacean parasites as phylogenetic indicators in decapod evolution. In: Martin JW, Crandall KA, Felder DL (eds) Crustacean issues 18: decapod crustacean phylogenetics. CRC Press, Boca Raton, Florida, pp 197-220

Boyko CB, Williams JD (2016) Methods of detection, collection and preservation of parasitic isopods (Isopoda: Epicaridea). Proc Biol Soc Wash 129(1):76-83

Brazenor AK, Hutson KS (2013) Effect of temperature and salinity on egg hatching and description of the life cycle of Lernanthropus latis (Copepoda: Lernanthropidae) infecting barramundi, Lates calcarifer. Parasitol Int 62(5):437-447

Brian A (1931) Il parasitismo frag li animali marini. Arti Grafiche Commercio Ed, Genova

Brooker AJ, Shinn AP, Bron JE (2007) A review of the biology of the parasitic copepod Lernaeocera branchialis (L., 1767) (Copepoda: Pennellidae). Adv Parasitol 65:297-341

Bruce NL, Wong H-L (2015) An overview of the marine isopods (Crustacea) of Singapore. Raffles Bull Zool 31:152-168

Brusca RC (1978) Studies on the cymothoid fish symbionts of the eastern Pacific (Isopoda, Cymothoidae) I. Biology of Nerocila californica. Crust 34:141-154

Brusca RC (1981) A monograph on the Isopoda Cymothoidae (Crustacea) of the eastern Pacific. Zool J Linnean Soc 73(2):117-199

Brusca RC, Gilligan MR (1983) Tongue replacement in a marine fish (Lutjanus guttatus) by a parasitic isopod (Crustacea: Isopoda). Copeia 1983:813-816

Bunkley-Williams L, Williams EH Jr (1994) Parasites of Puerto Rican freshwater sport fishes. Puerto Rico Department of Natural and Environmental Resources, San Juan, Puerto Rico

Bunkley-Williams L, Williams EH Jr (1998a) Isopods associated with fishes: a synopsis and corrections. J Parasitol 84:893-896

Bunkley-Williams L, Williams EH Jr (1998b) Ability of Pederson Cleaner Shrimp to remove juveniles of the parasitic cymothoid isopod, Anilocra haemuli, from the host. Crustaceana 71:862-869

Bunkley-Williams L, Williams EH Jr (1999) Nerocila benrosei n. sp. (Isopoda: Cymothoidae), an external parasite of hogfishes from the northern Bahamas. J Parasitol 85:1036-1040 
Bunkley-Williams L, Williams EH Jr (2003) The identity of the seldom found Caribbean and Gulf of Mexico fish-parasitic isopod, Cymothoa caraibica Bovallius, resolved: a neoteric synonym of C. oestrum (L.). Caribb J Sci 39:245-248

Bunkley-Williams L, Williams EH Jr, Bashirullah AKM (1998) Some isopods associated with Venezuelan fishes. Caribb Mar Stud 6:27-30

Bunkley-Williams L, Williams EH Jr, Garzon-Ferreira J (1999) Some isopod and copepod parasites (Crustacea) of Colombian marine fishes. Caribb J Sci 35:311-314

Bunkley-Williams L, Williams EH Jr, Bashirullah AKM (2006) Isopods (Isopoda: Aegidae, Cymothoidae, Gnathiidae) associated with Venezuelan marine fishes (Elasmobranchii, Actinopterygii). Rev Biol Trop 54(suppl 3):175-188

Carlson CJ, Burgio KR, Dougherty ER, Phillips AJ, Bueno VM, Clements CF, Castaldo G, Dallas TA, Cizauskas CA, Cumming GS, Doña J (2017) Parasite biodiversity faces extinction and redistribution in a changing climate. Sci Adv 3(9):e1602422

Castro P (2015) Symbiotic Brachyura. In: Castro P, Davie P, Guinot D, Schram F, von Vaupel Klein C (eds) Treatise on zoology - anatomy, taxonomy, biology. The Crustacea, vol 9 (Part C). Brill, Leiden, pp 543-581

Christoffersen ML, De Assis JE (2013) A systematic monograph of the recent Pentastomida, with a compilation of their hosts. Zool Med Leiden 87:1-206

Christoffersen ML, De Assis JE (2015) Class Eupentastomida Waloszek, Repetski \& Maas, 2006. In: von Vaupel KC, Charmantier-Daures M, Schram F (eds) Treatise on zoology - anatomy, taxonomy, biology. The Crustacea, vol 5. Brill, Leiden, pp 1-369

Cohen AC, Morin JG (2010) Two new bioluminescent ostracode genera, Enewton and Photeros (Myodocopida: Cypridinidae), with three new species from Jamaica. J Crustac Biol 30:1-55

Coile AM, Welicky RL, Sikkel PC (2014) Female Gnathia marleyi (Isopoda: Gnathiidae) feeding on more susceptible fish hosts produce larger but not more offspring. Parasitol Res 113:3875-3880

Colón-Llavina MM, Mignucci-Giannoni AA, Mattiucci S, Valentini A, Harvey TL, Williams EH Jr (2009) Additional records of metazoan parasites of marine mammals from the Caribbean. Parasitol Res 105:1239-1252

Connors BM, Krkosek M, Dill LM (2008) Sea lice escape predation on their host. Biol Lett 4:455-457

Connors BM, Lagasse C, Dill LM (2011) What's love got to do with it? Ontogenetic changes in drivers of dispersal in a marine ectoparasite. Behav Ecol 22:588-593

Conradi M, Martin I, Martin D (2012) An unexpected parasitic relationship between a new species of Anthessius (Copepoda: Cyclopoida) and a decapod crustacean, Alpheus macrocheles (Hailstone, 1835) from the NW Mediterranean Sea. J Crustac Biol 32:860-870

Cook C, Munguia P (2015) Sex change and morphological transitions in a marine ectoparasite. Mar Ecol 36(3):337-346

Cribb TH, Pichelin S, Dufour V, Bray RA, Chauvet C, Faliex E, Galzin R, Lo CM, Lo-Yat A, Morand S, Rigby MC (2000) Parasites of recruiting coral fish reef larvae in New Caledonia. Int J Parasitol 30:1445-1451

Dahms H-U, Chullasorn S, Schizas NV, Kangtia P, Anansatitporn W, Yang W-X (2000) Naupliar development among the Tisbidae (Copepoda: Harpacticidae) with a phylogenetic analysis and naupliar description of Tisbe thailandensis from Thailand. Zool Stud 48:780-796

De Bruyn C, De Ridder C, Rigaud T, David B (2011) Chemical host detection and differential attraction in a parasitic pea crab infecting two echinoids. J Exp Mar Biol Ecol 397(2):173-178

Domènech F, Tomás J, Crespo-Picazo JL, García-Párraga D, Raga JA, Aznar FJ (2017) To swim or not to swim: potential transmission of Balaenophilus manatorum (Copepoda: Harpacticoida) in Marine Turtles. PLoS One 12(1):e0170789

Duffy EJ, Macdonald KS (1999) Colony structure of the social snapping shrimp Synalpheus filidigitus in Belize. J Crustac Biol 19(2):283-292

Duffy JE, Morrison CL, Rios R (2000) Multiple origins of eusociality among sponge-dwelling shrimps (Synalpheus). Evolution 54(2):503-516 
Ďuriš Z, Horka I, Juračka PJ, Petrusek A, Sandford F (2011) These squatters are not innocent: the evidence of parasitism in sponge-inhabiting shrimps. PLoS One 6(7):e21987

Eckes M, Dove S, Siebeck UE, Grutter AS (2015) Fish mucus versus parasitic gnathiid isopods as sources of energy and sunscreens for a cleaner fish. Coral Reefs 34(3):823-833

Farquharson C, Smit NJ, Sikkel PC (2012) Gnathia marleyi sp. nov. (Crustacea, Isopoda, Gnathiidae) from the Eastern Caribbean. Zootaxa 3381:47-61

Felley SM, Vecchione ML, Hare SGF (1987) Incidence of ectoparasitic copepods on ichthyoplankton. Copeia 1987:778-782

Fogelman RM, Grutter AS (2008) Mancae of the parasitic cymothoid isopod, Anilocra apogonae: early life history, host-specificity, and effect on growth and survival of preferred young cardinal fishes. Coral Reefs 27:685-693

Fogelman RM, Kuris AM, Grutter AS (2009) Parasitic castration of a vertebrate: effect of the cymothoid isopod, Anilocra apogonae, on the five-lined cardinalfish, Cheilodipterus quinquelineatus. Intern J Parasit 39:577-583

Fryer G (1961) Larval development in the genus Chonopeltis (Crustacea: Branchiura). J Zool 137 (1):61-69

Garcia JR, Williams EH Jr (1985) Temporal dynamics of metazoan parasite infections in the White Mullet, Mugil curema Valenciennes, from Joyuda Lagoon, Puerto Rico. Caribb J Sci 21:39-53

Gasca R, Browne WE (2017) Symbiotic associations of crustaceans and a pycnogonid with gelatinous zooplankton in the Gulf of California. Mar Biodivers 11:1-9

Gasca R, Haddock SHD (2016) The rare deep-living hyperiid amphipod Megalanceoloides remipes (Barnard, 1932): complementary description and symbiosis. Zootaxa 4178(1):138-144

Gasca R, Suárez-Morales E, Haddock SH (2007) Symbiotic associations between crustaceans and gelatinous zooplankton in deep and surface waters off California. Mar Biol 151(1):233-242

Gentil-Vasconcelos HC, Tavares-Dias M (2015) First study on infestation of Excorallana berbicensis (Isopoda: Corallanidae) on six fishes in a reservoir in Brazilian Amazon during dry and rainy seasons. Lat Am J Aquat Res 43(5):936-943

Glenner H, Hebsgaard MB (2006) Phylogeny and evolution of life history strategies of the parasitic barnacles (Crustacea, Cirripedia, Rhizocephala). Molecul Phylogen Evol 41:528-538

Glenner H, Høeg JT, Grygier MJ, Fujita Y (2008) Induced metamorphosis in crustacean y-larvae: towards a solution to a 100-year-old riddle. BMC Biol 6(1):21

Glenner H, Høeg JT, Stenderup J, Rybakov AV (2010) The monophyletic origin of a remarkable sexual system in akentrogonid rhizocephalan parasites: a molecular and larval structural study. Exp Parasitol 125:3-12

González L, Carvajal J (2003) Life cycle of Caligus rogercresseyi, (Copepoda: Caligidae) parasite of Chilean reared salmonids. Aquaculture 220:101-117

Grundlingh MJ (1996) Aspects of the morphology of Chonopeltis Thiele, 1900 (Crustacea: Branchiura) with special reference to the reproductive systems. Dissertation, University of Johannesburg

Grutter AS (1997) Size-selective predation by the cleaner fish Labroides dimidiatus. J Fish Biol 50:1303-1308

Grygier MJ, Ohtsuka S (1995) SEM observation of the nauplius of Monstrilla hamatapex, new species, from Japan and an example of upgraded descriptive standards for monstrilloid copepods. J Crustac Biol 15:703-719

Hadfield KA, Smit NJ, Avenant-Oldewage A (2008) Gnathia pilosus sp. nov. (Crustacea, Isopoda, Gnathiidae) from the East Coast of South Africa. Zootaxa 1894:23-41

Hadfield KA, Smit NJ, Avenant-Oldewage A (2009) Life cycle of the temporary fish parasite, Gnathia pilosus (Crustacea: Isopoda: Gnathiidae) from the east coast of South Africa. J Mar Biol Assoc UK 89(7):1331-1339

Hamre LA, Eichner C, Caipang CM, Dalvin ST, Bron JE, Nilsen F, Boxshall G, Skern-Mauritzen R (2013) The Salmon Louse Lepeophtheirus salmonis (Copepoda: Caligidae) life cycle has only two chalimus stages. PLoS One 8(9):e73539 
Hargis WJ (1958) The fish parasite Argulus laticauda as a fortuitous human epizoon. J Parasitol 44:45

Hatcher MJ, Dunn AM (2011) Parasites in ecological communities: from interactions to ecosystems. Cambridge University Press, Cambridge

Heppell SS, Caswell H, Crowder LB (2000) Life histories and elasticity patterns: perturbation analysis for species with minimal demographic data. Ecology 81(3):654-665

Hernández JE, Bolaños JA, Palzón JL, Hernández G, Lira C, Baeza JA (2012) The enigmatic life history of the symbiotic crab Tuniclotheres moseri (Crustacea: Brachyura: Pinnotheridae): implications for its mating system and population structure. Biol Bull Woods Hole 223:278-290

Herrera G (1984) Parasitismo de juveniles de copépodos caligoideos sobre larvas de peces de la Bahía Coliumo (36 32’S; 75 57’W), Chile. Biol Pesq 13:31-38

Herrera G (1990) Incidence of anchovy (Engraulis ringens) larvae parasitized by caligid developmental stages. Bull Mar Sci 47:571-575

Hispano C, Bulto P, Blanch AR (2014) Life cycle of the fish parasite Gnathia maxillaris (Crustacea: Isopoda: Gnathiidae). Folia Parasitol 61:277-284

Høeg JT, Pérez-Losada M, Glenner H, Kolbasov GA, Crandall KA (2009) Evolution of morphology, ontogeny and life cycles within the Crustacea Thecostraca. Arthropod Syst Phylo 67:199-217

Høeg JT, Chan BKK, Kolbasov GA, Grygier MJ (2014) Facetotecta. In: Martin J, Olesen J, Høeg JT (eds) Atlas of Crustacean Larvae. John Hopkins University Press, Baltimore, pp 100-103

Humes AG (1985) Cnidarians and copepods: a success story. Trans Am Microsc Soc 104:313-320

Huys R, Llewellyn-Hughes J, Conroy-Dalton S, Olson PD, Spinks JN, Johnston DA (2007) Extraordinary host switching in siphonostomatoid copepods and the demise of the Monstrilloida: Integrating molecular data, ontogeny and antennulary morphology. Mol Phylogenet Evol 43(2):368-378

Ismail N, Ohtsuka S, Maran BAV, Tasumi S, Zaleha K, Yamashita H (2013) Complete life cycle of a pennellid Peniculus minuticaudae Shiino, 1956 (Copepoda: Siphonostomatoida) infecting cultured threadsail filefish, Stephanolepis cirrhiferi. Parasitology 20:42

Izawa K (2008) Amaterasia amanoiwatoi nov. gen., nov. sp. (Copepoda, Siphonostomatoida, Amaterasidae nov. fam.), with gall-forming juveniles parasitic on the fins of a balistid actinopterygian fish. Crustaceana 81:1331-1346

Izawa K (2010) Free-living stages of the parasitic copepod, Gangliopus pyriformis Gerstaecker, 1854 (Siphonostomatoida, Pandaridae) reared from eggs. Crustaceana 83:829-837

Jones CM, Miller TL, Grutter AS, Cribb TH (2008) Natatory-stage cymothoid isopods: description, molecular identification and evolution of attachment. Int J Parasitol 38(3-4):477-491

Jossart Q, Wattier RA, Kastally C, Aron S, David B, De Ridder C, Rigaud T (2014) Genetic evidence confirms polygamous mating system in a crustacean parasite with multiple hosts. PLoS One 9(3):e90680

Kaliszewska ZA, Seger J, Barco SG et al (2005) Population histories of Right Whales (Cetacea: Eubalaena) inferred from mitochondrial sequence diversities and divergences of their whale lice (Amphipoda: Cyamus). Mol Ecol 14:3439-3456

Kik MJ, Janse M, Benz GW (2011) The sea louse Lepeophtheirus acutus (Caligidae, Siphonostomatoida, Copepoda) as a pathogen of aquarium-held elasmobranchs. J Fish Dis 34:793-799

Klompmaker AA, Boxshall GA (2015) Fossil crustaceans as parasites and hosts. Adv Parasitol 90:233-289

Klompmaker AA, Artal P, van Bakel BWM, Fraaije RHB, Jagt JWM (2014) Parasites in the fossil record: a cretaceous fauna with isopod-infested decapod crustaceans, infestation patterns through time, and a new ichnotaxon. PLoS One 9(3):e92551

Klompmaker AA, Portell RW, Van Der Meij SE (2016) Trace fossil evidence of coral-inhabiting crabs (Cryptochiridae) and its implications for growth and paleobiogeography. Sci Rep 6:23443

Knudsen SW, Kirkegaard M, Olesen J (2009) The tantulocarid genus Arcticotantalus removed from Basipodellidae into Deoterthridae (Crustacea: Maxillopoda) after the description of a new 
species from Greenland, with first live photographs and an overview of the class. Zootaxa 2035:41-68

Kolbasov GA (2009) Acrothoracica, burrowing crustaceans. KMK Scientific Press Ltd, Moscow

Kolbasov GA, Chan BKK, Petrunina AS (2015) Gorgonolaureus bicornutus sp. nov (Crustacea: Thecostraca: Ascothoracida) from off South-East Taiwan with notes on morphology and distribution. Zootaxa 3972:328-342

Kretzler JE (1984) Echinophilus xiphidion, new species (Ostracoda: Paradoxostomatidae) parasitic on regular echinoids of the northeastern Pacific. J Crustac Biol 4:333-340

Kudinova-Pasternak RK (1987) Au sujet de la distribution de lespece abissale Expina typica (Crustacea, Tanaidacea) et du mode de nutrition des crustaces tanaidaces probablement parasitaire. Zool Zhurn 66:1094-1096

Kuris AM, Lafferty KD, Torchin ME (2005) Biological control of the European green crab, Carcinus maenas: natural enemy evaluation and analysis of host specificity. Second international symposium on biological control of arthropods, pp 102-115

Lafferty KD, Kuris AM (2002) Trophic strategies, animal diversity and body size. Trends Ecol Evol 17(11):507-513

Lafferty KD, Harvell CD, Conrad JM, Friedman CS, Kent ML, Kuris AM, Powell EN, Rondeau D, Saksida SM (2015) Infectious diseases affect marine fisheries and aquaculture economics. Annu Rev Mar Sci 7:471-496

Lanzing WJR, O'Connor PF (1975) Infestation of luderick (Girella tricuspidata) populations with parasitic isopods. Austral J Mar Freshw Res 26:355-361

Legrand JJ (1952) Contribution à l'étude expérimentale et statistique de la biologie d'Anilocra physodes L. Archiv Zool Exp Gén 89:1-56

Lester RJG (2005) Isopoda (isopods). In: Rohde K (ed) Marine parasitology. CSIRO Publishing, Clayton, Australia, pp 138-144

Lewis AG (1964) Caligoid copepods (Crustacea) of the Hawaiian Islands: parasitic on fishes of the family Acanthuridae. Proc U S Natl Mus 115:137-244

Li HX, Ma LS, Yu XJ, Li L, Yang CP, Yan Y (2015) Colonization of Octolasmis (Cirripedia) on the crab Portunus sanguinolentus (Brachyura: Portunidae): impacts of the parasitism of Diplothylacus sinensis (Cirripedia: Rhizocephala). J Crustac Biol 35(2):159-165

Li J, He F-N, Zheng H-X, Zhang R-X, Ren Y-J, Hu W (2016) Complete mitochondrial genome of a tongue worm Armillifer agkistrodontis. Korean J Parasitol 54(6):813-817

Lovrich GA, Roccatagliata D, Peresan L (2004) Hyperparasitism of the cryptoniscid isopod Liriopsis pygmaea on the lithodid Paralomis granulosa from the Beagle Channel, Argentina. Dis Aquat Org 58:71-77

López-González PJ, Bresciani J, Huys R, Af G, Guerra A, Pascual S (2000) Description of Genesis vulcanoctopusi gen. et sp. nov. (Copepoda: Tisbidae) parasitic on a hydrothermal vent octopod and a reinterpretation of the life cycle of cholidyinid harpacticoids. Cah Biol Mar 41:241-253

Madinabeitia I, Nagasawa K (2011) Chalimus stages of Caligus latigenitalis (Copepoda: Caligidae) parasitic on blackhead seabream from Japanese waters, with discussion of terminology used for developmental stages of caligids. J Parasitol 97:221-236

Mahmoud NE, Fahmy MM, Abouwarda M (2017) An investigation of cymothoid isopod invasion in Lake Qarun fishes with preliminary trial for biological control. Int J ChemTech Res 10 (2):409-416

Martin JW, Olsenson J, Høeg JT (eds) (2014) Atlas of crustacean larvae. John Hopkins University Press, Baltimore

McGill BJ, Enquist BJ, Weiher E, Westoby M (2006) Rebuilding community ecology from functional traits. Trends Ecol Evol 21(4):178-185

Meadows DW, Meadows CM (2002) Behavioral and ecological correlates of Foureye Butterflyfish, Chaetodon capistratus, (Perciformes: Chaetodontidae) infected with Anilocra chaetodontis (Isopoda: Cymothoidae). Rev Biol Trop 51(Suppl 4):77-81

Mignucci-Giannoni AA, Hoberg EP, Siegel-Causey D, Williams EH Jr (1998) Metazoan parasites and other symbionts of cetaceans in the Caribbean. J Parasitol 84:939-946 
Mikheev VN, Pasternak AF, Valtonen ET (2015) Behavioural adaptations of argulid parasites (Crustacea: Branchiura) to major challenges in their life cycle. Parasit Vectors 8:394

Mladineo I (2003) Life cycle of Ceratothoa oestroides, a cymothoid isopod parasite from sea bass Dicentrarchus labrax and sea bream Sparus aurata. Dis Aquat Org 57:97-101

Mladineo I, Valic D (2002) The mechanisms of infection of the buccal isopod Ceratothoa oestroides (Risso, 1836), under experimental conditions. Bull Eur Assoc Fish Pathol 22:304-310

Møller OS (2009) Branchiura (Crustacea). Survey of historical literature and taxonomy. Arthropod Syst Phylo 67(1):41-55

Møller OS (2015) Class Branchuria: Order Arguloida. Revista IDE@ - SEA, no 103B (30-062015): $1-8$

Møller OS, Olesen J, Waloszek D (2007) Swimming and cleaning in the free-swimming phase of Argulus larvae (Crustacea, Branchiura)-Appendage adaptation and functional morphology. J Morphol 268:1-11

Monod T (1923) Notes carcinologiques (parasites et commensaux). Bull Inst Océanogr Monaco 427:1-5

Muñoz G, Landaeta MF, Palacios-Fuentes P, López Z, González MT (2015) Parasite richness in fish larvae from the nearshore waters of central and northern Chile. Folia Parasitol 62:029

Murphy AE, Williams JD (2013) New records of two trypetesid burrowing barnacles (Crustacea: Cirripedia: Acrothoracica: Trypetesidae) and their predation on host hermit crab eggs. J Mar Biol Assoc UK 93:107-133

Nagasawa N, Uyeno D, Toda M (2015) Sarcotaces sp. (Copepoda: Philichthyidae), a parasite of a blacktip grouper, Epinephelus fasciatus, from off the Ryukyu Islands, southern Japan. Biogeographica 17:103-106

Nagler C, Hyžný M, Haug JT (2017) 168 million years old "marine lice" and the evolution of parasitism within isopods. BMC Evol Biol 17(1):76

Neethling LAM, Avenant-Oldewage A (2016) Branchiura - a compendium of the geographical distribution and a summary of their biology. Crustaceana 89(11-12):1243-1446

Nielson JD, Perry RI, Scott JS, Valerio P (1987) Interactions of caligid ectoparasites and juvenile gadids on Georges Bank. Mar Ecol Prog Ser 39:221-232

Ogawa K, Matsuzaki K, Misaki H (1997) A new species of Balaenophilus (Copepoda: Harpacticoida), an ectoparasite of a sea turtle in Japan. Zool Sci 14(4):691-700

Ohtsuka S, Koike K, Lindsay D, Nishikawa J, Miyake H, Kawahara M, Mujiono N, Hiromi J, Komatsu H (2009) Symbionts of marine medusae and ctenophores. Plankon Benthos Res 4 (1):1-3

Ohtsuka S, Horiguchi T, Hanamura Y, Yamaguchi A, Shimomura M, Suzaki T, Ishiguro K, Hanaoka H, Yamada K, Ohtani S (2011) Symbiosis of planktonic copepods and mysids with epibionts and parasites in the North pacific: diversity and interactions. In: Asakura A (ed) New frontiers in crustacean biology (Crustaceana monographs 15). Brill, Leiden, pp 1-14

Okawachi H, Uyeno D, Ogino K, Nagasawa K (2012) Redescription of Peniculus minuticaudae Shiino, 1956 (Copepoda: Pennellidae) from aquarium-held marine fishes in Japan, with notes on its occurrence and life cycle in captivity. Zoosymposia 8:56-68

Økland AL, Nylund A, Øvergård AC, Blindheim S, Watanabe K, Grotmol S, Arnesen CE, Plarre H (2014) Genomic characterization and phylogenetic position of two new species in Rhabdoviridae infecting the parasitic copepod, salmon louse (Lepeophtheirus salmonis). PLoS One 9(11):e112517

Ommundsen A, Noever C, Glenner H (2016) Caught in the act: phenotypic consequences of a recent shift in feeding strategy of the shark barnacle Anelasma squalicola (Lovén, 1844). Zoomorphology 135:51-65

Osman HAM, Hassan MA, El-Refaey AME (2014) Studies on Sarcotaces sp. (Copepoda, Philichthyidae) infestation (Black Bag Disease) among some marine fish species of Arabian Gulf, Saudi Arabia. World Appl Sci J 32:1780-1788 
Östlund-Nilsson S, Curtis L, Nilsson GE, Grutter AS (2005) Parasitic isopod Anilocra apogonae, a drag for the cardinal fish Cheilodipterus quinquelineatus. Mar Ecol Prog Ser 287:209-216

Ota Y, Hoshino O, Hirose M, Tanaka K, Hirose E (2012) Third-stage larva shifts host fish from teleost to elasmobranch in the temporary parasitic isopod, Gnathia trimaculata (Crustacea; Gnathiidae). Mar Biol 159:2333-2347

Otake S, Wakabayashi K, Tanaka Y, Nagasawa K (2016) Life-cycle of Choniomyzon inflatus Wakabayashi, Otake, Tanaka \& Nagasawa, 2013 (Copepoda: Siphonostomatoida: Nicothoidae) with the morphological descriptions of the nauplius, copepodid and adult male. Syst Parasitol 93:145-157

Pagès F (2000) Biological associations between barnacles and jellyfish with emphasis on the ectoparasitism of Alepas pacifica (Lepadomorpha) on Diplulmaris malayensis (Scyphozoa). J Nat Hist 34(11):2045-2056

Pascual S, Vega M, Rocha F, Guerra A (2002) First report of an endoparasitic epicaridean isopod infecting cephalopods. J Wildl Dis 38:473-477

Peiró DF, Mantelatto FL (2011) Population dynamics of the pea crab Austinixa aidae (Brachyura, Pinnotheridae): a symbiotic of the ghost shrimp Callichirus major (Thalassinidea, Callianassidae) from the southwestern Atlantic. Iheringia, Sér Zool, Porto Alegre 101:5-14

Piasecki W, Avenant-Oldewage A (2008) Diseases caused by Crustacea. In: Fish diseases, vol 2. CRC Press, Boca Raton, FL

Poly WJ (2003) Argulus ambystoma, a new species parasitic on the salamander Ambystoma dumerilii from Mexico (Crustacea: Branchiura: Argulidae)(PDF). Ohio J Sci 103(3):52-61

Poly WJ (2008) Global diversity of fishlice (Crustacea: Branchiura: Argulidae) in freshwater. Hydrobiologia 595:209-212

Poulin R (2011a) Evolutionary ecology of parasites. Princeton University Press, Princeton

Poulin R (2011b) The many roads to parasitism: a tale of convergence. Adva Parasit 74:1-40

Poulin R, Randhawa HS (2015) Evolution of parasitism along convergent lines: from ecology to genomics. Parasitology 142(Suppl 1):S6-S15

Quattrini AM, Demopoulos AW (2016) Ectoparasitism on deep-sea fishes in the western North Atlantic: in situ observations from ROV surveys. Int J Parasitol Parasites Wildl 5(3):217-228

Rees DJ, Noever C, Høeg JT, Ommundsen A, Glenner H (2014) On the origin of a novel parasiticfeeding mode within suspension-feeding barnacles. Curr Biol 24:1429-1434

Robinson MP (2005) Role of the isopod Anilocra partiti in the health, behavior and mating success of the bicolor damselfish, Stegastes bipartitus. Dissertation, University of Miami

Roff D (ed) (1993) Evolution of life histories: theory and analysis. Springer

Rohde C (ed) (2005) Marine parasitology. CSIRO Publishing, Clayton, Australia

Rosim DF, Boxshall GA, Ceccarelli PS (2013) A novel microhabitat for parasitic copepods: a new genus of Ergasilidae (Copepoda: Cyclopoida) from the urinary bladder of a freshwater fish. Parasitol Int 62(4):347-354

Sala-Bonzano M, Van Oosterhou C, Mariani S (2012) Impact of a mouth parasite in a marine fish differs between geographical areas. Biol J Linn Soc 105:842-852

Sanders KL, Lee MSY (2010) Arthropod molecular divergence times and the Cambrian origin of pentastomids. Syst Biodivers 8:63-74

Sawada K, Yoshida R, Yasuda K, Yamaguchi S, Yusa Y (2015) Dwarf males in the epizoic barnacle Octolasmis unguisiformis and their implications for sexual system evolution. Invertebr Biol 134(2):162-167

Schmid Hempel P (2011) Evolutionary parasitology. The integrated study of infections, immunology, ecology, and genetics. Oxford University Press, Oxford, England

Serra-Llinares RM, Bjørn PA, Finstad B, Nilsen R, Asplin L (2016) Nearby farms are a source of lice for wild salmonids: a reply to Jansen et al. (2016). Aquac Environ Interact 8:351-356

Shin MH, Coleman CO, Kim W (2013) Discovery of a new species of Melita (Amphipoda: Melitidae) associated with Barnea dilatata (Bivalvia, Mollusca) from South Korea. J Crustac Biol 33(6):882-893 
Sikkel PC, Schaumburg C, Mathenia J (2006) Diel infestation patterns of gnathiid isopod larvae on Caribbean reef fishes. Coral Reefs 25:683-689

Sikkel PC, Welicky RL, Artim JM, McCammon AM, Sellers JC, Coile AM, Jenkins WG (2017) Nocturnal migration reduces exposure to micropredation in a coral reef fish. Bull Mar Sci 93 (2):475-489

Silva LAF, Morais DH, Aguiar A, Almeida WO, Silva RJ (2015) First record of Sebekia oxycephala (Pentastomida: Sebekidae) infecting Helicops infrataeniatus (Reptilia: Colubridae), São Paulo State, Brazil. Braz J Biol 75:497-498

Siveter DJ, Briggs DEG, Sieter DJ, Sutton MD (2015) A 425-million-year-old silurian pentastomid parasitic on ostracods. Curr Biol 25:1632-1637

Smit NJ, Davies AJ (2004) The curious life-style of the parasitic stages of gnathiid isopods. Adv Parasitol 58:289-391

Smit NJ, Hadfield KA (2018) A systematic survey of parasites of freshwater fish in Africa Crustacea. In: Scholz T, Vanhove MPM, Smit N, Jayasundera Z, Gelnar M (eds) A guide to the parasites of African freshwater fishes, vol 18. ABC Taxa, Belgium, pp 333-355

Smit NJ, Basson L, Van As JG (2003) Life cycle of the temporary fish parasite, Gnathia africana (Crustacea: Isopoda: Gnathiidae). Folia Parasitol 50:135-142

Smit NJ, Bruce NL, Hadfield KA (2014) Global diversity of fish parasitic isopod crustaceans of the family Cymothoidae. Int J Parasitol: Parasites Wildl 3:188-197

Smith RJ (2017) Ostracod research at the Lake Biwi Museum. www.lbm.go.jp/smith/ostracod food.html. Accessed 20 Aug 2017

Stearns SC (1992) The evolution of life histories, vol 249. Oxford University Press, Oxford

Stepien CA, Brusca RC (1985) Nocturnal attacks on nearshore fishes in southern California by crustacean zooplankton. Mar Ecol Prog Ser 25:91-105

Stone I, Heard RW (1989) Excorallana delaneyi, n. sp.(Crustacea: Isopoda: Excorallanidae) from the northeastern Gulf of Mexico, with observations on adult characters and sexual dimorphism in related species of Excorallana Stebbing, 1904. Gulf Caribb Res 8(2):199-211

Suárez-Morales E (2001) An aggregation of monstrilloid copepods in a western Caribbean reef area: Ecological and conceptual implications. Crust 74:689-696

Suárez-Morales E (2011) Diversity of the Monstrilloida (Crustacea: Copepoda). PLoS One 6(8): e22915

Suárez-Morales E, Moralez-Vela B, Padilla-Saldivar J, Da Silva PM (2010a) The copepod Balaenophilus manatorum (Ortiz, Lalana, and Torres, 1992) (Harpacticoida), an epibiont on the Caribbean Manatee. J Nat Hist 44:847-859

Suárez-Morales E, Scardua MP, Da Silva PM (2010b) Occurrence and histopathological effects of Monstrilla sp. (Copepoda: Monstrilloida) and other parasites in the brown mussel Perna perna from Brazil. J Mar Biol Assoc UK 90(5):953-958

Suárez-Morales E, Londoño-Mesa M, Heard RW (2011) Discovery of a new genus of tanaidacean (Crustacea: Tanaidacea: Mirandotanaidae) found associated with a deep-sea terebellid polychaete. Contrib Zool 80:157-167

Suárez-Morales E, Harris LH, Ferrari FD, Gasca R (2014) Late postnaupliar development of Monstrilla sp. (Copepoda: Monstrilloida), a protelean endoparasite of benthic polychaetes. Invertebr Reprod Dev 58:60-73

Tanaka K (2007) Life history of gnathiid isopods-current knowledge and future directions. Plankon Benthos Res 2:1-11

Tang D, Benz GW, Nagasawa K (2012) Description of the male of Prosaetes rhinodontis (Wright, 1876) (Crustacea, Copepoda, Siphonostomatoida), with a proposal to synonymize Cecropidae Dana, 1849 and Amaterasidae Izawa, 2008 with Pandaridae Milne Edwards, 1840. Zoosympos 8:7-19

Thatcher VE (2000) The isopod parasites of South American fishes. In: Salgado-Maldonado G, Garcia Aldrete AN, Vidal-Martinz VM (eds) Metazoan parasites in the neotropics: a systematic and ecological perspective. Instituto de Biologia, UNAM, México, pp 193-226 
Thatcher VE, Williams EH Jr (1998) Comparative morphology of three native lernaeids (Copepoda: Cyclopoida) from Amazonian fishes and descriptions of two new genera. J Aquat Anim Health 10:300-308

Thorstad EB, Todd CD, Uglem I, Bjørn PA, Gargan PG, Vollset KW, Halttunen E, Kålås S, Berg M, Finstad B (2015) Effects of salmon lice Lepeophtheirus salmonis on wild sea trout Salmo trutta a literature review. Aquac Environ Interact 7(2):91-113

Towanda T, Thuesen EV (2006) Ectosymbiotic behavior of Cancer gracilis and its trophic relationships with its host Phacellophora camtschatica and the parasitoid Hyperia medusarum. Mar Ecol Prog Ser 315:221-236

Trottier O, Jeffs AG (2015) Mate locating and access behaviour of the parasitic pea crab, Nepinnotheres novaezelandiae, an important parasite of the mussel Perna canaliculus. Parasite 22:13

Van As LL, Van As JG (2015) Branchiuran parasites (Crustacea: Branchiura) from fishes in the Okavango (Botswana) and Zambezi (Namibia) systems. Afr J Aquat Sci 40:9-20

Van Der Meij SE (2014) Host species, range extensions, and an observation of the mating system of Atlantic shallow-water gall crabs (Decapoda: Cryptochiridae). Bull Mar Sci 90(4):1001-1010

Vehof J, Van Der Meij SET, Türkay M, Becker C (2016) Female reproductive morphology of coralinhabiting gall crabs (Crustacea: Decapoda: Brachyura: Cryptochiridae). Acta Zool 97:117-126

Venmathi Maran BA, Ohtsuka S (2008) Descriptions of caligiform copepods in plankton samples collected from East Asia: accidental occurrences or a new mode of life cycle? Plankon Benthos Res 3(4):202-215

Venmathi Maran BA, Moon SY, Ohtsuka S, Oh S-Y, Ho Y-S, Myoung J-G, Iglikowska A, Boxshall GA (2013) The caligid life cycle: new evidence from Lepeophtheirus elegans reconciles the cycles of Caligus and Lepeophtheirus (Copepoda: Caligidae). Parasite 20:15

Vinogradov ME (1964) Hyperiidea Physosomata severnoj chasti Indijskogo okeana. [Hyperiidea Physosomata from the Northern Part of the Indian Ocean]. Tr Inst Okeanologii 65:101-151

Vinogradov ME, Volkov AF, Semenova TN (1996) Hyperiid amphipods (Amphipoda, Hyperiidea) of the world oceans. Science, Lebanon

Waiho K, Fazhan H, Glenner H, Ikhwanuddin M (2017) Infestation of parasitic rhizocephalan barnacles Sacculina beauforti (Cirripedia, Rhizocephala) in edible mud crab, Scylla olivacea. PeerJ 5:e3419

Wei T-P, Chen H-C, Lee Y-C, Tsai M-L, Hwang J-S, Peng S-H, Chiu Y-W (2013) Gall polymorphism of coral-inhabiting crabs (Decapoda, Cryptochiridae): a new perspective. J Mar Sci Technol 21(Suppl):304-307

Welicky RL, Sikkel PC (2015) Decreased movement related to parasite infection in a diel migratory coral reef fish. Behav Ecol Sociobiol 69:1437-1446

Williams EH Jr (1974) Treatments employed for control of parasites of selected fishes stocked in mariculture experiments (1969-1972). Proc World Maricult Soc 5:291-296

Williams EH Jr (1978) Conchoderma virgatum (Spengler) (Cirripedia, Thoracica) in association with Dinemoura latifolia (Steenstrup and Lutken) (Copepoda, Caligidea), a parasite of the Shortfin Mako, Isurus oxyrhynchus Rafinesque (Pisces, Chondrichthyes). Crustaceana 34:109-111

Williams EH Jr (1995) Underrated tongue worms. Nat Hist 104(5):4

Williams JD, Boyko CB (2012) The global diversity of parasitic isopods associated with crustacean hosts (Isopoda: Bopyroidea and Cryptoniscoidea). PLoS One 7(4):e35350

Williams JD, Boyko CB (2016) Abdominal bopyrid parasites (Crustacea: Isopoda: Bopyridae: Athelginae) of diogenid hermit crabs from the western Pacific, with descriptions of a new genus and four new species. Raffles Bull Zool 64:33-69

Williams EH Jr, Britton AA (1995) Parasites of Spectacled Caiman in Puerto Rico. IUCN - The World Conservation Union and the Species Survival Commission, Crocodile Specialist Group Newsletter 14(4):18-19

Williams EH Jr, Bunkley-Williams L (1994) Four cases of unusual crustacean-fish associations and comments on parasitic processes. J Aquat Anim Health 6:202-208 
Williams EH Jr, Bunkley-Williams L (1996) Parasites of offshore, big game sport fishes of Puerto Rico and the western North Atlantic. Puerto Rico Department of Natural and Environmental Resources, San Juan, Puerto Rico, and Department of Biology, University of Puerto Rico, Mayagüez, Puerto Rico

Williams EH Jr, Bunkley-Williams L (2008) Quest for the exact locality of an important new fossil discovery. J Avocat Paleont 14:6-7

Williams EH Jr, Bunkley-Williams L (2010) Checklists of the parasites of Dolphin, Coryphaena hippurus, and Pompano Dolphin, C. equiselis with corrections and comments on the literature. Rev Fish Sci 18:73-93

Williams EH Jr, Williams LB (1980) Four new species of Renocila (Isopoda: Cymothoidae), the first reported from the New World. Proc Biol Soc Wash 93:573-592

Williams LB, Williams EH Jr (1981) Nine new species of Anilocra (Crustacea: Isopoda: Cymothoidae) external parasites of West Indian coral reef fishes. Proc Biol Soc Wash 94:1005-1047

Williams EH Jr, Williams LB (1982) Mothocya bohlkeorum new species (Isopoda: Cymothoidae) from West Indian cardinalfishes (Apogonidae). J Crustac Biol 2:570-577

Williams EH Jr, Williams LB (1985a) A new cymothoid isopod, Glossobius hemiramphi, from the mouth of the ballyhoo, Hemiramphus brasiliensis (Linnaeus) (Exocoetidae), in the Caribbean Sea. Crust 48:147-152

Williams EH Jr, Williams LB (1985b) Cuna insularis n. gen. and n. sp. (Isopoda: Cymothoidae) from the gill chamber of the sergeant major, Abudefduf saxatilis (Linnaeus), (Osteichthyes) in the West Indies. J Parasitol 71:209-214

Williams LB, Williams EH Jr (1985c) Brood pouch release of Anilocra chromis Williams \& Williams (Isopoda: Cymothoidae) a parasite of Brown Chromis, Chromis multilineatus (Guichenot) in the Caribbean. Crust 49:92-95

Williams EH Jr, Williams LB (1986a) The first Anilocra and Pleopodias isopods (Crustacea: Cymothoidae) parasitic on Japanese fishes, with three new species. Proc Biol Soc Wash 99:647-657

Williams EH Jr, Williams LB (1986b) The first association of Conchoderma virgatum (Spengler) (Cirripedia: Thoracica) with a euryphodid copepod in the mouth of a fish. Galaxea 5:209-211

Williams LB, Williams EH Jr (1986c) Ichthyological notes about fishes collected for parasite examination around Sesoko Island, Okinawa. Galaxea 5:217-221

Williams LB, Williams EH Jr (1987) Three new species of Renocila (Crustacea: Isopoda: Cymothoidae), external parasites of coral reef fishes from the Ryukyu Islands of Japan. Proc Biol Soc Wash 100:417-432

Williams EH Jr, Wolfe-Walters TJ (1990) An abnormal incidence of the commensal copepod, Doridicola astrophyticus Humes, associated with injury of its host, the basketstar, Astrophyton muricatum (Lamarck). Crust 59:302

Williams EH Jr, Williams LB, Waldner RE, Kimmel JJ (1982) Predisposition of a pomacentridae fish, Chromis multilineatus (Guichenot) to parasitism by a cymothoid isopod, Anilocra chromis Williams and Williams. J Parasitol 68:942-945

Williams EH Jr, Bunkley-Williams L, Rand TG (1994a) Some copepod and isopod parasites of Bermuda marine fishes. J Aquat Anim Health 6:279-280

Williams EH Jr, Bunkley-Williams L, Sanner CJ (1994b) New host and locality records for copepod and isopod parasites of Colombian marine fishes. J Aquat Anim Health 6:362-364

Williams EH Jr, Bunkley-Williams L, Dyer WG (1996) Metazoan parasites of some Okinawan coral reef fishes with a general comparison to the parasites of Caribbean coral reef fishes. Galaxea 13:1-13

Williams EH Jr, Bunkley-Williams L, Kruitwagen G, Nagelkerken I (2007) A new host and locality record: Gnathia sp (Isopoda: Gnathiidae) on the Barred Mudskipper, Periophthalmus argentilineatus Valenciennes, 1837 (Perciformes: Gobiidae), from Tanzania. J Egypt Soc Parasitol 37:851-852 
Williams EH Jr, Bunkley-Williams L, Ebert DA (2010) An accidental attachment position of Elthusa raynaudii (Isopoda: Cymothoidae) in Etmopterus sp. (Squaliformes: Etmopteridae). Acta Parasitol 55:99-101

Williams JD, Gallardo A, Murphy AE (2011) Crustacean parasites associated with hermit crabs from the western Mediterranean Sea, with first documentation of egg predation by the burrowing barnacle Trypetesa lampas (Cirripedia: Acrothoracica: Trypetesidae). Integr Zool 6:13-27

Wilson CB (1904) A new species of Argulus, with a more complete account of two species already described. Proc US Natl Mus 27:627-655

Wilson CB (1913) Crustacean parasites of West Indian fishes and land crabs, with descriptions of new genera and species. Proc U S Natl Mus 44:189-277

Winch JM, Riley J (1986) Studies on the development and behavior in fish of Subtriquetra subtriquetra: a uniquely free-living pentastomid larvae from a crocodilian. Parasitology 93:81-98

Woo PTK (ed) (2006) Fish diseases and disorders: Part 1. Protozoan and metazoan infections, 2nd edn. CABI, Wallingford

WoRMS Editorial Board (2018) World register of marine species. Available from http://www. marinespecies.org at VLIZ. Accessed 2018-10-01. doi:https://doi.org/10.14284/170

Yusa Y, Yamato S, Kawamura M, Kubota S (2015) Dwarf males in the barnacle Alepas pacifica Pilsbry, 1907 (Thoracica, Lepadidae), a symbiont of jellyfish. Crustaceana 88(3):273-282

Zhang Z-Q (2013) Phylum Arthropoda. In: Zhang Z-Q (ed) Animal Biodiversity: An outline of higher-level classification and survey of taxonomic richness (addenda 2013). Zootaxa 3703:1-82

Zitzler K, Cai Y (2006) Caridina spongicola, new species, a freshwater shrimp (Crustacea: Decapoda: Atyidae) from the ancient Malili lake system of Sulawesi, Indonesia. Raffles Bull Zool 54(2):271-276

Zwerner DE (1967) Neoscutellidium yeatmani n. g., n. sp. (Copepoda: Harpacticoida) from the Antarctic fish Rhigophila dearborni Dewitt, 1962. Trans Am Microsc Soc 86:152-157 